\title{
Molecular Control of Pyramidal Neuron Fate Determination in the Developing Neocortex
}

\section{PhD Thesis}

\author{
in partial fulfilment of the requirements \\ for the degree "Doctor of Philosophy (PhD)/Dr. rer. nat." \\ in the Neuroscience Program \\ at the Georg August University Göttingen, \\ Faculty of Biology
}

Submitted by

\section{Srinivas Parthasarathy \\ born in}

Chennai, India

Göttingen, 2014 


\section{Declaration}

This thesis has been written independently and with no other sources and aids than quoted.

Srinivas Parthasarathy

$28^{\text {th }}$ March 2014, Göttingen. 


\section{TABLE OF CONTENTS}

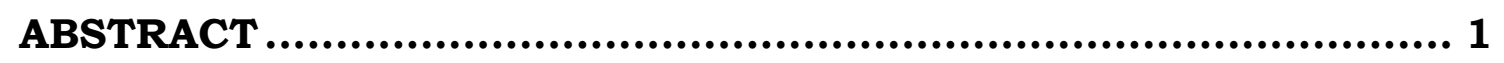

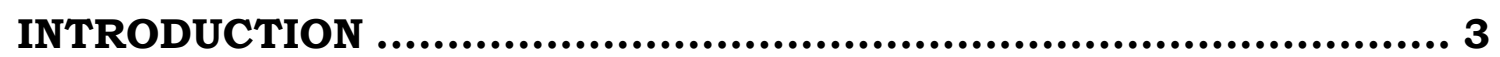

1. Cortical Development ........................................................

1.1 Types of Progenitors.................................................... 3

1.2 Progenitor Cell fate switch ......................................................6

1.3 Cortical Cell Identity .................................................. 8

2. Sip 1 controls cortical feedback signaling .................................... 9

3. Neurotrophin Signaling ..................................................... 10

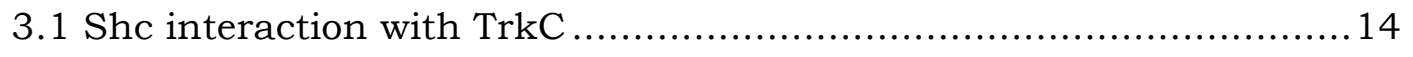

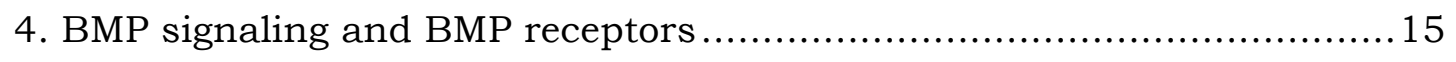

5. Cbln family of Transneuronal cytokines .................................. 18

MATERIALS AND METHODS ............................................. 19

1. Mouse mutants ................................................................ 19

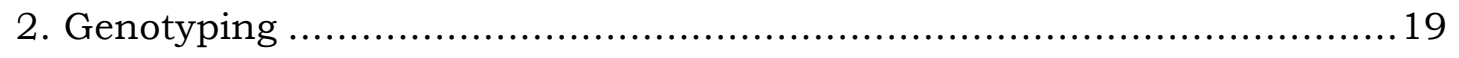

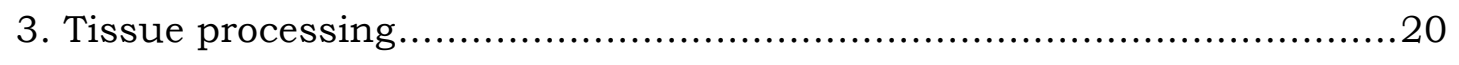

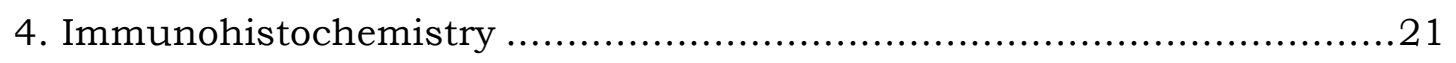

5. List of Primary Antibodies ........................................................22

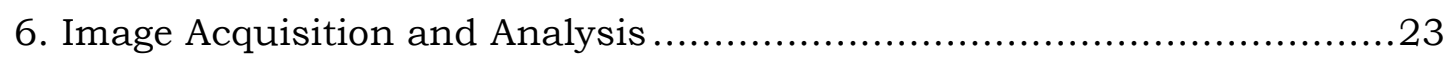

7. Plasmids ...........................................................................24

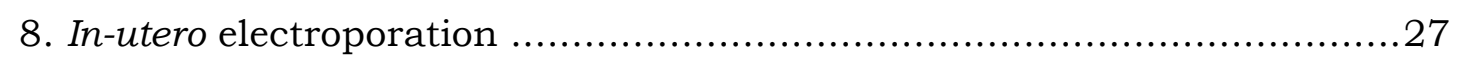

9. Cell Transfection and Stimulation ...........................................28

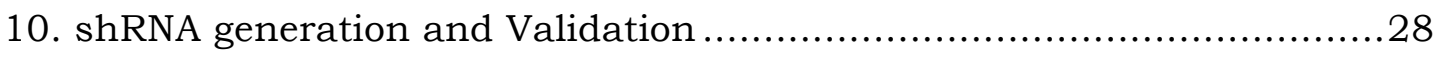

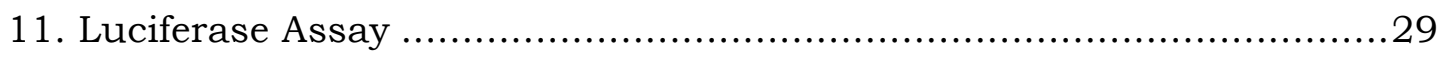

12. Western Blotting and Immunoprecipitation .................................29

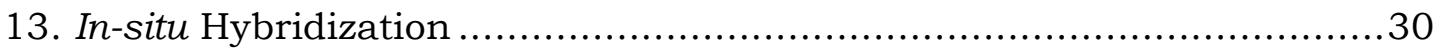

14. AP staining of Sections and Cells......................................... 32

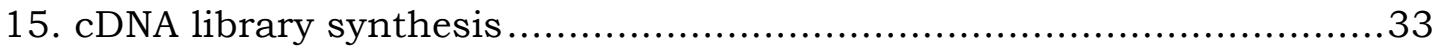

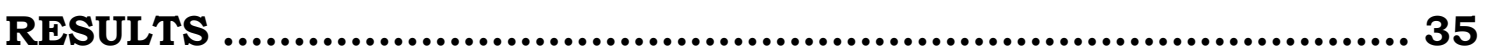

1. Mosaic deletion of Sip1 in young cortical neurons phenocopies the Sip1

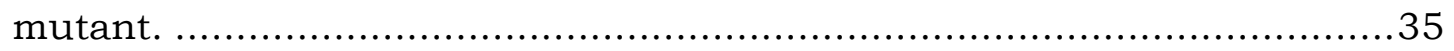


2. Ntf3 is upregulated in the Sip1 mutant cortex.

3. Ntf3 promotes an increase in the basal progenitor population.

4. Ntf3 promotes upper layer neurogenesis at the expense of deep layer neurons.

5. Deletion of $N t f 3$ increases the number of layer VI neurons but the Ntf3-

Sip 1 compound mutant does not rescue Sip 1 mutant phenotype.

6. Localizing the receptors for Ntf3 in the developing cortex ...................42

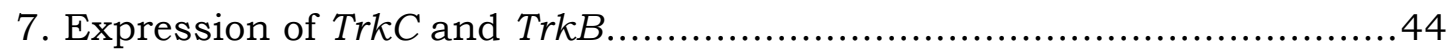

8. Expression of Non-Catalytic (NC) TrkC and TrkB ..........................45

9. NC-TrkC protein is also absent from the E15.5 ventricular zone ...........48

10. Over-expression of $N C$-TrkC leads to over-production of deep layer neurons at the expense of upper layer neurons ...............................50

11. NC-TrkC and pERK1/2 share opposing expression domains in the developing neocortex. .54

12. NC-TrkC negatively regulates ERK signaling in vitro. 55

13. NC-TrkC interacts with BMPRIA both in vivo and in vitro .56

14. The Intracellular Domain of $\mathrm{NC}-\mathrm{TrkC}$ is required for interaction with BMPRIA .59

15. NC-TrkC Y516F also binds to BMPRIA 60

16. BMPRIA is expressed throughout neurogenesis in the $\mathrm{VZ}$ of the developing cortex

17. BMPRII and NC-TrkC share opposing expression patterns

18. NC-TrkC enhances the kinase activity of BMPRIA in a ligand independent manner.

19. Generation of shRNA constructs to knock-down the expression of BMPRIA .64

20. Down-regulating BMPRIA leads to a premature production of upper layer neurons.....

21. NC-TrkC and BMPRIA controlled pathways interact genetically to control cortical cell fate. .65

22. FL-TrkC also interacts with BMPRIA .67

23. Cbln 4 is also upregulated in the Sip 1 mutant cortex. 69

24. Sip 1 can bind to the Cbln 4 enhancer region in vitro .70

25. Cbln4, 1 and 2 can also signal back to influence the proportions of basal and apical progenitors .71

26. Cbln 4 also promotes premature upper layer neurogenesis .74 
27. Receptors for Cbln4 are located along the radial glial process 75

28. Preparation of an E14.5 cortical cDNA library

DISCUSSION 80

1. Ntf3 mediated feedback signaling. 80

2. Expression Pattern of $N C$-TrkC mirrors the transition from deep layer to upper layer production. 84

3. NC-TrkC influences cell fate by favoring deep layer neurogenesis 86

4. A Ligand for the receptor? 90

5. NC-TrkC interacts with BMPRIA 91

6. Multiple pathways control cortical feedback signaling .93 


\section{TABLE OF FIGURES}

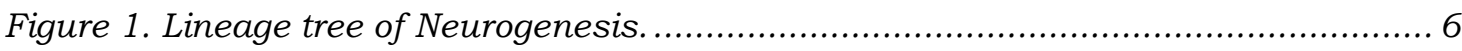

Figure 2. General scheme for Trk mediated intracellular signaling. ........................... 12

Figure 3. ShcA protein interactome .............................................................................. 15

Figure 4. General scheme for BMP signaling. .................................................... 17

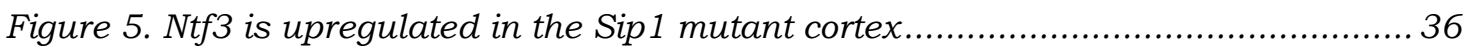

Figure 6. Ntf3 promotes an increase in the basal progenitor and decrease in apical progenitor population.

Figure 7. Ntf3 promotes upper layer neurogenesis at the expense of deep layer neurons

Figure 8. Deletion of Ntf3 from the Sip1 mutant cortex does not rescue the Sip1 mutant

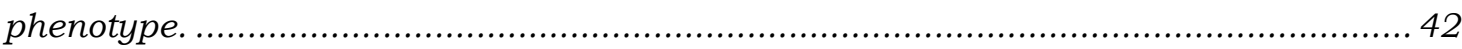

Figure 9. Localizing the receptors for Ntf3 in the developing cortex .......................... 43

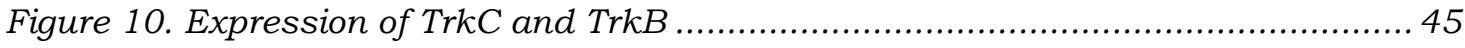

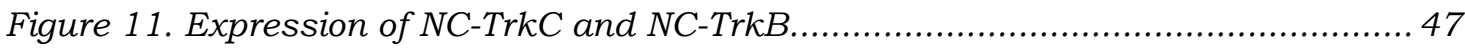

Figure 12. Ratio of NC-TrkC to FL-TrkC shifts from E13.5 to E15.5 ............................. 49

Figure 13. NC-TrkC over-expression leads to an increase in deeper layer production... 53

Figure 14. Comparison of NC-TrkC and p-ERK1/2 expression patterns. ......................54

Figure 15. NC-TrkC negatively regulates ERK signaling in vitro .................................. 56

Figure 16. NC-TrkC and BMPRIA interact in vivo and in vitro................................ 58

Figure 17. The Intracellular Domain of NC-TrkC is required for interaction with BMPRIA.

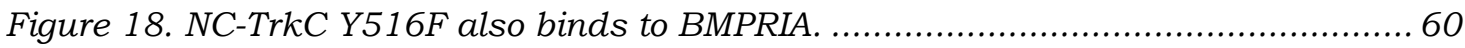

Figure 19. Expression pattern of BMPRIA............................................................. 61

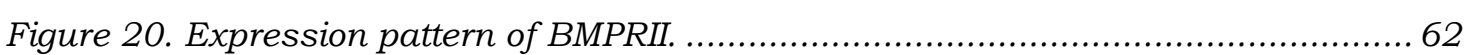

Figure 21. NC-TrkC enhances the kinase activity of BMPRIA. ..................................... 63

Figure 22. Generation of shRNA clones for the knock-down of BMPRIA expression...... 64

Figure 23. Down-regulation of BMPRIA leads to an increased production of upper layer neurons and NC-TrkC-BMPRIA controlled pathways interact genetically ..................... 66

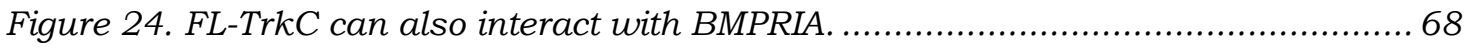

Figure 25. Cbln 4 is upregulated in the Sip 1 mutant cortex........................................ 69

Figure 26. Sip 1 can bind to the Cbln4 enhancer region in vitro.................................. 70

Figure 27. Over-expression of Cbln 1, 2 and 4 leads to an increase in Tbr2+ basal

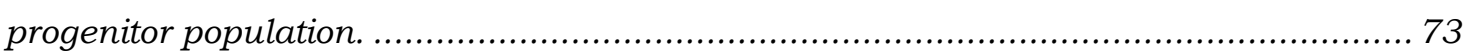

Figure 28. Cbln4 promotes premature upper layer neurogenesis............................... 75 
Figure 29. Receptor for Cbln4 is located within the developing cortex ......................... 76

Figure 30. Construction of an E14.5 cortex specific cDNA library .............................. 78

Figure 31. Model depicting the two possible modes of Ntf3 mediated signaling............ 83

Figure 32. Expression pattern of NC-TrkC and p-ERK1/2 _..................................... 89

Figure 33. Model proposing NC-TrkC control over cell fate determination. .................... 93 


\section{ACKNOWLEDGMENTS}

There are so many people who were responsible for making sure things turned out the way they did, and to them I owe a debt of gratitude.

Firstly, none of this would have happened (and I mean this in the nicest way possible!) without the support of my supervisor- Prof. Victor Tarabykin. Having spent close to half a decade working with him, I probably have taken all that he did and does for me, granted. For the great supervision he provided, for never letting his excitement levels drop and most importantly, for supporting me at every stage of my $\mathrm{PhD}$ Thank you Victor!

Considering that a $\mathrm{PhD}$ student spends more than half his day in the lab, life would have been extremely boring and hard, had it not been for the great people I encountered in the lab- Anjana, for supporting and mentoring me during my initial steps; Manu- for being an inspiration to all who strive to be a perfectionist in the lab; Ingo- for being a storehouse of patience and possessing a godly nature of going out of the way to help anyone; Kuo- for all our fun filled moments, Marta for all the great advice and support and everyone else in the lab over the years whom I've greatly enjoyed working with.

I would also like to thank Roman, Denis, Jutta and Marni for all the technical and administrative support they have extended to me over the years. I would also like to acknowledge everyone in the Institute for Cell and Neurobiology, for providing a great collaborative environment to work in. I would specially like to thank Ele, for being a very special friend- I'll miss our coffee breaks!!

My PhD wouldn't have been half as special without my association with the Boehringer Ingelheim Fonds. My heartfelt gratitude to the entire BIF team for supporting my $\mathrm{PhD}$ so generously, believing in my project, making me feel so special and most importantly organizing our BIF meetings, which according to me are the golden standard for any kind of scientific meeting. 
A warm note of thank you to Prof.Michael Hörner, Sandra Drube and the neuroscience program for talking such good care of us. I would also like to thank my thesis committee members-Dr.Judith Stegmüller and Dr.Till Marquardt for their invaluable suggestions and time.

Finally, the person whom I would like to thank the most for making this entire journey so memorable- Swathi. I'm so glad you decided to join the lab when you did! Science would have probably seen new lows had it not been for the support I found in you. Living away from home, I found the greatest friend in you one could ask for. We literally shared almost every single waking moment with each other during the last four yearsand for that one reason alone, I'd say a PhD wasn't that hard!!

Most importantly, my family- who has probably still not made me feel I live away from home and will always be my biggest support! My dad for inspiring me to be a workaholic (and yes that's a good thing), my mom for still spending her day thinking if I'm fine, my grandmother for teaching me that learning never ends and my sister- apart from all that she means to me....for giving us our biggest bundle of joy- my lil nephew Ranga!

And last and most importantly- my Acharyan HH the $45^{\text {th }}$ jeeyar of Sri Ahobilam Mutt. I long to see his smile everyday that I live! 


\section{ABSTRACT}

The pyramidal neurons of the neocortex, which form the neural substrate for our higher cognitive abilities, arise from a single layer of neuroepithelium lining the dorsal ventricles. It has been of immense interest to study how cell fate specification within the developing cortex dictates the generation of these numerous classes of pyramidal neurons from a small pool of cortical progenitors.

Others and we had previously shown that postmitotic neurons signal back to their progenitors and instruct the timing of cell fate switch. This process governs both the switch from producing one neuronal type to the other and from neurogenesis to gliogenesis. We have previously shown that Fgf9 controls the switch from neurogenesis to gliogenesis. While a similar mechanism governing the switch from deep layer to upper layer neuronal production was predicted, the precise molecular pathway was not shown.

In this thesis, we show that the neurotrophin Ntf3, signals back to cortical progenitors and initiates the shift from deep to upper layer cell fate. It does so by shifting the ratio of apical progenitors to basal progenitors, which in turn govern the production of cortical neurons.

We go on to show that the effect of Ntf3 is most likely mediated by the truncated- Non Catalytic isoform of TrkC- NC-TrkC. NC-TrkC, to our knowledge, is the first molecule to show an expression pattern that parallels the timing of deep layer neurogenesis. Through gain-offunction experiments, we show that $N C$-TrkC expression tilts neurogenesis in favor of deeper layer neurons. We also show that the effect of NC-TrkC is most likely through the negative regulation of ERK signaling. We provide further evidence that signaling via the binding site for the signaling molecule Shc, on NC-TrkC is important for its role in cell fate determination. Further, we show a novel interaction between NC-TrkC and the BMP class I receptor BMPRIA. These receptors interact in vitro and in vivo. The genetic programs controlled by them interact to govern neuronal fate during corticogenesis. 
Finally, we study the role of a family of transneuronal cytokines-Cbln, as molecules that function in parallel to Ntf3 in controlling neuronal fate switch in the cortex. We show that over-expression of the Cbln family members can also alter the proportions of apical and basal progenitors, thereby providing insights into new modes of signaling between postmitotic neurons and their progenitors. 


\section{INTRODUCTION}

\section{Cortical Development}

The mammalian neocortex is a six-layered structure that is considered to be responsible for our higher cognitive abilities. Within the neocortex hundreds of different cell subtypes are arranged into specific neuronal networks that are engaged in receiving, processing and responding to complex stimuli. The neocortex consists of two major neuronal subtypes- excitatory projection neurons and inhibitory interneurons. While interneurons are born in the ganglionic eminence, cortical projection neurons arise from progenitors lining the dorsal aspects of the lateral ventricles. These progenitors give rise to the different cortical layers sequentially. During this process, later born neurons must migrate past earlier born neurons to occupy their final position in the cortex, thus giving rise to the 'inside first-outside last' cortex (Angevine and Sidman, 1961; Rakic, 1974). The various layers of the cortex show a high degree of heterogeneity with respect to their functions. This correlates to the fact that these neurons also show great variation with respect to their molecular and morphological characteristics (Fishell and Hanashima, 2008). However, such a diverse group of neurons are born from a relatively homogenous progenitor population. Thus, how progenitors undergo successive fate restriction to generate the entire repertoire of cortical neurons, has invited detailed study and research over the last two decades.

\subsection{Types of Progenitors}

The developing cortex can be sub-divided into the ventricular zone (VZ), subventricular zone (SVZ), Intermediate zone (IZ) and the cortical plate (CP). The earliest born cortical neurons form the preplate. Subsequently born neurons split the preplate to form the outer marginal zone and the inner subplate. The subplate comprises of a group of transient neuronal populations, which are mostly important 
for their pioneering function in early axonal guidance (McConnell et al., 1989).

\subsubsection{Ventricular zone}

The ventricular zone is the primary progenitor pool for the developing neocortex. The primitive cortical VZ comprises of neuroepithelial cells. These early neuroepithelial cells, owing to their interkinetic nuclear movement, give the appearance of a pseudo-stratified structure. With the beginning of neurogenesis, neuroepithelial cells give birth to radial glial cells which in-turn serve as the main progenitor population for the cortex. Radial glial cells maintain certain epithelial like characteristics in addition to developing astroglial features. The epithelial characteristics include the maintenance of strong apical-basal polarity, interkinetic nuclear movement and the expression of epithelial markers such as the intermediate filament- Nestin. Radial glial cells also undergo mitotic division with their nuclei at the apical surface, similar to neuroepithelial cells. However, unlike neuroepithelial cells, their interkinetic nuclear migration does not span the entire apical-basal length of the cell. Their astroglial features include the expression of the glial fibrillary acidic protein (GFAP), brain lipid binding protein (BLBP), the $\mathrm{Ca}^{2+}$ binding protein $\mathrm{S} 100 ß$ and the astrocyte specific glutamate transporter GLAST (Götz and Huttner, 2005).

Radial glial progenitors also undergo either symmetric or asymmetric division. Symmetric divisions give rise to two progenitors, thus increasing the progenitor pool. Symmetric divisions arise as result of a vertical (perpendicular to the apical surface) cleavage plane. Asymmetric divisions on the other hand give rise to a progenitor and a neuron (Iacopetti et al., 1999; Miyata et al., 2001; Noctor et al., 2004; Götz and Huttner, 2005).

Radial glial progenitors serve as the source for all projection neurons, oligodendrocytes and astrocytes that inhabit the future cortex (Malatesta et al., 2000; Anthony et al., 2004). These radial glial cells 
have been shown to not only generate neurons, but also provide a scaffold for the young neuron to migrate on (Rakic, 2003). Retroviral lineage tracing experiments showed that radial glia give rise to clones of neurons that migrate along the radial glial process, giving rise to radial columns (Noctor et al., 2001). Radial glia are marked by the expression of the transcription factor Pax6 (Heins et al., 2002; Englund et al., 2005a). Pax6 promotes the asymmetric and hence neurogenic cell division of apical progenitors, which is supported by the finding that the number of neurons in the cortex are reduced by half in the Pax6 mutant (Heins et al., 2002).

\subsubsection{Subventricular Zone}

The cortical subventricular zone (SVZ) harbors another type of progenitor termed as basal or intermediate progenitors. Radial glial progenitors give rise to these basal or subventricular zone progenitors, thereby serving as the direct or indirect source of all cortical neurons. These basal progenitors have also been shown to contribute to neurogenesis (Haubensak et al., 2004; Noctor et al., 2004). While basal progenitors are present from the very beginning of neurogenesis, they are believed to contribute more towards the production of upper layer neurons (Tarabykin et al., 2001; Haubensak et al., 2004; Zimmer et al., 2004; Arnold et al., 2008). However, it has also been shown that they are capable of producing all the different layers of the cortex (Kowalczyk et al., 2009). Basal progenitors undergo symmetric divisions, giving rise to two neuronal cells (Haubensak et al., 2004; Noctor et al., 2004). Thus, basal progenitors are believed to help increase the number of neurons produced from a single apical progenitor by acting as an intermediate amplification step (Götz and Huttner, 2005). The proportion of basal progenitors has increased with mammalian and primate evolution and is believed to be one of the reasons for the increase in the size of the neocortex seen in higher 
primates (Martínez-Cerdeño et al., 2006; Nonaka-Kinoshita et al., 2013b; Stahl et al., 2013).

Basal progenitors are marked by the expression of the non-coding RNA SVET1 and the transcription factor Tbr2 and Cux2 (Tarabykin et al., 2001; Zimmer et al., 2004; Englund et al., 2005). Inactivation of the Tbr2 gene leads to a reduction in the number of basal progenitors and a concomitant reduction in the number of cortical upper layer neurons (Arnold et al., 2008).

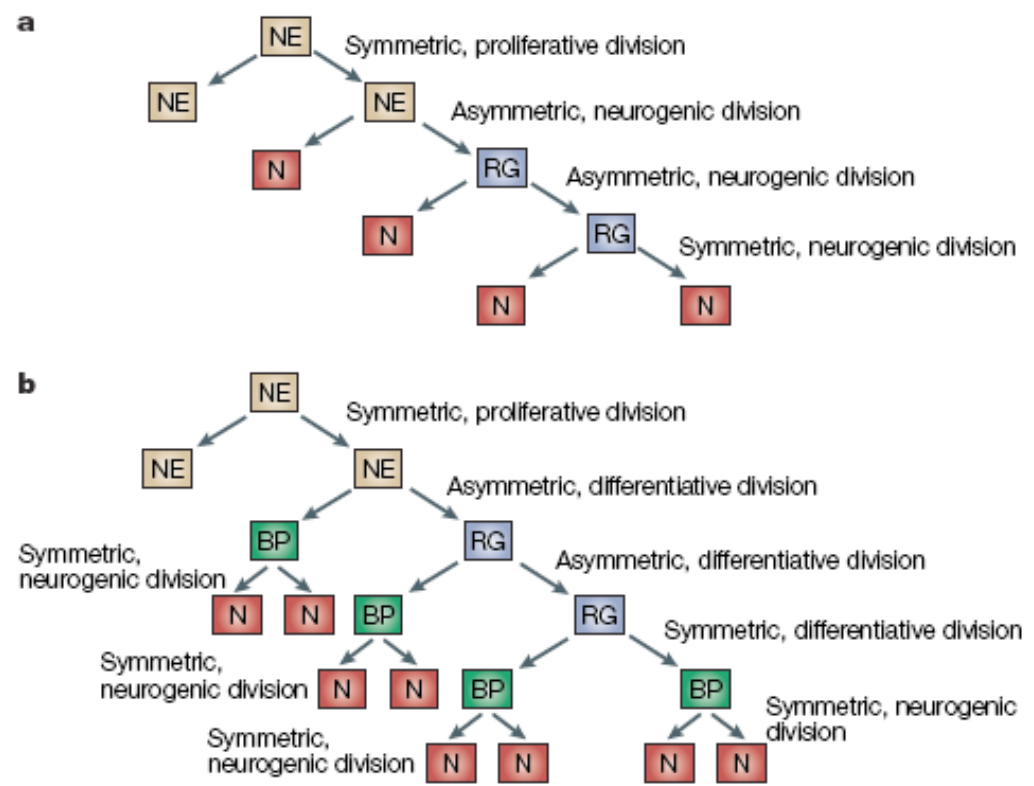

Figure 1. Lineage tree of Neurogenesis.

Adapted from (Götz and Huttner, 2005). During cortical development neuroepithelial cells (NE) give rise to radial glial (RG) cells, which in turn give rise to neurons. Alternatively, RG cells give rise to basal progenitors (BP), which serve to amplify the number of neurons generated per RG cell.

\subsection{Progenitor Cell fate switch}

Similar to all progenitor populations, cortical progenitors too loose their multi-potency over time. As development progresses, cortical progenitors become more restricted with respect to the types of cells they can produce. Individual cortical progenitors cultured in vitro can 
faithfully recapitulate the entire sequence of corticogenesis (Shen et al., 2006). This suggests that successive fate restriction is hardwired into a progenitor cell. Cortical progenitors also show an increase in cell cycle length with progression of neurogenesis, suggesting that the cell cycle length and neural cell fate are intertwined (Takahashi, 1995). Interestingly, progenitors briefly over-expressing a constitutively active form of the Notch receptor at early stages, leading to increased cycling of progenitors, skip the production of deep layers and start generating upper layer neurons (Mizutani and Saito, 2005).

Transplantation experiments showed that when younger cortical progenitors are transplanted into an older brain, they adapt to producing neurons appropriate to their new environment (Desai and McConnell, 2000). This would suggest that environmental cues also dictate the ability of a progenitor to produce one neuronal subtype over another. However, consistent with the progressive fate restriction theory, older progenitors when transplanted into an younger environment, do not adapt and continue to produce late born upper layer neuron (Desai and McConnell, 2000). Thus, collectively it is well established that while cortical progenitors undergo self programmed fate restriction, environmental cues influence this process to a large extent.

More recent work has even suggested the presence of lineage specific progenitors, as compared to the multi-potent progenitor theory. Using genetic fate mapping, Cux2 was shown to label upper layer neuron specific radial glial cells (Franco et al., 2012). These progenitors were shown to undergo symmetric divisions during early cortical development, thus increasing the progenitor pool, and undergoing neurogenic divisions during mid-late corticogenesis (Franco et al., 2012). However, work by others has contradicted this finding, wherein Cux2 positive radial glial cells were shown to generate all the different layers of the cortex (Guo et al., 2013). This work also showed that the transcription factor Fezf2 marks radial glial progenitors that also give 
rise to cortical neurons of all layers and then subsequently to glia (Guo et al., 2013).

Work from our lab suggested that cortical postmitotic neurons signal back to the progenitors thereby forming a negative feedback loop (Seuntjens et al., 2009). We proposed that neurons within each cortical layer signal back to the progenitors, instructing them to change their fate and start producing the next layer of neurons. This would ensure that neurons of a particular kind are not over-produced, thereby laying the foundation for the generation of the different layers at the right time and in the right amount.

While, others and we had shown the presence of such signals initiating the switch from neurogenesis to gliogenesis, no formal evidence was provided for the existence of such a mechanism for controlling interlayer fate switch during neurogenesis (Barnabé-Heider et al., 2005; Seuntjens et al., 2009).

In this study, we have looked at the Neurotrophin Ntf3 and it's role in cortical feedback signaling and cell fate determination.

\subsection{Cortical Cell Identity}

The different layers of the neocortex express a unique set of transcription factors that govern the appropriate maturation of these neurons. The six layers of the cortex can be divided into the following classes:

a) Layer VI: Layer VI neurons mostly project to the thalamus. They express markers such as Sox5, Tbr1 and FoxP2. These neurons are largely born between E11.5 and E13.5 in the mouse, with the peak of production being E12.5.

b) Layer V Cortico-fugally projecting neurons: Principle output neurons of the cortex. Express the layer markers Ctip2, ER81 and are easily recognized by their large cell body and long apical dendrite. Layer $\mathrm{V}$ neurons mostly project to the spinal cord, optic tectum 
(superior colliculus), principle and spinal trigeminal nuclei and the striatum. These neurons are born between E12.5 and E14.5 in the mouse, with the peak of production being E13.5.

c) Layer V Callosally Projecting Neurons: These neurons also occupy layer $\mathrm{V}$, but project interhemispherically via the corpus callosum. These neurons do not express the marker Ctip2, but instead express the transcription factor Satb2. They are born at the same time as layer $\mathrm{V}$ cortico-fugal projection neurons.

d) Layer IV: The principle input layer for the cortex, which receives connections from the thalamus. They express the layer marker Rorß and are different in morphology from the rest of the cortical neurons. These neurons are born between E13.5 and E14.5 in the mouse.

e) Layer II-III: These neurons are the last-born neurons of the cortex. They are generated between E14.5 and E16.5, with E15.5 being the peak of upper layer neuronal production. They express markers such as Brn1, Brn2, Cux1, Cux2 and Satb2. These neurons primarily project interhemispherically through the corpus callosum and to other cortical areas intrahemispherically.

f) Layer I: Also called the molecular layer or the marginal zone is a largely cell free layer. It is also the only cortical layer born outside the cortex. The apical dendrites of cortical neurons terminate here and branch extensively. This layer is occupied by Cajal-Retzius cells that act as a source of Reelin, which plays an important role in controlling migration of cortical neurons.

\section{Sip1 controls cortical feedback signaling}

Sip1 or Smad-interacting-protein-1 was identified as a postmitotic specific transcription repressor. Sip1 was shown to interact with the activated Smads and SIP1 mutations have been implicated in the Mowat-Wilson syndrome (Verstappen et al., 2008). Sip 1 mutants fail to develop beyond E9.5 and show defects in neural tube closure and 
defective cranial neural crest cell migration (Van de Putte et al., 2003). Sip1 conditional mutants (crossed to either Nex-Cre or Emx1-Cre) showed a reduction in deeper layer cortical neurons and an increase in upper layer neurons. BrdU birth-dating experiments showed that this was a result of a premature end of deep layer neuronal production coupled to precocious upper layer neuronal generation. This was followed with a premature end of neurogenesis and an early onset of gliogenesis (Seuntjens et al., 2009). Thus Sip1 was hypothesized to be a postmitotic specific transcription factor controlling cortical feedback signaling. In the absence of Sip1, these signals are heightened prematurely, leading to an early cell fate switch. Indeed, Sip1 was shown to regulate the expression of Fgf9, which signals from postmitotic neurons to progenitors instructing the shift from neurogenesis to gliogenesis. Fgf9 coated agarose beads, when ectopically placed within the cortical plate, lead to an enhanced number of Olig2 positive oligodendrocytic precursors. Similarly, Sip1 was shown to regulate the expression of $N t f 3$, a well-characterized neurotrophin. Since Sip1 mutants showed an upregulation of Ntf3 expression coinciding with the shift from deep layer to upper layer neurogenesis, it was hypothesized that $\mathrm{Ntf3}$ acts as a feedback signal during neurogenesis. Although no formal experiment validating the presence of such cortical feedback signaling during neurogenesis was performed (Seuntjens et al., 2009).

In this current work, we investigated the role of $\mathrm{Ntf3}$ and the signaling pathway downstream that causes a shift from deep layer to upper layer neurogenesis.

\section{Neurotrophin Signaling}

Neurotrophins are a class of small-secreted molecules that have profound influence on a large variety of neuronal functions. Neurotrophins and their receptors are relatively new in evolution and cannot be found in D.melanogaster and C.elegans. This paved way for 
the thinking that these molecules are not essential for the development of neuronal circuitry. Indeed, deletion of the neurotrophins does not affect early development in mammals (Chao, 2003). The neurotrophin family primarily consists of Nerve growth factor (NGF), Brain-derivedneurotrophic factor (BDNF), Neurotrophin factor 3 (Ntf3) and Neurotrophin factor 4(NT-4). Each of the family member binds to a specific Tropomyocin related kinase (Trk) receptor with maximum affinity and to a lesser extent with one or more of the other receptors. Trks are a family of receptor tyrosine kinases with NGF binding to TrkA, BDNF and NT-4 to TrkB and Ntf3 to TrkC (Cordon-Cardo et al., 1991; Klein et al., 1991; Lamballe et al., 1991; Soppet et al., 1991). While TrkA is largely expressed in the Peripheral nervous system (PNS), TrkB and TrkC are expressed within the CNS (Klein et al., 1990; Martin-Zanca et al., 1990; Lamballe et al., 1991). In addition, the Trk receptors interact with another receptor termed p75-NTR. Interaction of Trk receptors with p75-NTR can alter their binding affinity for neurotrophins (Chao, 2003).

Neurotrophin signaling begins upon ligand binding to its cognate Trk receptor, which leads to receptor dimerization (Lamballe et al., 1991; Jing et al., 1992; Lemmon and Schlessinger, 1994). Upon dimerization, the receptors autophosphorylate specific tyrosine residues, which serve as docking stations for downstream effector molecules. The classical Neurotrophin-Trk signaling involves the recruitment and phosphorylation of either the downstream adaptor molecule Shc or PLC- $\gamma$. These in-turn activate the PI3K or ERK pathways (Chao, 2003).

Trk receptor mediated signaling has been shown to be important in the context of the developing cortex. Over-expression of dominant negative TrkB or TrkC leads to a decrease in progenitor proliferation of cortical progenitors (Bartkowska et al., 2007). TrkB mutant mice also display migration defects in the cortex. While single mutants for the Shc or Plc- $\gamma$ binding site does not display major defects, cortical neurons 
carrying mutations in both these sites, show defects similar to the TrkB knock-out (Medina et al., 2004).

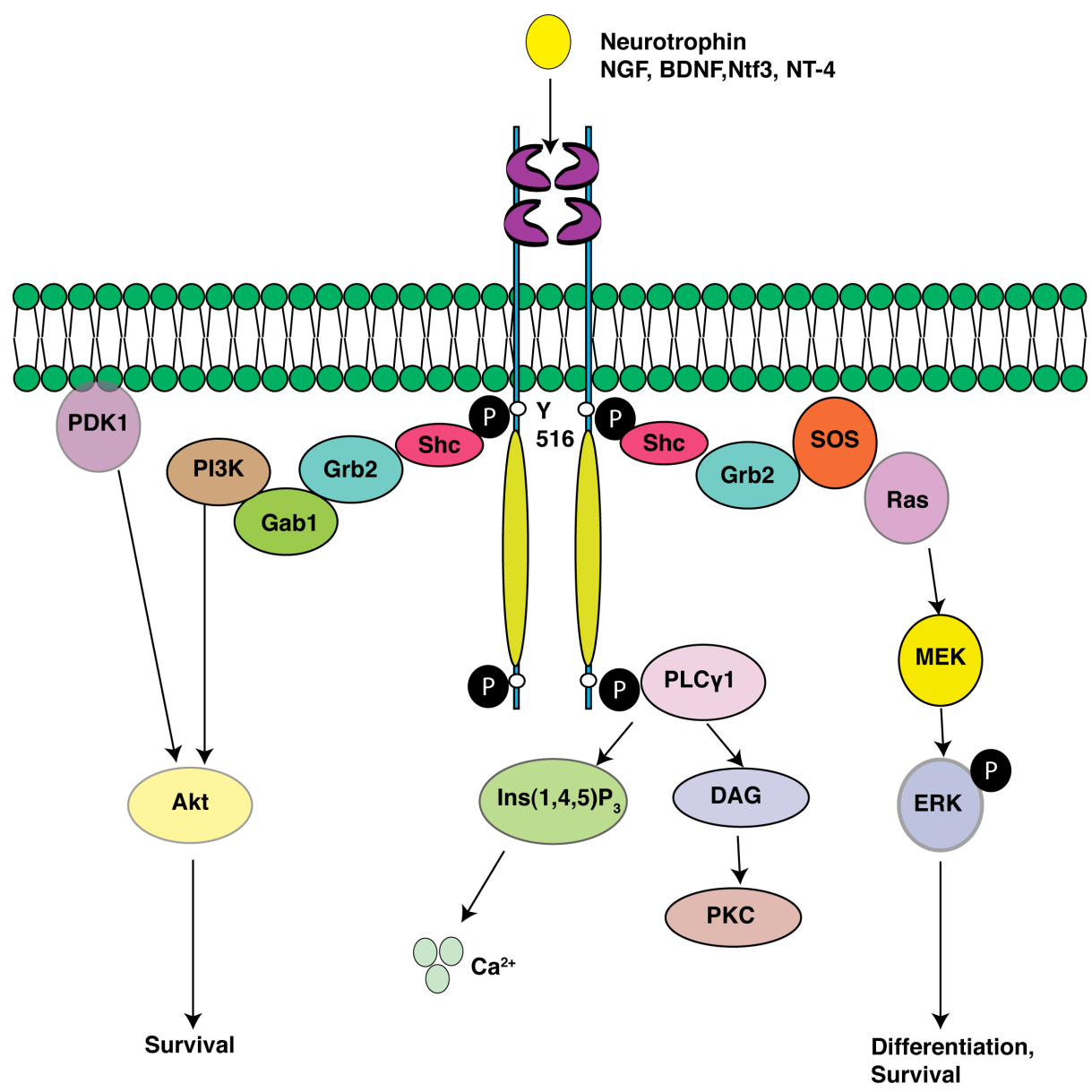

Figure 2. General scheme for Trk mediated intracellular signaling.

Modified from (Chao, 2003; Minichiello, 2009). Ligand binding induces receptor dimerization leading to autophosphorylation of the receptors. Phosphorylation of the tyrosine at residue 516 (in TrkC) leads to recruitment of ShcA. Phosphorylation of Shc1 in turn leads to the activation of the Akt or ERK pathway. Alternatively, phosphorylated $\operatorname{Trk}(\mathrm{s})$ recruit Plc $\gamma 1$ and thereby activate the PKC or the $\operatorname{Ins}(1,4,5) \mathrm{P}_{3}$ pathways.

The identification of alternate splice variants of the Trk receptors has further fuelled interest in understanding the signaling cascade downstream of these receptors (Klein et al., 1990; Middlemas et al., 1991; Fenner, 2012). Splice variants of TrkB and C have been reported, in each case lacking the intracellular kinase domain (Tsoulfas et al., 1993; Valenzuela et al., 1993). Interestingly, the 
number of alternate splice variants for $\operatorname{TrkC}$ and $\operatorname{TrkB}$ has increased with mammalian evolution, suggesting that the fine control of signaling cascades downstream of these receptor-isoforms might play an important role.

While these receptors bind to their neurotrophin partner with the same affinity as the full-length receptors, they are incapable of initiating a signaling cascade. This hence encouraged the idea that these receptors act as dominant negative isoforms, impairing the classical signaling pathways (Dorsey et al., 2012; Yanpallewar et al., 2012). However, a plethora of recent work has shown that these receptors not only initiate signaling cascades; they are also most often different from the classical signaling pathways (Rose et al., 2003; Esteban et al., 2006; Carim-Todd et al., 2009; Renn et al., 2009; Fenner, 2012). In addition, owing to the lack of a catalytic domain, research into the possibility of these receptors employing different signaling molecules has lead to the discovery of new binding partners (Esteban et al., 2006). Additionally, in some systems the expression pattern of the different isoforms is non-overlapping, which is further suggestive of the divergent functions of the full length and truncated isoforms (Menn et al., 1998, 2000). In some systems the different isoforms have also been shown to modulate each other's expression levels. For example, excitotoxicity in hippocampal neurons leads to the downregulation of the full length TrkB and an increase in the expression of the truncated TrkB (Gomes et al., 2012).

In the current study we focus on the role of $\mathrm{Ntf3}$ and the truncated TrkC isoforms- NC-TrkC (Non catalytic-TrkC) in cortical neuronal fate switch. 


\subsection{Shc interaction with TrkC}

Ligand dependent receptor autophosphorylation of $\mathrm{TrkC}$ at tyrosine 516 leads to the recruitment of the downstream adapter molecule Src homologous and collagen-like adaptor protein (Shc). Although some results suggest that Shc maybe constitutively bound to the Trk receptors and only a conformational change occurs upon the phosphorylation of Y516 (De Vries et al., 2010). Three shc genes, namely $S h c A, S h c B, \quad S h c C$ have been identified in mammals (Ravichandran, 2001). Three different isoforms of ShcA are found- p66, 52 and 46. Though, initially considered to be ubiquitously present, more recent work has shown that both ShcA mRNA and protein are down-regulated upon neuronal differentiation and is replaced by $S h c C$ in postmitotic neurons (Conti et al., 2001). ShcA expression pattern within the developing cortex coincides with the proliferative neurogenic ventricular zone, thus suggesting an important role in controlling corticogenesis (Conti et al., 1997). ShcA contains an SH2phosphotyrosine binding domain and a PTB domain, which also binds phosphotyrosines. Further, phosphorylation of ShcA on different Tyrosines and Serine/ Threonine leads to the initiation of downstream signaling cascades. The site of phosphorylation has been linked to the diversification of the downstream signaling cascade initiated (Zheng et al., 2013). Interestingly, recent work showed that ShcA is additionally phosphorylated on Serine 29, upon EGFR stimulation. This Serine phosphorylation however occurs a little later than the Tyrosine phosphorylation initiated by the receptor itself (Zheng et al., 2013). This raises the question as to whether receptor tyrosine kinases (of which the Trks are a subclass) may also interact with other Serine/Threonine kinases, which could be responsible for this Serine phosphorylation. 


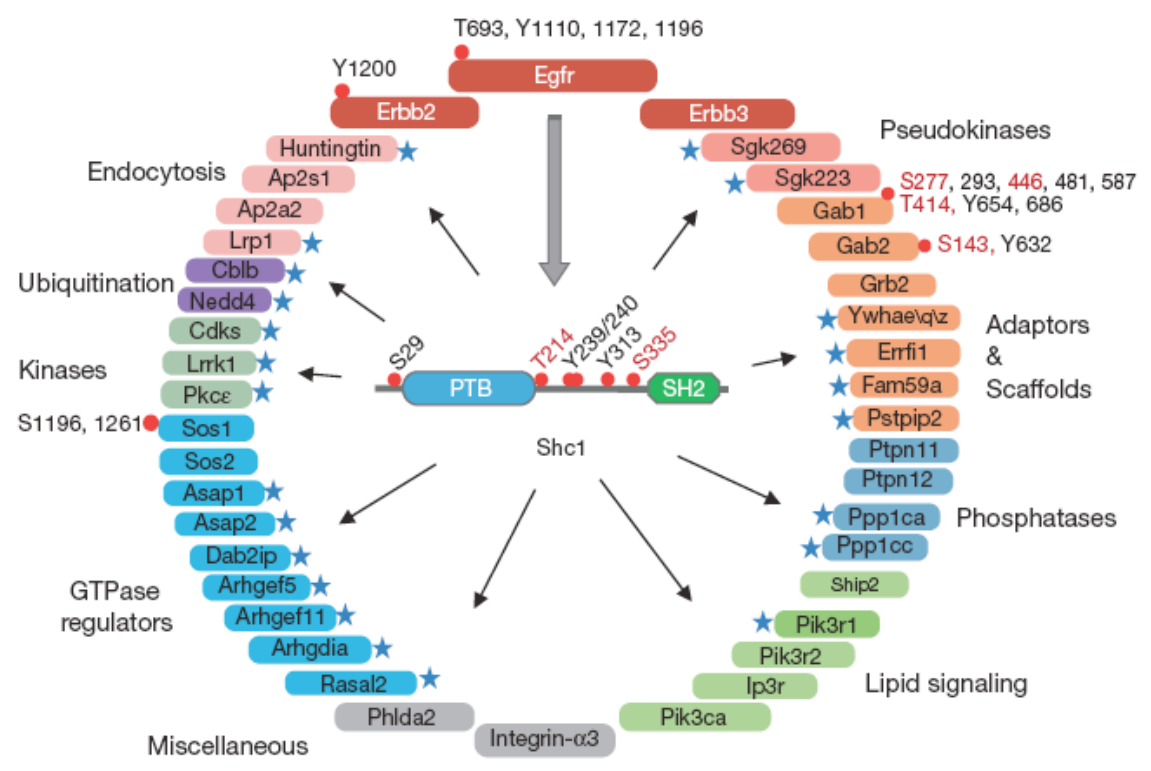

Figure 3. ShcA protein interactome

(adapted from (Zheng et al., 2013)). Receptor Tyrosine kinase activation leads to the recruitment and phosphorylation of ShcA. ShcA in-turn interacts and regulates a wide range of proteins with diverse functions. ShcA is also phosphorylated on multiple Tyrosines and Serine/Threonines, which are believed to modify the function and targets of ShcA.

\section{BMP signaling and BMP receptors}

An important part of the work presented in this thesis focused on the role of NC-TrkC in regulating cell fate decision in the cortex. Since, NCTrkC does not have any intracellular kinase domain, we wondered if it could interact with other receptors that could serve as co-receptors. Amongst the family of proteins we studied, we found an interaction between NC-TrkC and the BMP class I receptor BMPRIA.

BMPs are members of the TGFß protein family of extracellular ligands. The TGFß superfamily also includes, apart from the BMPs, TGFß and Activin subfamilies. Each of these extracellular ligands bind to two types of receptors- Class I (ALK2, ALK3/BMPRIA and ALK6/BMPRIB) and Class II (BMPRII, ACTRIIA, ACTRIIB) (Liu and Niswander, 2005). These receptors belong to the class of receptor Serine-Threonine kinases. Upon ligand binding, Class I receptors heterotetramerize with Class II receptors, which in turn now phosphorylate and activate the 
Class I receptors. Activated Class I receptors now recruit downstream effectors called R-Smads (receptor activated- Smads) and phosphorylate these in turn. The activated R-Smads multimerize with Co-Smad (common mediator Smad/Smad4) and translocate to the nucleus, where they regulate gene expression. Bmp signaling employs Smads 1, 5, 8 while TGFß signaling uses Smad 2 and 3. Inhibitory Smads 6 and 7 compete with R-Smads for binding to the receptor, thereby modulating the downstream signaling pathway (Liu and Niswander, 2005; Anderson and Darshan, 2008; Guo and Wang, 2009).

During early embryogenesis, BMP signaling needs to be blocked for neural induction. Later, BMP signaling has been shown to be necessary for the development of dorsal neural structures. The roof plate that forms post the closure of the neural tube, acts as one of the main sources of BMPs (Liu and Niswander, 2005). This dorsal BMP signaling is also necessary for the development of neural crest cells, which give rise to the PNS, amongst other cellular populations (Dickinson et al., 1995). The roof plate and dorsal neural tube derived BMPs have been shown to play a critical role in the dorso-ventral patterning of the spinal cord (Nguyen et al., 2000). Ectopic overexpression of constitutively active forms of the BMP class I receptors in the ventral spinal cord has been shown to induce dorsal cell identities (Timmer et al., 2002).

Bmp signaling has also been shown to play an important role within the developing cortex. Bmp signaling was shown to promote cell death and inhibit the proliferation of early cortical precursors in vitro (Mabie et al., 1999). 


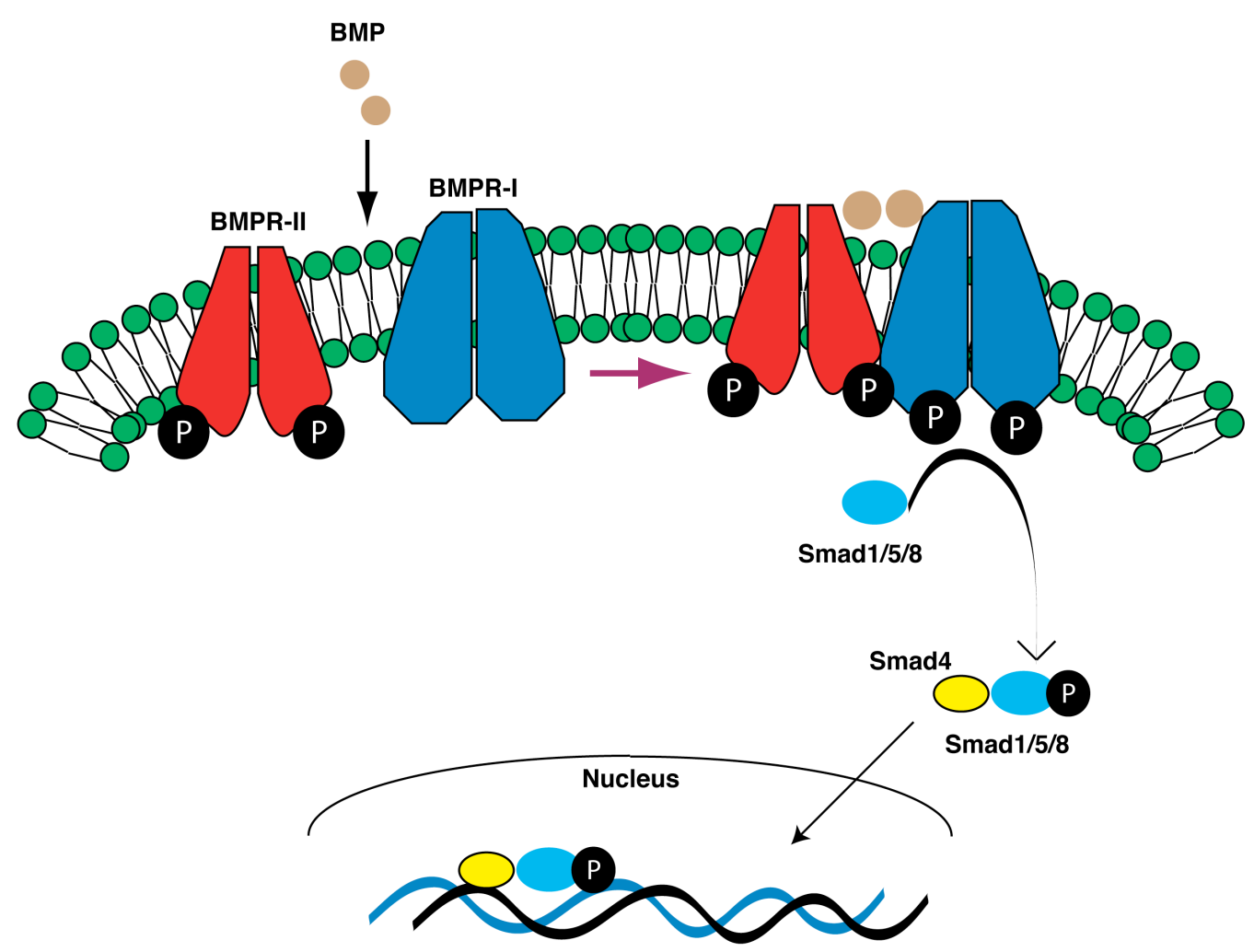

\section{Figure 4. General scheme for BMP signaling.}

Modified from (Anderson and Darshan, 2008). Ligand binding leads to the multimerization of BMPR class II and I. Class II receptors then phosphorylate Class I receptors which leads to the recruitment and phosphorylation of R-Smads $1 / 5 / 8$. Activated R-Smads now bind to the Co-Smad (Smad4) and translocate to the nucleus to affect gene regulation.

Transgenic mice that express a constitutively active form of BMPRIA showed that signaling via the IA receptor leads to the generation of dorsalized precursor. Signaling via BMPRIB was however shown to lead to mitotic arrest and differentiation (Panchision et al., 2001). BMPRIA null mutants have a shortened cell-cycle length in the ventral SVZ (Samanta et al., 2007). Meningial BMP7 is also known to inhibit the formation of the corpus callosum (Choe et al., 2012).

Here, we study the role of the BMP class I receptor BMPRIA in cortical development and the interaction of the pathways governed by NC-TrkC and BMPRIA. 


\section{Cbln family of Transneuronal cytokines}

In this current study, we also investigated if factors apart from the upregulation of Ntf3 in the Sip1 mutant cortex could also be responsible for the enhanced feedback signaling seen in these mutants. We found through microarray analysis that a member of the transneuronal cytokine-Cbln4 was upregulated in the Sip1 mutant cortex (Nityanandam, 2009). Cbln4 belongs to a family of four-transneuronal cytokines: Cbln1-Cbln4. These molecules belong to the $\mathrm{C} 1 \mathrm{q} /$ tumor necrosis factor (TNF) superfamily (Bodmer et al., 2002; Kishore et al., 2004). While Cbln 1,2 and 4 are secreted; Cbln 3 is localized to the endoplasmic reticulum (ER). Cbln3 is secreted only in conjugation with one of the other three family members. All four members form homo and heterodimers and are secreted as glycoproteins (Iijima et al., 2007). Cbln 1 is the only family member with well-characterized

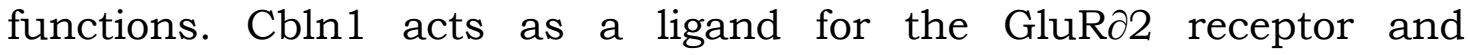
functions as both a pre and postsynaptic organizer (Matsuda et al., 2010). Cbln 1 is also known to bind to Nrxn 1 , thus mediating the transsynaptic interaction of GluR $\partial 2$ and Neurexins (Uemura et al., 2010). However, the function of these molecules at earlier stages of development is largely unknown. Cbln 1,2 and 4 expression has been detected as early as embryonic day 10-13 in the mouse (Miura et al., 2006).

Cbln 4 has been shown to function as a ligand for the Netrin 1 receptorDCC (Wei et al., 2012). Cbln 4 competes with Netrin 1 for DCC binding, thus making it an important molecule that could aid in axon guidance in the developing brain and spinal cord (Wei et al., 2012).

Here, we investigated if the Cbln family can influence cell fate switch in the developing cortex. We also developed a full length E14.5 cDNA library to screen for new receptors for Cbln4. 


\section{MATERIALS AND METHODS}

\section{Mouse mutants}

All mouse experiments were carried out in compliance with German law and according to the guidelines approved by the Bezirksregierung Braunschweig or Landesamt für Gesundheit und Soziales, Berlin. Both male and female mouse embryos were used. Sip1 conditional mutants carried a loxP flanked exon 7 crossed to either Nex or Emx1-Cre (Gorski et al., 2002; Higashi et al., 2002; Goebbels et al., 2006). Ntf3 mutant was kindly provided by Dr.Michael Sendtner, University of Würzburg. Sip1-Ntf3 double mutants were generated by crossing $\mathrm{Sip} 1^{\mathrm{loxP} /+} \mathrm{Nex} \mathrm{Cre} / \mathrm{wt} \mathrm{Ntf3}^{+/-}$parents. The day of vaginal plug was considered as E0.5

\section{Genotyping}

Tail tissue was digested in $0.3 \mathrm{ml}$ Lysis buffer $(100 \mathrm{mM}$ Tris- $\mathrm{HCl} \mathrm{pH} 8.5$, $5 \mathrm{mM}$ EDTA, $200 \mathrm{mM} \mathrm{NaCl}, 0.2 \% \mathrm{SDS}, 100 \mu \mathrm{g} / \mathrm{ml}$ Proteinase $\mathrm{K}$ ) at $55^{\circ} \mathrm{C}$ for $2 \mathrm{hrs}$ to overnight. Strands of hair were removed by centrifugation at $9000 \mathrm{rpm}$ for 5 minutes. The DNA in the supernatant was precipitated by adding $300 \mu 1$ of isopropanol, followed by vigorously mixing and centrifugation at $13000 \mathrm{rpm}$ for 15 minutes. The DNA precipitate was washed in $80 \%$ ethanol, air dried and re-suspended in 100 to $200 \mu 1$ sterile distilled water.

All PCR reactions were prepared in a final volume of $20 \mu 1$ containing the following:

10x Buffer (Genecraft) - $\quad 2 \mu 1$

$10 \mathrm{mM}$ dNTPs (Invitrogen) - $\quad 0.4 \mu 1$

$10 \mathrm{nmol} / \mathrm{ml}$ Forward/Reverse primers - $\quad 0.4 \mu 1$ each

GoTAQ polymerase (Promega) - $\quad 0.1 \mu 1$ 
Template DNA -

$1 \mu 1$

ddH2O -

The following primer sequences and reactions were used-

1. Sip1-floxed and wildtype alleles

Forward- 5' TGGACAGGAACTTGCATATGCT 3'

Reverse- 5' GTGGACTCTACATTCTAGATGC 3'

Amplification program-

$94^{\circ} \mathrm{C}-10^{\prime \prime}$

$59^{\circ} \mathrm{C}-20^{\prime \prime}$

$72^{\circ} \mathrm{C}-40 "$

31 cycles; wildtype allele yields a product of $\sim 450 \mathrm{bp}$ and the floxed Sip1 allele yields a product of $\sim 600 \mathrm{bp}$.

2. Cre allele (for both Emx1-IRES-Cre and Nex-Cre)

Forward- 5' TCGATGCAACGAGTGATGAG 3'

Reverse- 5' TTCGGCTATACGTAACAGGG 3'

Amplification program-

$94^{\circ} \mathrm{C}-10 "$

$55^{\circ} \mathrm{C}-30^{\prime \prime}$

$72^{\circ} \mathrm{C}-40 "$

30 cycles; presence of at least one Cre allele yields a product of 500bp.

\section{Tissue processing}

Pregnant females were sacrificed by first anesthetizing with Avertin followed by cervical dislocation. Newborn pups were sacrificed by decapitation. Brains (E15.5 onwards) or whole heads (E12.5-E14.5) were fixed in 4\% PFA for 4-8 hrs (E12.5-E15.5) or overnight (E16.5 onwards). Thereafter, the tissue was washed twice in $1 \mathrm{X}$ PBS. Following this, the tissue was either processed for cryo sectioning or paraffin sectioning. For cryoprotection, the brains were incubated in 
$15 \%$ and $30 \%$ sucrose (5-8 hours each), followed by embedding in OCT (TissueTek) on dry ice. The brains were then sectioned on a Leica cryotome. Alternatively, the brains were passed through a series of ethanol solutions (30\%-100\%) to progressively dehydrate the tissue. Following which, the brains were incubated in toluol for 6 hours. This was followed by two Paraplast wax incubations for 6-8 hours each at $60^{\circ} \mathrm{C}$. The brains were then embedded in paraplast and sectioned into $10 \mu \mathrm{m}$ thick sections using a Leica microtome.

\section{Immunohistochemistry}

For immunohistochemistry, paraffin sections were dewaxed in xylol. Subsequently, the sections were rehydrated by passing through a descending series of ethanol concentrations. They were then washed in 1X PBS for 10mins, prior to heat mediated antigen retrieval. Using a microwave, the sections were boiled for 3 mins in a preheated $0.96 \%$ antigen unmasking solution (Vector Labs). The solution was them allowed to cool to $50^{\circ} \mathrm{C}$, which was followed by heating again for $3 \mathrm{mins}$ in the unmasking solution. After the sections cooled to room temperature, the slides were rinsed in $1 \mathrm{X}$ PBS for $10 \mathrm{mins}$. They were then incubated in a blocking solution $(2 \% \mathrm{BSA}+0.3 \%$ TritonX-100 in $1 \mathrm{X}$ PBS) for $1 \mathrm{hr}$ at room temperature (RT) to block all non- specific binding sites on the tissue. Primary antibodies were prepared in the same solution and incubated overnight at $4{ }^{\circ} \mathrm{C}$. This was followed by four rounds of $2+3+5+10 \mathrm{~min}$ washes in $1 \mathrm{X}$ PBS. The sections were then incubated in Alexa or Dylight Fluor- tagged secondary antibodies (1:500 in blocking solution, Molecular Probes or Jackson immunoresearch) for 45-60mins at RT. The slides were then washed twice in 1X PBS for 10mins per wash and incubated either in Hoechst dye 33342 (SIGMA, 1:500) or Draq5 (1:1000, ebiosciences) for 10min and mounted in a fluorescent mounting medium (DAKO Cytomation). For immunostaining of $\mathrm{BrdU}$, the slides were pretreated by incubating 
them in pre-warmed $2 \mathrm{~N} \mathrm{HCl}$ at $37^{\circ} \mathrm{C}$ for $30 \mathrm{mins}$, followed by neutralization in borate buffer $\left(0.1 \mathrm{M} \mathrm{Na} \mathrm{Na}_{4} \mathrm{O}_{7}, \mathrm{pH} 8.5\right)$. After two washes in PBS, the slides were incubated in blocking solution and processed as described above.

For chromogenic immunohistochemistry using alkaline phosphatase coupled secondary antibodies, the tissue sections were first subjected to antigen retrieval by boiling them for 3 mins in a preheated $0.96 \%$ antigen unmasking solution (Vector Labs). This was done to ensure inactivation of endogenous alkaline phosphatase. After the washes that follow incubation in the secondary antibody, the sections were washed twice with AP reaction buffer $(100 \mathrm{mM}$ Tris $\mathrm{pH} 9.5,100 \mathrm{mM} \mathrm{NaCl}$, $50 \mathrm{mM} \mathrm{MgCl}_{2}$ and $0.05 \%$ Tween-20). This was followed by addition of alkaline phosphatase substrate (NBT/BCIP, Roche, 1:50 in AP reaction buffer) until the desired staining intensity was reached. The sections were then washed twice in PBS and mounted in an aqueous mounting media.

\section{List of Primary Antibodies}

Following is the list of Primary antibodies used:

\begin{tabular}{|c|c|c|c|}
\hline Antigen & Source Species & Dilution & Company \\
\hline BMPRIA & Rabbit & $1: 500 \mathrm{WB}$ & Abcam \\
\hline BrdU & Rat & $1: 200$ & Abcam \\
\hline BrdU & Mouse & $1: 200$ & Milipore \\
\hline Brn2 & Goat & $1: 200$ & Santa Cruz \\
\hline Cre & Mouse & $1: 200$ & Sigma \\
\hline Ctip2 & Rat & $1: 250$ & Abcam \\
\hline Cux1 & Rabbit & $1: 100$ & Santa Cruz \\
\hline ERK1/2 & Rabbit & $1: 1000 \mathrm{WB}$ & Cell Signaling \\
\hline GFP & Goat & $1: 500$ & Rockland \\
\hline
\end{tabular}


Materials and Methods

\begin{tabular}{|c|c|c|c|}
\hline GFP & Chicken & $1: 1000$ & Abcam \\
\hline HA & Mouse & $1: 500 \mathrm{WB}$ & Sigma \\
\hline Myc-tag & Mouse & $1: 2000 \mathrm{WB}$ & Cell Signaling \\
& & $1: 200 \mathrm{IP}$ & \\
\hline p-Smad1/5/8 & Rabbit & $1: 1000 \mathrm{WB}$ & Cell Signaling \\
& & $1: 100 \mathrm{IHC}$ & \\
\hline p-TrkA & Rabbit & $1: 1000 \mathrm{WB}$ & Cell Signaling \\
\hline (490)/TrkB(516) & & & \\
\hline Pax6 & Rabbit & $1: 300$ & Milipore \\
\hline Phospho- & Rabbit & $1: 1000 \mathrm{WB}$ & Cell Signaling \\
ERK1/2 & & $1: 100 \mathrm{IHC}$ & \\
\hline pTyrosine & Mouse & $1: 1000 \mathrm{WB}$ & Santa Cruz \\
\hline Satb2 & Rabbit & $1: 1000 / 1: 300$ & Generated in \\
& & & the lab \\
\hline Shc & Rabbit & $1: 1000 \mathrm{WB}$ & Cell Signaling \\
\hline Smad1 & Rabbit & $1: 1000 \mathrm{WB}$ & Cell Signaling \\
\hline Sox5 & Goat & $1: 200$ & Santa Cruz \\
\hline Tbr1 & Rabbit & $1: 200$ & Abcam \\
\hline Tbr2 & Rabbit & $1: 150$ & Abcam \\
\hline TrkC & Rabbit & $1: 1000 \mathrm{WB}$ & Cell Signaling \\
& & $1: 100 \mathrm{IHC}$ & \\
\hline TrkC-T1 & Rabbit & $1: 100 \mathrm{IP}$ & Rockland \\
\hline
\end{tabular}

Dylight (Jackson Immunoresearch) or Alexa (Molecular probes) coupled secondary antibodies were used at a dilution by 1:500. HRP linked secondary antbodies (Jackson Immunoresearch) were used for western blot analysis at a dilution of 1:5000.

\section{Image Acquisition and Analysis}

Images were procured on a Zeiss or leica-SL confocal system. Images were processed using Fiji and Adobe photoshop. Statistical analysis was done using Excel and Graphpad Prism. Student's t-test was used for 
measuring statistical significance. Data is presented as mean \pm standard deviation, unless specified. Two-tailed student's T-test was used for determining statistical significance.

\section{Plasmids}

E17.5 telencephalon specific first strand cDNA was used as a template for PCR amplification. Alternatively, P3 genomic DNA was used for cloning promoter sequences.

All clones were verified by DNA sequencing.

The following primers were used for cloning the fragments used for making the anti-sense probe used in in-situ hybridization:

\begin{tabular}{|l|c|c|}
\hline GENE & Forward Primer (5’-3') & Reverse Primer (5'-3') \\
\hline NC-TrkC & GGGTCTTTTCAAACATAGACAATCA & CTGGAGGAGGCCAGGTTTTTACTT \\
\hline FL-TrkC & AAGCCAGACACATATGTTCAGCACAT & $\begin{array}{c}\text { GCGGCCGCCTACAGATCCTCTTCTGAGA } \\
\text { TGAGTTTTTGTTCTCCGCCAAGAATGTCC } \\
\text { AGGTAGATCGGG }\end{array}$ \\
\hline NC-TrkB & GGGTAGCTGAGATAAAGGAAAGACA & GGGTGGACTTTGAAAGCAATCGTTA \\
\hline BMPRIA & $\begin{array}{r}\text { TCGAATTCGCCGCCACCATGACTCAGCT } \\
\text { ATACACTTACATCA }\end{array}$ & $\begin{array}{c}\text { TAGCGGCCGCCTACAGATCCTCTTCTGA } \\
\text { GATGAGTTTTTGTTCACCACCAATCTTTAC } \\
\text { ATCCTGGGATTCAACC }\end{array}$ \\
\hline Cbln 1 & CGAGGGAGAGGCGTAGTGGCCCGG & GGATGAGGACGCCGTTGCTGGCGG \\
\hline Cbln2 & CCGTAAGGGCTCAGAACGAC & TTAAGGCTACACACACACAG \\
\hline Cbln4 & ATCATCATCTTCCCCTCTGGGGATAT & TGATCTGTGAAACTTTGTGTCTGTCC \\
\hline
\end{tabular}

The following primers were used for cloning the Promoter sequences used in the luciferase assays: 


\begin{tabular}{|l|c|c|}
\hline GENE & Forward Primer (5'-3') & Reverse Primer (5'-3') \\
\hline Ntf3 & $\begin{array}{c}\text { ATCGAATTCCTCTCAGCCTTAACCGGTG } \\
\text { GGTGCA }\end{array}$ & $\begin{array}{c}\text { ATCGGATCCTTCGGTCATTCAGTCTCGCC } \\
\text { CACCC }\end{array}$ \\
\hline Cbln4 & $\begin{array}{c}\text { ATCGAATTCAAGGCCTGGCAAGCTTTTC } \\
\text { TGTTTT }\end{array}$ & $\begin{array}{c}\text { ATCGGATCCCTGCCAAGGTCTGAGGTCA } \\
\text { CTTGA }\end{array}$ \\
\hline
\end{tabular}

The following primers were used for cloning the full-length cDNA constructs:

\begin{tabular}{|c|c|c|}
\hline GENE & Forward Primer (5'-3') & Reverse Primer (5'-3') \\
\hline NC-TrkC & $\begin{array}{c}\text { GATATCGCCGCCACCATGGATGTCTCTC } \\
\text { TTTGCCCAGCC }\end{array}$ & $\begin{array}{c}\text { ACCTCGAGAAAGCCATGACGTCCTTTGCT } \\
\text { GAAAT }\end{array}$ \\
\hline $\begin{array}{c}\text { NC-TrkC } \\
\Delta \mathrm{ECD}\end{array}$ & CTGGGCACGGCCAACCAG & GCAAGCCAGCACGGAGCC \\
\hline $\begin{array}{l}\text { NC-TrkC } \\
\quad \Delta \mathrm{ICD}\end{array}$ & CTCAAGCTTCGAATTCTG & TGATGGTGTAGTGATGCC \\
\hline $\begin{array}{l}\text { NC-TrkC } \\
\text { Y516F }\end{array}$ & GAACCCCCAGTTTTTCCGTCAGG & TCAATGACTGGGATGCGG \\
\hline NC-TrkB & $\begin{array}{c}\text { GAATTCGCCGCCACCATGTCGCCCTGG } \\
\text { CTGAAGTGGCATG }\end{array}$ & $\begin{array}{c}\text { ACGAGCTCCCCATCCAGTGGGATCTTAT } \\
\text { GAAACA }\end{array}$ \\
\hline BMPRIA & $\begin{array}{c}\text { TCGAATTCGCCGCCACCATGACTCAGCT } \\
\text { ATACACTTACATCA }\end{array}$ & $\begin{array}{c}\text { TAGCGGCCGCCTACAGATCCTCTTCTGA } \\
\text { GATGAGTTTTTGTTCACCACCAATCTTTAC } \\
\text { ATCCTGGGATTCAACC }\end{array}$ \\
\hline Ntf3 & $\begin{array}{l}\text { AATTATTTAAATTGCCATGGTTACTTCTG } \\
\text { CCACGATCT }\end{array}$ & GGACAGATGCCAATTCATGTTCTTCC \\
\hline $\begin{array}{l}\text { Cbln1- } \\
\text { EGFP }\end{array}$ & $\begin{array}{c}\text { ATTAAGATCTATGCTGGGCGTCGTGGAG } \\
\text { CTG }\end{array}$ & $\begin{array}{c}\text { GGCCGGTCGACTGGAGGGGAAACACGA } \\
\text { GGAATC }\end{array}$ \\
\hline $\mathrm{Cbln} 2$ & $\begin{array}{c}\text { AGTTGAATTGAGCCCAGATGCCCGCGC } \\
\text { CTGG }\end{array}$ & $\begin{array}{c}\text { GTTAGCGGCCGCCTGGTGGCTCTGAGTC } \\
\text { TATAGAGGAAAA }\end{array}$ \\
\hline
\end{tabular}


Materials and Methods

\begin{tabular}{|c|c|c|}
\hline $\begin{array}{l}\text { Cbln4- } \\
\text { EGFP }\end{array}$ & $\begin{array}{c}\text { ATTAAGATCTATGGGCTCCGCGCGCCG } \\
\text { GGCG }\end{array}$ & $\begin{array}{c}\text { GGCCGGTCGACTGTAGAGGAAACACCAG } \\
\text { AAAGC }\end{array}$ \\
\hline Cbln4-AP & $\begin{array}{c}\text { AGCTGCTAGCATGGGCTCCGCGCGCCG } \\
\text { GGCGCTG }\end{array}$ & $\begin{array}{c}\text { AGCTTCCGGACGATAGAGGAAACACCAG } \\
\text { AAAGCCAGAA }\end{array}$ \\
\hline Ntf3-AP & $\begin{array}{c}\text { AGCTGCTAGCATGGTTACTTCTGCCACG } \\
\text { ATCTT }\end{array}$ & $\begin{array}{c}\text { AGCTTCCGGACGATGTTCTTCCAATTTTT } \\
\text { CTCGACAA }\end{array}$ \\
\hline Smad 1 & $\begin{array}{l}\text { TCGGTACCGCCGCCACCATGAATGTGA } \\
\text { CCAGCTTGTTTTCATTCACA }\end{array}$ & $\begin{array}{c}\text { ATGCGGCCGCTTAAGACACGGATGAAAT } \\
\text { AGGATTGTGGGG }\end{array}$ \\
\hline p66-ShcA & $\begin{array}{l}\text { TCGAATTCGCCGCCACCATGGATCTTCT } \\
\text { ACCCCCCAAGCCGA }\end{array}$ & $\begin{array}{c}\text { TAGCGGCCGCCTACGCATAATCCGGCAC } \\
\text { ATCATACGGATACACTTTCCGATCCACGG } \\
\text { GTTGCTGT }\end{array}$ \\
\hline p52-ShcA & $\begin{array}{c}\text { GAATTCGCCGCCACCATGAACAAGCTGA } \\
\text { GTGGAGGCGGCG }\end{array}$ & $\begin{array}{c}\text { TAGCGGCCGCCTACGCATAATCCGGCAC } \\
\text { ATCATACGGATACACTTTCCGATCCACGG } \\
\text { GTTGCTGT }\end{array}$ \\
\hline $\begin{array}{c}\text { Sip1 } \\
\text { fragment } 1\end{array}$ & $\begin{array}{c}\text { TCGATATCGCCGCCACCATGAAGCAGC } \\
\text { CGATCATGGCGGATG }\end{array}$ & GAAAGCTTCCCGGGCCCTATTCCCCTGC \\
\hline $\begin{array}{c}\text { Sip1 } \\
\text { fragment } 2\end{array}$ & $\begin{array}{c}\text { GCAGGGGAATAGGGCCCGGGAAGCTTT } \\
\text { C }\end{array}$ & $\begin{array}{c}\text { TAGCGGCCGCCTACAGATCCTCTTCTGA } \\
\text { GATGAGTTTTTGTTCACCACCTTCCATGC } \\
\text { CATCTTCCATATTGTCT }\end{array}$ \\
\hline
\end{tabular}

The NC-TrkC $\triangle \mathrm{ICD}, \triangle \mathrm{ECD}, \mathrm{Y} 516 \mathrm{~F}$ clones were generated by using the Q5 site directed mutagenesis kit (NEB). All PCR products were amplified using either Phusion polymerase or Q5 hot-start polymerase (NEB). The NC-TrkC $\triangle \mathrm{ECD}$ and $\triangle \mathrm{ICD}$ deletion constructs lacked amino acids 33-383 and 393-614 of the mouse NC-TrkC protein sequence respectively (Takahashi et al., 2011).

Cre recombinase was subcloned into a NeuroD1 promoter plasmid (a kind gift from Dr. Gordon Fishel, NYU). A mCherry coding region followed by polyA sequence was amplified using primers carrying the $34 \mathrm{bp}$ loxP sequence. The resulting PCR product was cloned upstream of the multiple cloning site of pCAGIG (Addgene). This plasmid thus 
allowed the expression of a gene of interest only upon Cre mediated recombination.

GFP fusion of Cbln 1 and Cbln 4 was cloned by inserting the Cbln 1 and Cbln4 ORF into pEGFP-N1 (Clontech). The entire sequence was then subcloned into a pCAG vector (Addgene).

\section{In-utero electroporation}

The procedure was carried out as described earlier (Saito, 2006). Time mated pregnant females were anesthetized using Isofluran inhalation. During the entire procedure the animal was placed on a heating pad to prevent heat loss. Tamgesic was administered subcutaneously as a painkiller. Hair around the abdomen was shaved off with a regular shaver. The skin was cleaned two to three times with $70 \%$ ethanol and then an Iodine solution to minimize the risk of infections. A $30 \mathrm{~mm}$ incision was made into the skin and then the abdominal wall along the midline. Carefully without damaging any blood vessels and organs, embryos from either side of the uterine wall were pulled out with the help of blunt forceps. Embryos were continuously bathed with a warm solution of Penicillin (1000 units/ml)-Streptomycin $(1000 \mu \mathrm{g} / \mathrm{ml})$ to prevent the embryos from drying and to minimize chances of infection. The plasmid solution mixed with fast green was injected into the lateral ventricles with the help of a picospritzer (WPI). Plasmid solution was injected until visual confirmation of the blue solution in the ventricle was achieved. Electroporation was carried out by applying 6 electric pulses of $35 \mathrm{~V}$ each, 50ms duration and 950ms interval. Post injection and electroporation, embryos were returned into the abdomen and the abdominal cavity was flushed three times with the PenicillinStreptomycin solution. The muscle was carefully sutured and surgical staples were used to staple the skin. The animals were allowed to recover and then returned to their cage and kept under observation. 


\section{Cell Transfection and Stimulation}

Cells were cultured in DMEM $+10 \% \mathrm{FBS}+1 \% \mathrm{P} / \mathrm{S}$. Cells were split one day prior to transfection and the media was changed to DMEM $+10 \%$ FBS. Cells were transfected with lipofectamine 2000 (Invitrogen) according to the manufacturer's protocol. 12 hours post transfection, the media was changed to Optimem+1\% P/S (no serum) and the cells were kept in this media for 12-16 hours prior to stimulation. Cells were stimulated with EGF (Peprotech, $100 \mathrm{ng} / \mathrm{ml}$ ) or Ntf3 (Peprotech, 50ng/ml) or BMP-4 (Invitrogen, 10ng/ml).

\section{0. shRNA generation and Validation}

shRNA clones targeting the following sequences of mouse BMPRIA were cloned into pSuper.Retro.Neo.GFP (Oligoengine):

1) GCTGTCTGTATAGTTGCTATG

2) GCTAGCTGGTTTAGAGAAACA

3) GGACTCAGCTGTATTTGATTA

4) GCCTAGCTGTTAAATTCAACA

Targeting sequences were designed using the Block-IT RNAi Designer (Invitrogen). The loop sequence used was TCTCTTGAA. Positive clones were transfected along with a Myc-tagged BMPRIA expression construct in HEK293T cells using lipofectamine 2000 (invitrogen). Four days post transfection, cells were lysed in $50 \mathrm{mM}$ Tris- $\mathrm{HCl} \mathrm{pH} 7.5$, $150 \mathrm{mM} \mathrm{NaCl}, 1 \mathrm{mM}$ EDTA, $1 \%$ Triton X-100, 1x protease inhibitor cocktail (Sigma) and pepstatin. Lysates were centrifuged for 20 minutes at $12000 \mathrm{~g}, 4^{\circ} \mathrm{C}$. Protein concentration was measured using the BCA assay kit (Thermo scientific). 30 $\mathrm{g}$ protein was loaded on a SDS-PAGE gel and transferred onto a PVDF membrane. Anti-Myc antibody and anti-GAPDH antibodies were used to measure the relative amount of BMPRIA. A scrambled shRNA was used as the control. 


\section{Luciferase Assay}

Cbln4 and Ntf3 enhancer regions were cloned upstream of a Gaussia luciferase coding sequence (Thermo scientific). This was then cotransfected with a CMV promoter driven Alkaline phosphatase in COS or HEK293T cells using lipofectamine 2000 according to the manufacturers protocol (Invitrogen). Supernatant from the cells was collected 48-72h post transfection. The gaussia luciferase and Alkaline phosphatase mediated luminescence was detected using the secrete pair DUAL luminescence kit (GeneCopoeia) and read using a Glomax luminometer (Promega). Data was collected from three independent experiments, each probed in triplicates and presented as the relative luminescence ratio (Gaussia luciferase: Alkaline phosphatase).

\section{Western Blotting and Immunoprecipitation}

Cultured cells or fresh cortical tissue were lysed either in Flag buffer (50mM Tris pH7.5, 100mM NaCl, 1mM EDTA, 1\% v/v Triton X-100) or RIPA buffer (50mM Tris pH7.5, 150mM NaCl, 1\%NP-40, 0.5\% Sodium deoxycholate, $0.1 \% \mathrm{SDS}$ ) containing $1 \mathrm{x}$ protease inhibitor cocktail (SIGMA) and PhosphoStop (Roche). The samples were then centrifuged for 20 minutes at 14000 at $4^{\circ} \mathrm{C}$. The protein concentration was estimated using the BCA protein assay kit (Thermo Scientific). The samples were denatured by boiling for 5 minutes at $95^{\circ} \mathrm{C}$ in $1 \mathrm{x}$ SDS loading buffer and equal amounts of protein were separated by SDSPAGE. The protein samples were then transferred onto a PVDF transfer membrane (Immobilon-P, Milipore). The membrane was subsequently blocked for one hour in 3\% BSA in TBST (TBS + 0.5\% Tween-20), followed by overnight incubation in the primary antibody at $4{ }^{\circ} \mathrm{C}$. The following day, the membranes were washed in TBST and incubated for one hour in peroxidase coupled secondary antibodies (Jackson Laboratory). Chemiluminescence (ECL western blotting detection 
reagent, Perkin Elmer) was used for visualizing the protein bands. The chemiluminescence was captured using the Image lab software on a ChemiDoc XRS+ detector (Bio-Rad). For stripping, the membranes were washed three times in PBS followed by two-ten minute washes in the stripping buffer $(25 \mathrm{mM}$ glycine- $\mathrm{HCl} \mathrm{pH} 2,1 \%$ (w/v) SDS). The membranes were then equilibrated in $1 \mathrm{M}$ Tris $\mathrm{pH} 6.8$ followed by three PBS washes. After blocking the membranes in 5\% BSA in TBST, they were incubated overnight with the primary antibody.

For Immunoprecipitation, after lysis, the samples were pre-cleared using $20 \mu 1$ of ProteinG sepharose beads (GE) for one hour at $4^{\circ} \mathrm{C}$ on a rotor. The samples were then briefly centrifuged and the required antibody was added to the supernatant and incubated for 2 hours at $4^{\circ} \mathrm{C}$ on a rotor. The antigen-antibody complex was captured by adding $20 \mu 1$ of pre-washed ProteinG sepharose beads for 1 hour at $4^{\circ} \mathrm{C}$ on a rotor. The samples were briefly centrifuged and washed four times in lysis buffer and once in TBS. After removing as much of the buffer as possible, $20 \mu$ of $2.5 \mathrm{X}$ SDS loading buffer was added to each sample and boiled for five minutes at $95^{\circ} \mathrm{C}$. Alternatively, the proteins were eluted from the beads using a glycine elution buffer (Thermo scientific).

\section{In-situ Hybridization}

For cloning probes used in in-situ hybridization, PCR fragments were either amplified using GoTaq (Promega) or Phusion Polymerase (NEB). Whenever Phusion polymerase was used, an additional ' $\mathrm{A}$ ' tailing step was done with GoTaq for one hour at $72^{\circ} \mathrm{C}$. Amplicons were cloned into a pGEMT vector (Promega) following the manufacturers protocol. After verifying the directionality of the insert, the vector was linearized and the anti-sense probe was generated using either the T7, T3 or Sp6 RNA polymerases (Roche). The in-vitro transcription consisted of the following components: 
10X Transcription buffer

Polymerase

DIG RNA labeling mix

Linerarized Plasmid

RNase inhibitor

DEPC- $\mathrm{H}_{2} \mathrm{O}$

Total Volume
$2 \mu 1$

$2 \mu 1$

$2 \mu 1$

$1-2 \mu \mathrm{g}$

$2 \mu 1$

variable

After incubation for 2 hours at $37^{\circ} \mathrm{C}$, the sample was treated with DNase for 30 minutes, followed by overnight precipitation of the RNA using $\mathrm{LiCl}$. The RNA probe was finally dissolved in $20 \mu \mathrm{DEPC}-\mathrm{H}_{2} \mathrm{O} .1 \mu \mathrm{l}$ was used for running on an agarose gel to verify the size of the RNA product.

For the in situ hybridization $12-14 \mu \mathrm{m}$ thick cryosections were used. The sections were fixed in 4\% PFA followed by two 5 minute PBS washes. The sections were then subjected to Proteinase-K treatment (2-3 minutes, $37^{\circ} \mathrm{C}, 20 \mu \mathrm{g} / \mathrm{ml}$ ) to permeabilize the cells in order to allow for better probe penetration. The Proteinase-K activity was inhibited by washing the sections in $0.2 \%$ glycine in PBS. Following this, the slides were rinsed in PBS and post-fixed in 4\% PFA/ 0.2\% Glutaraldehyde in PBS for 20 minutes at RT. After washing the slides twice in PBS, the sections were incubated for 2 hours in hybridization buffer $(50 \%$ formamide, 5X SSC pH 7.0, 1\% Boehringer block, 2.5mM EDTA, 0.1\% Tween-20, 0.1\% CHAPS, $0.1 \mathrm{mg} / \mathrm{ml}$ Heparin, $100 \mu \mathrm{g} / \mathrm{ml}$ Yeast RNA, $50 \mu \mathrm{g} / \mathrm{ml}$ Salmon sperm DNA and $1 \mathrm{x}$ Denhardt's solution) at $65^{\circ} \mathrm{C}$. After the prehybridization step, the slides were incubated in the antisense probe (diluted in hybridization buffer) at $65^{\circ} \mathrm{C}$ for $16-20$ hours. The following day, the slides were washed in 2X SSC pH4.5 (20X SSC= $3 \mathrm{M} \mathrm{NaCl}$ and $300 \mathrm{mM}$ Trisodium citrate), followed by an RNase treatment for 30 minutes at $37^{\circ} \mathrm{C}(20 \mu \mathrm{g} / \mathrm{ml}$ in $0.5 \mathrm{M} \mathrm{NaCl}, 10 \mathrm{mM}$ Tris $\mathrm{pH}$ 7.5). The slides were then rinsed in $2 \mathrm{X}$ SSC $\mathrm{pH} 4.5$, followed by three washes of 30 minutes each in $2 \mathrm{X} \mathrm{SSC} \mathrm{pH4.5/50 \%} \mathrm{formamide} \mathrm{at}$ 
$65^{\circ} \mathrm{C}$. The slides were then washed twice in KTBT $(50 \mathrm{mM}$ Tris $\mathrm{pH} 7.5$, $150 \mathrm{mM} \mathrm{NaCl}, 10 \mathrm{mM} \mathrm{KCl}$ and $1 \%$ Triton X-100) before blocking in 20\% sheep serum prepared in KTBT. Anti-DIG Alkaline phosphatase conjugated antibody (Sheep, Roche, 1:1000) was added and the slides were incubated overnight at $4^{\circ} \mathrm{C}$. The next day, the slides were washed in KTBT, followed by three washes in NTMT (100mM Tris pH 9.5, $100 \mathrm{mM} \mathrm{NaCl}, 50 \mathrm{mM} \mathrm{MgCl}_{2}$ and $0.05 \%$ Tween-20). The colorimetric reaction was developed by adding the alkaline phosphatase substrate NBT/BCIP (1:50, Roche) prepared in NTT (100mM Tris pH 9.5, 100mM $\mathrm{NaCl}$, and $0.05 \%$ Tween-20) to the slides. The reaction was stopped by washing the slides in PBST (PBS $+0.1 \%$ Triton $\mathrm{X}-100)$ and progressively dehydrating the slides in Ethanol. The slides were mounted using Eukitt mounting medium.

\section{AP staining of Sections and Cells}

AP tagged constructs were expressed transiently in HEK293T cells. The media was changed 24 hours post transfection. Thereafter, the media was collected 5-6 days later and checked for Alkaline phosphatase activity using NBT-BCIP as a substrate. The recombinant proteins were also run on a SDS-PAGE gel and blotted to verify the size of the fusion proteins. AP fusion staining was carried out as described earlier (Flanagan et al., 1990; Flanagan and Cheng, 2000; Brennan and Fabes, 2003). For AP-fusion protein binding on tissue, fresh-frozen (unfixed) tissue was sectioned using a Leica cryostat. Sections were mounted on slides and stored inside the cryostat to avoid air-drying. Subsequently, the sections were fixed in dry ice cooled 100\% methanol for 8-10 minutes and then washed three times in PBS with $4 \mathrm{mM}$ $\mathrm{MgCl}_{2}$. Sections were then blocked in PBS (containing $\mathrm{MgCl}_{2}$ ) with $10 \%$ FBS for one hour at room temperature. Varying dilutions of the APfusion protein were made in the blocking solution and added to the 
sections. After incubating the sections in the AP-fusion protein for two hours, the sections were washed five times for five minutes each in $1 \mathrm{X}$ PBS. The bound AP-fusion protein was fixed for 90 seconds with $4 \%$ PFA, 60\% acetone and 20mM HEPES pH 7.0. The slides were washed for three more times in $1 \mathrm{X}$ PBS and then the endogenous phosphatases were inactivated by heating the slides in a water bath at $65^{\circ} \mathrm{C}$ for 100 minutes. After washing the slides in PBS, they were washed twice in the AP reaction buffer $(100 \mathrm{mM}$ Tris pH 9.5, $100 \mathrm{mM}$ $\mathrm{NaCl}, 5 \mathrm{mM} \mathrm{MgCl}{ }_{2}$ ). NBT-BCIP substrate (Roche) was then added to the slides and they were incubated at room temperature until the desirable color was attained.

For AP-fusion protein staining on cells, COS-7 cells were used. The cells were washed in HBHA $(0.137 \mathrm{M} \mathrm{NaCl}, 5.4 \mathrm{mM} \mathrm{KCl}, 0.25 \mathrm{mM}$ $\mathrm{Na}_{2} \mathrm{HPO}_{4}, 0.44 \mathrm{mM} \mathrm{KH}_{2} \mathrm{PO}_{4}, 1.3 \mathrm{mM} \mathrm{CaCl}_{2}, 1.0 \mathrm{mM} \mathrm{MgSO}_{4}, 4.2 \mathrm{mM}$ $\mathrm{NaHCO}_{3}, 0.5 \mathrm{mg} / \mathrm{ml} \mathrm{BSA}$ ) buffer, followed by incubation of the APfusion protein for 90 minutes at room temperature. The cells were then washed in HBHA five times and then fixed for 15 seconds in 4\% PFA, $60 \%$ acetone and 20mM HEPES $\mathrm{pH}$ 7.0. The cells were then washed three times in $\mathrm{HBS}\left(0.137 \mathrm{M} \mathrm{NaCl}, 5.4 \mathrm{mM} \mathrm{KCl}, 0.25 \mathrm{mM} \mathrm{Na}_{2} \mathrm{HPO}_{4}\right.$, $0.44 \mathrm{mM} \mathrm{KH}_{2} \mathrm{PO}_{4}, 1.3 \mathrm{mM} \mathrm{CaCl}_{2}, 1.0 \mathrm{mM} \mathrm{MgSO}_{4}, 4.2 \mathrm{mM} \mathrm{NaHCO}_{3}$ ) for five minutes each, followed by heat inactivation for two hours at $65^{\circ} \mathrm{C}$. The cells were then washed in AP reaction buffer. NBT-BCIP substrate (Roche) was then added to the cells and they were incubated at room temperature until the desirable color was attained. The reaction was stopped by fixing the cells in 4\% PFA.

\section{5. cDNA library synthesis}

E14.5 cortices were used for RNA isolation. RNA was isolated using Trizol reagent following the manufacturer's protocol (Invitrogen). The quality of the RNA was assessed using agarose gel-electrophoresis. $500 \mu g$ of total RNA was used for purifying mRNA using the Fast track 
MAG mRNA isolation kit (Invitrogen) following the manufacturer's protocol. $10 \mu \mathrm{g}$ of purified mRNA was used for preparing the cDNA library. The cDNA library was made using the SuperScript Full Length cDNA library construction Kit II (Invitrogen) following the manual provided. The kit allowed a size exclusion chromatography separation of the cDNA molecules to enrich for larger insert size. Accordingly, two separate cDNA libraries were prepared in the entry vector- pDONR 222. 24-30 random clones were selected and digested using the enzyme BsrGI to estimate the average insert size. Upon complete quality check of the cDNA library, the clones were grown briefly and DNA was isolated. 25ng of the cDNA library in the entry vector pDONR 222 was transferred into the destination vector pDEST 40 using the gateway LR recombination reaction (Invitrogen). The clones were again screened randomly to confirm the successful shuttling of the cDNA library from the entry vector into the destination vector. 


\section{RESULTS}

\section{Mosaic deletion of Sip1 in young cortical neurons phenocopies the Sip1 mutant.}

We have previously demonstrated that deletion of Sip1 in young neocortical neurons changes the proportion of deep layer versus upper layer neurons (Seuntjens et al., 2009). In order to test whether this effect is cell intrinsic or cell extrinsic we decided to employ in utero electroporation (IUE). We electroporated a plasmid encoding GFP-IRESCre, that expresses Cre recombinase together with GFP, into the lateral ventricles of E12.5 Sip $1^{f l / f l}$ and Sip $1^{f l / w t}$ mouse embryos. To see if this relatively low efficiency deletion of Sip1 would replicate the phenotype of Sip 1 fl/fl:NexCre mutants we performed immunohistochemistry with the layer $\mathrm{V}$ marker Ctip2. Like in Sip $1^{f l / f l}: N e X^{C r e}$, the proportion of Ctip2 cells had decreased in Sip $1^{f l / f l}$ as compared to the control (Figure5A). Interestingly, within the electroporated region where the loss of Ctip2 positive cells was observed, GFP positive cells did not show a preference to being Ctip2 positive or negative. This shows that Sip 1 affects cortical cell fate not due to its cell intrinsic action but through cell extrinsic mechanisms. This data demonstrates that IUE, despite its relatively low cell targeting efficiency can be used to study cell extrinsic effects. On the other hand it also shows that Sip1 affects cortical cell fate not due to its cell intrinsic action but through cell extrinsic mechanisms.

\section{2. $N t f 3$ is upregulated in the Sip1 mutant cortex.}

We have previously shown that upon loss of Sip1 in the developing cortex, there is an ectopic upregulation of $N t f 3$ in the cortical plate (Figure 5B,(Seuntjens et al. 2009)). This upregulation correlates to the premature generation of upper layer neurons in the Sip1 mutant. We had also shown through Chromatin immunoprecipitation (ChIP) assay 
that Sip1 directly binds to the Ntf3 promoter region (Seuntjens, et al. 2009). In order to investigate the functionality of this binding we performed a luciferase assay. A $1.7 \mathrm{~Kb}$ fragment of the Ntf3 enhancer region (Figure $5 \mathrm{C}$ ) was inserted into a plasmid encoding the gaussia luciferase gene and co-transfected into COS-7 cells with a plasmid encoding Sip1 cDNA.
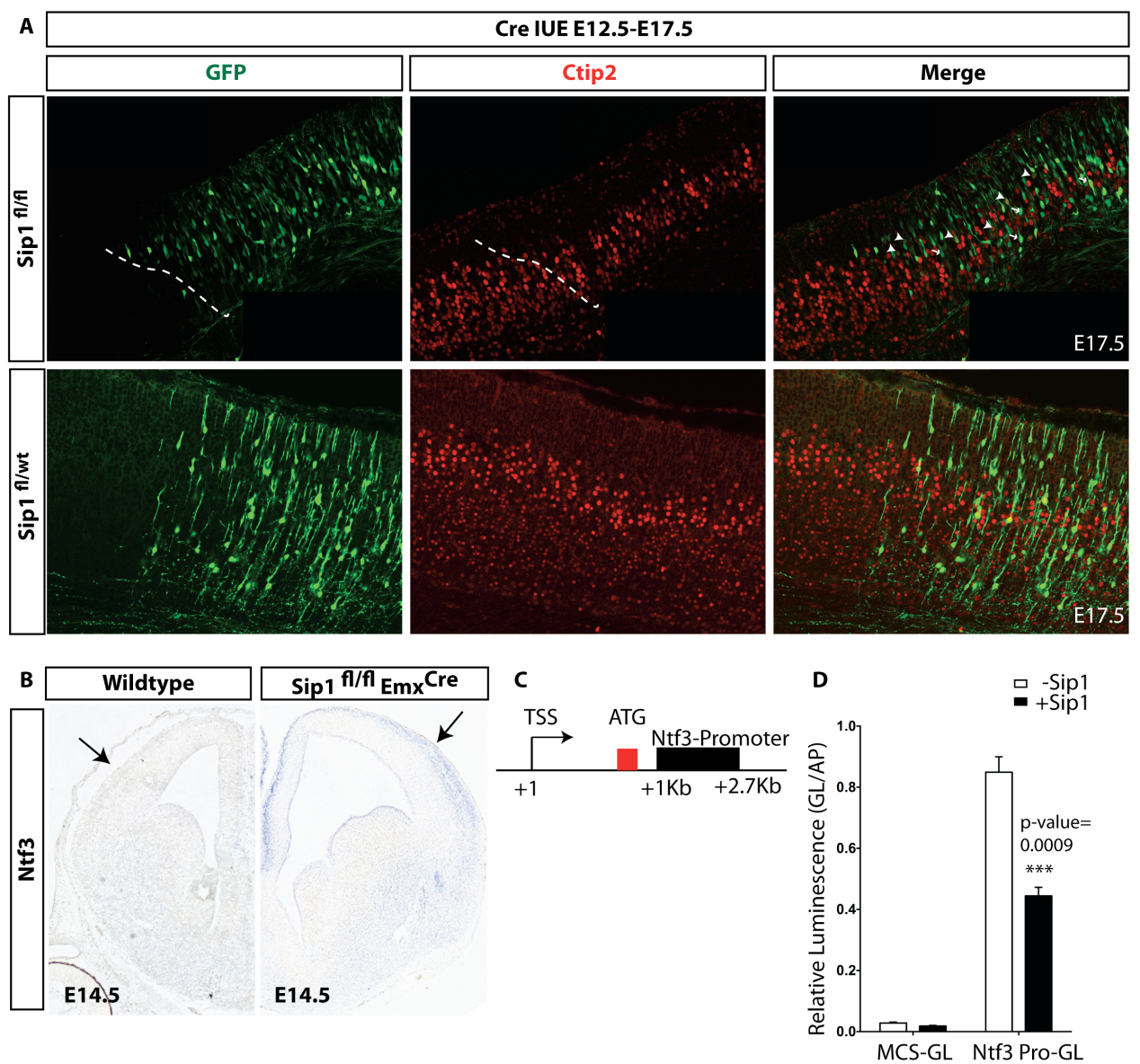

\section{Figure 5. Ntf3 is upregulated in the Sip1 mutant cortex}

(A) In utero electroporation of Cre in Sip1fl/fl and Sip1fl/wt embryos at E12.5. Proportion of Ctip2 positive cells decreased within the electroporated region of Sip 1flfl embryos at E17.5, while no difference was observed in Sip $1 f l / w t$ embryos. Filled arrowheads point to GFP+/Ctip2+ and arrows point to GFP+/Ctip2- cells (B) In situ hybridization shows that Ntf3 is upregulated in the Sip1 mutant cortex at E14.5, while no expression can be detected in the wildtype. (C) Scheme showing the Ntf3 enhancer region used for the luciferase assay (D) Luciferase assay shows that upon co-transfection of Sip1, the transcription of luciferase driven by the $N t f 3$ enhancer element reduced by 1.9 fold $(\mathrm{n}=3$, relative luminescence without $\operatorname{Sip} 1=0.85 \pm .05$ as compared to $0.44 \pm 0.03$ with $\operatorname{Sip} 1, \mathrm{p}$ value $=0.0009$ ).

We observed a decrease in transcription activity of the Ntf3 enhancer by 1.9 -fold (Figure 5D, n=3, p-value $=0.0009$ ). These results indicate that Sip1 can directly repress Ntf3 transcription. 


\section{Ntf3 promotes an increase in the basal progenitor} population.

A

-CAG-mCherry PA -Nt+3 -IRES-EGFP -
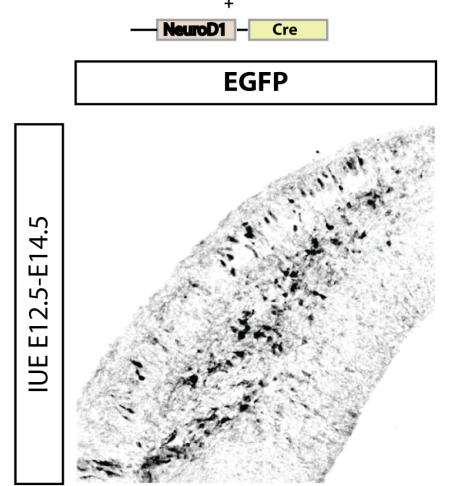

B

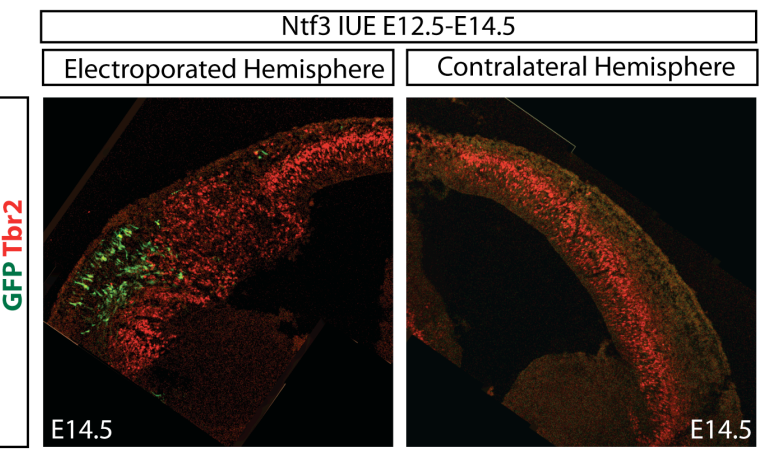

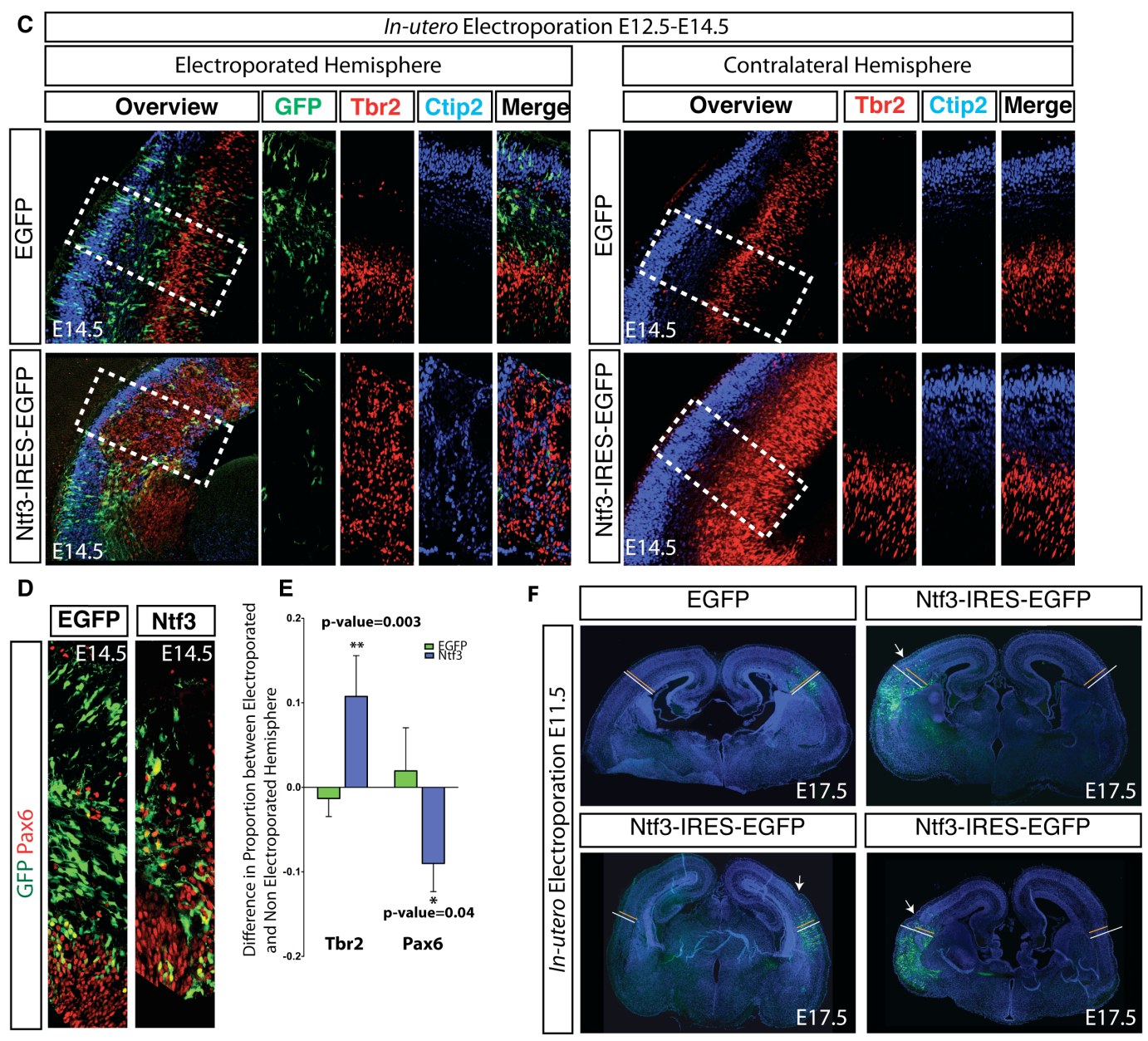


Figure 6. Ntf3 promotes an increase in the basal progenitor and decrease in apical progenitor population.

(A) Plasmid system for restricting expression to postmitotic neurons. A postmitotic neuron specific promoter (NeuroD1) drives Cre expression. Cre mediated recombination switches expression from mCherry to Ntf3 and EGFP. A representative image shows that GFP expression is largely restricted to postmitotic neurons (B) Overview image showing that upon Ntf3 over-expression, Tbr2+ basal progenitor population is expanded (C) Electroporation of GFP does not lead to any change in the size or distribution of Tbr2+ and Ctip2+ cells. Over-expression of Ntf 3 leads to an expansion of Tbr2+ cells. Ctip2+ cells are displaced, probably due to a secondary effect of this increase in Tbr2+ cells. The contralateral hemisphere serves as an internal control. (D) Pax6+ cells are also displaced and reduced in number in $N t f 3$ over-expression brains (E) Differences in the proportion of Tbr2+ and Pax6+ cells in a radial unit of the cortex between electroporated and nonelectroporated hemisphere $(10.75 \pm 4.8 \%$ higher Tbr2+ cells in the electroporated hemisphere upon Ntf3 over expression compared to $-1.3 \pm 2.1 \%$ in EGFP electroporations, $\mathrm{n}=5, \mathrm{p}$-value $=0.003 ; 9 \pm 3.3 \%$ lesser Pax6 + cells in the electroporated hemisphere upon $N t f 3$ over expression compared to $1.9 \pm 5.1 \%$ in control plasmid electroporations, $n=3, p$-value $=0.04$ ). All electroporation were done at E12.5 and analyzed at E14.5. (F) Radial expansion of the cortex on Ntf3 overexpression. White and orange bars indicate the thickness of the electroporated and non-electroporated hemisphere respectively. The bars were placed parallel to the apical process of the cells. Arrows indicate the physical fold in the cortical plate highlighting the expansion.

To study if the upregulation of $N t f 3$ in the Sip1 mutant has any effect on the proportion of apical and basal progenitors, we decided to overexpress $N t f 3$ in the wildtype cortex. In order to restrict the expression of $N t f 3$ to postmitotic neurons, we designed a plasmid system using the Cre-loxP system. In this plasmid Ntf3-IRES-eGFP cassette was preceded by a $m$ Cherry-polyA sequence flanked by loxP sites. The Cre recombinase used here was driven by the postmitotic specific NeuroD1 promoter, which switches expression from mCherry to $N t f 3$ and EGFP specifically in postmitotic neurons (Figure6A). EGFP expression verified that most of the recombined cells were indeed postmitotic (Figure 6A). In order to avoid variations that arise from comparing different medio-lateral and rostro-caudal levels while analyzing electroporated brains, we performed all analysis as the difference between the electroporated and non-electroporated hemispheres at the same medio-lateral and rostro-caudal level. We firstly looked at any possible effects of $N t f 3$ over expression on the ratio of apical and basal progenitors. To do so, we electroporated wildtype E12.5 embryos 
and analyzed the brains at E14.5. We noticed that upon Ntf3 over expression there was a vast expansion of the number of Tbr2 positive basal progenitors and correspondingly on the size of the SVZ (Figure $6 \mathrm{~B}, \mathrm{C}, \mathrm{E} 10.75 \pm 4.8 \%$ higher Tbr2 positive cells in the electroporated hemisphere upon $N t f 3$ over expression compared to $-1.3 \pm 2.1 \%$ in control plasmid electroporations, $\mathrm{n}=5$ each, $\mathrm{p}$-value $=0.003$ ) Interestingly, there was also a decrease in the Pax6 positive apical progenitor population on Ntf3 over-expression (Figure 6D, E; $9 \pm 3.3 \%$ lesser Pax6 positive cells in the electroporated hemisphere upon Ntf3 over-expression compared to $1.9 \pm 5.1 \%$ in control plasmid electroporations, $n=3$ each, $p$-value=0.04). Interestingly, the expansion of Tbr2 positive SVZ was not always found to be restricted to the electroporated region of the cortical plate but expanded into the regions flanking the electroporation site as well (Figure 6B, C). Following the expansion in Tbr2 positive progenitors, we also observed a radial expansion of the cortex (Figure 6F). Since in all these experiments $N t f 3$ expression was restricted to postmitotic neurons, the changes in apical or basal progenitor populations are most likely a result of feedback signaling from postmitotic neurons to the progenitors.

\section{Ntf3 promotes upper layer neurogenesis at the expense of deep layer neurons.}

The above results show that $N t f 3$ promotes a shift from apical to basal progenitor production. Consequently, this might lead to an increase in upper layer production at the expense of deeper layer neurons (Arnold et al. 2008). In order to test this hypothesis, we over-expressed Ntf3 in postmitotic neurons at E11.5 and analyzed the brains at E17.5. We observed a decrease in Ctip2 positive layer $\mathrm{V}$ neurons in the Ntf3 electroporated regions (Figure 7A). When analyzed, $N t f 3$ electroporated brains showed a $3.4 \pm 1.35 \%$ decrease in Ctip2 cells compared to the 
contralateral hemisphere, while EGFP electroporated brains did not show any difference $(-0.05 \pm 1.2 \%)$ between electroporated and nonelectroporated hemispheres (Figure 7B, C, n=5, p-value=0.003).

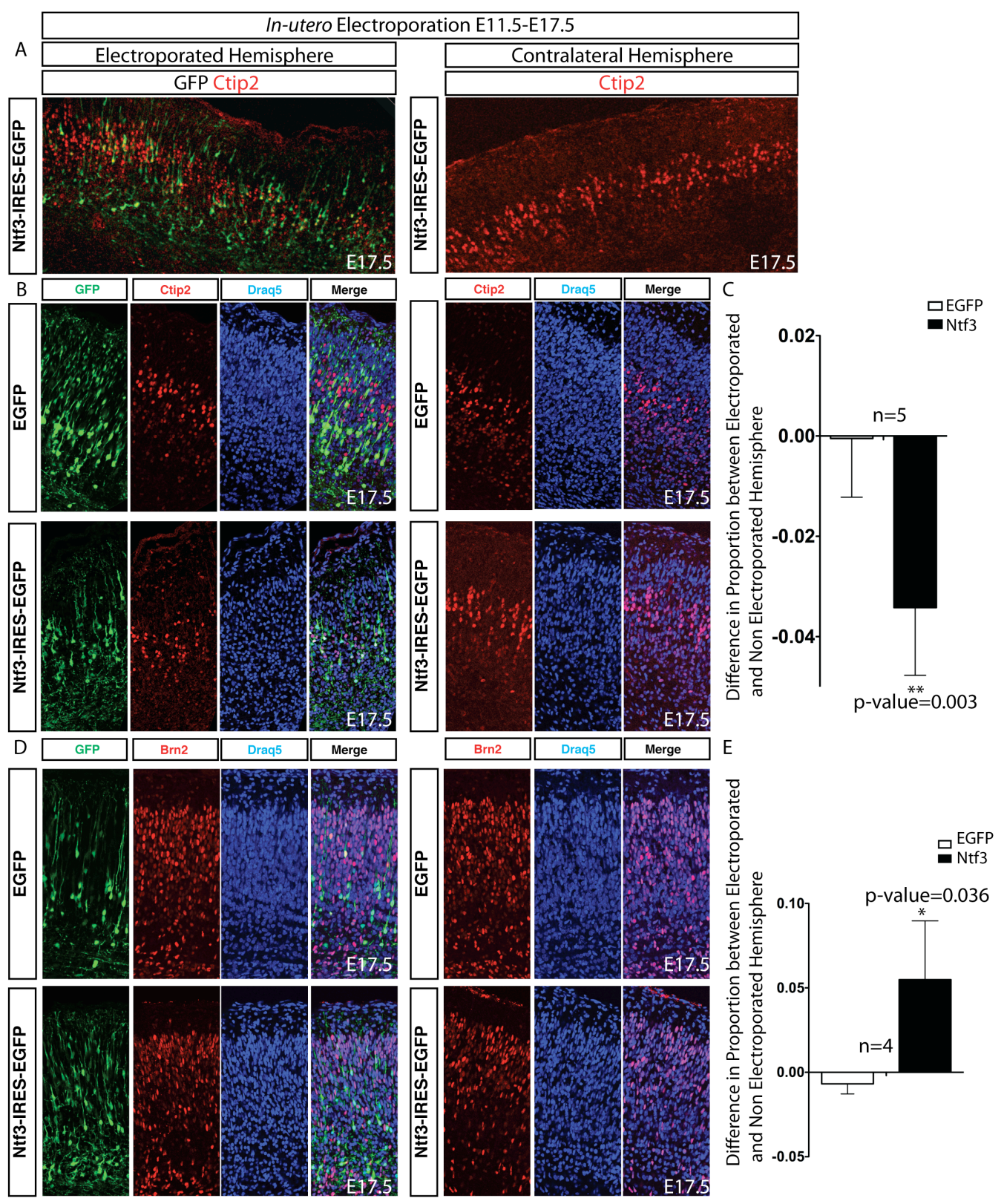

Figure 7. Ntf3 promotes upper layer neurogenesis at the expense of deep layer neurons

(A) Decline in Ctip2 numbers within the Ntf3 electroporated hemisphere (B-C) Ntf3 overexpression leads to a $3.4 \pm 1.35 \%$ decrease in deep layer Ctip $2+$ cells compared to the non-electroporated hemisphere, while EGFP expression does not alter the proportion $(-0.05 \pm 1.2 \%), \mathrm{n}=5, \mathrm{p}$-value $=0.003$ (D-E) $N t f 3$ electroporated brains show a $5.4 \pm 3.47 \%$ increase in Brn2+ Upper layer neurons while EGFP does not affect the proportion $(-0.68 \pm .6 \%, n=4$ each, $p$-value $=0.036)$. 
We also observed a $5.4 \pm 3.47 \%$ increase in Brn2 positive upper layer neurons in Ntf3 electroporated hemispheres compared to EGFP electroporation $(-0.68 \pm .6 \%$, Figure $7 \mathrm{D}, \mathrm{E} \mathrm{n}=4$, p-value $=0.036)$.

\section{Deletion of $N t f 3$ increases the number of layer VI neurons but the Ntf3-Sip 1 compound mutant does not rescue Sip1 mutant phenotype.}

We have previously reported that in the absence of Sip1, cortical progenitors precociously produce upper layer neurons at the expense of deep layer neurons (Seuntjens et al. 2009). To investigate if this phenotype can be reverted on Ntf3 deletion, we generated Sip1-Ntf3 compound mutants. We compared the proportion of the different cortical layers between the wildtype, Ntf3 single mutant, Sip1 single mutant and Sip1-Ntf3 compound mutant. We did not find any significant difference in the proportions of Satb2 positive (layer II-V), Ctip2 positive (layer V), Brn2 positive (layer II-IV) and Sox5 positive (layer VI) cells between Sip1 single and Sip1-Ntf3 double mutants (Figure 8A-D, all $\mathrm{p}$-value $\geq 0.05$ ). Further, we did not find any difference between wildtype and Ntf3 mutants with respect to the proportion of Satb2, Brn2 and Ctip2 positive populations (Figure 8A, $\mathrm{B}, \mathrm{D})$. Interestingly, we noticed an increase in the Sox5 positive layer VI population in $N t f 3$ mutants compared to wildtype controls (36.5 \pm $2.9 \%$ in $N t f 3$ mutants compared to $29.3 \pm 2.3 \%$ in wildtype controls, $\mathrm{n}=3, \mathrm{p}$-value $=0.029 ;$ student's $\mathrm{t}$-test). This might suggest that Ntf3 indeed plays an important role in cortical lamination in the wild type scenario. 
A
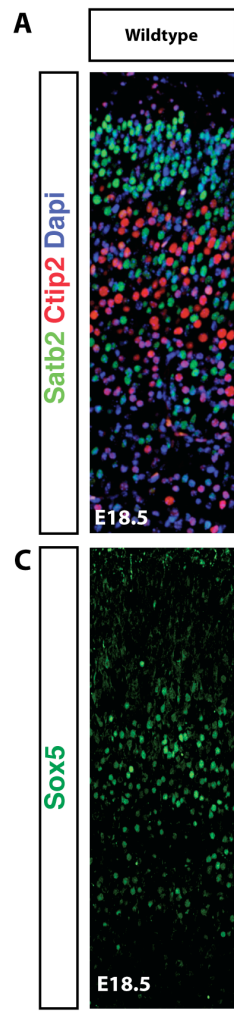
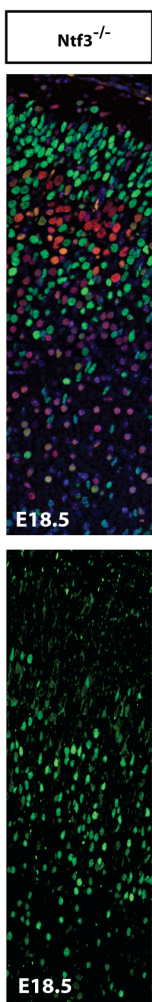
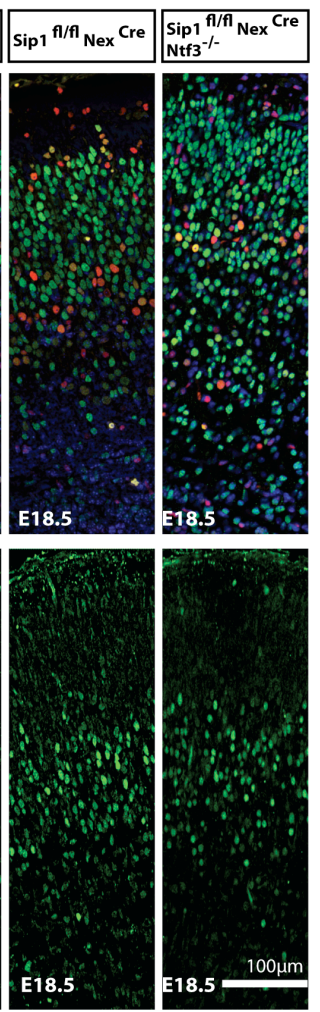

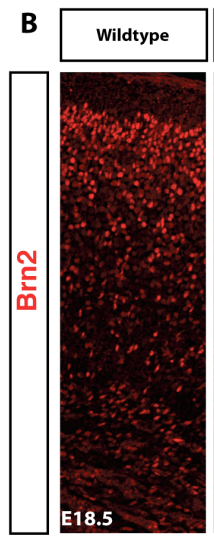

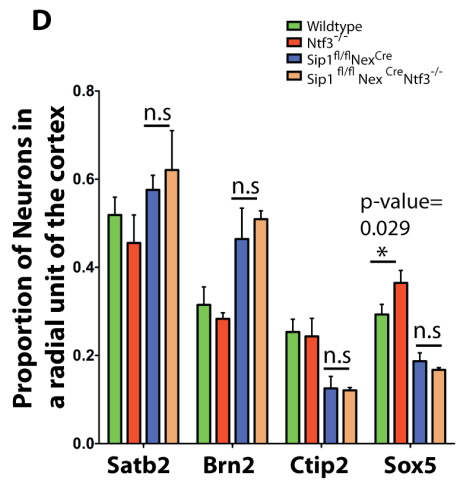

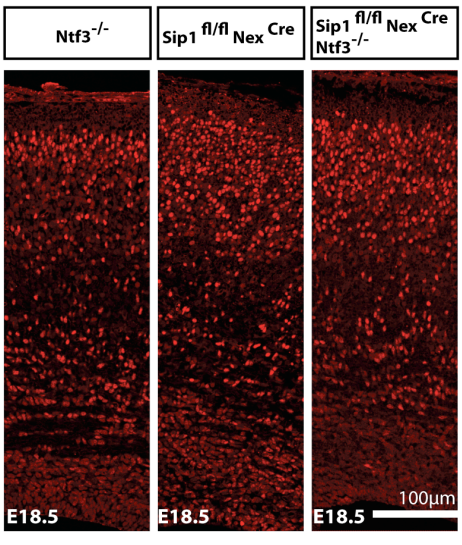

Figure 8. Deletion of $N$ tf 3 from the Sip1 mutant cortex does not rescue the Sip1 mutant phenotype.

(A) Satb2 and Ctip2 immunohistochemistry marking upper layer and layer V cells in wildtype, Ntf3-\%, Sip 1fl/fl; NexCre and Sip1-Ntf3 double mutants. The decrease in Ctip2 cells in Sip1 mutants is not restored in the Sip1-Ntf3 double mutant. Similarly the increase in Satb2+ cells is also not restored. Another upper layer marker (B) Brn2 and layer VI marker (C) Sox5 also confirm that the excessive production of upper layer neurons at the expense of deep layer neurons in the Sip1 mutant is not restored in the Sip1-Ntf3 double mutant. (D) $n=3$ for wildtype, Sip1 mutant and Ntf3 mutant, $\mathrm{n}=2$ for Sip1-Ntf3 double mutants. The differences between Sip1 mutant and Sip1-Ntf3 double mutant are not significant for any of the layer markers. The proportion of Sox $5+$ cells is higher in Ntf 3 mutant compared to wildtype $(36.5 \pm 2.9 \%$ in $N t f 3$ mutant compared to $29.3 \pm 2.3 \%$ in wildtype controls, $\mathrm{p}$-value $=0.029$ ).

\section{Localizing the receptors for $\mathrm{Ntf3}$ in the developing cortex}

To understand how Ntf3 functions as a feedback signaling molecules, it was essential to locate the cognate receptor. To study the location of possible receptors of $\mathrm{Ntf3}$, we made an Ntf3-alkaline phosphatase (AP) fusion construct (Figure 9A). We then transfected this construct in HEK293T cells and collected the supernatant, which was enriched in Ntf3-AP recombinant protein (Figure 9A). In order to verify the 
biological activity of the AP fused Ntf3, we used this recombinant protein to immunoprecipitate two known Ntf3 receptors- TrkC and TrkB.

A

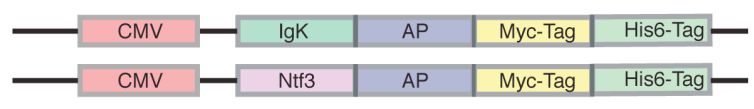

B
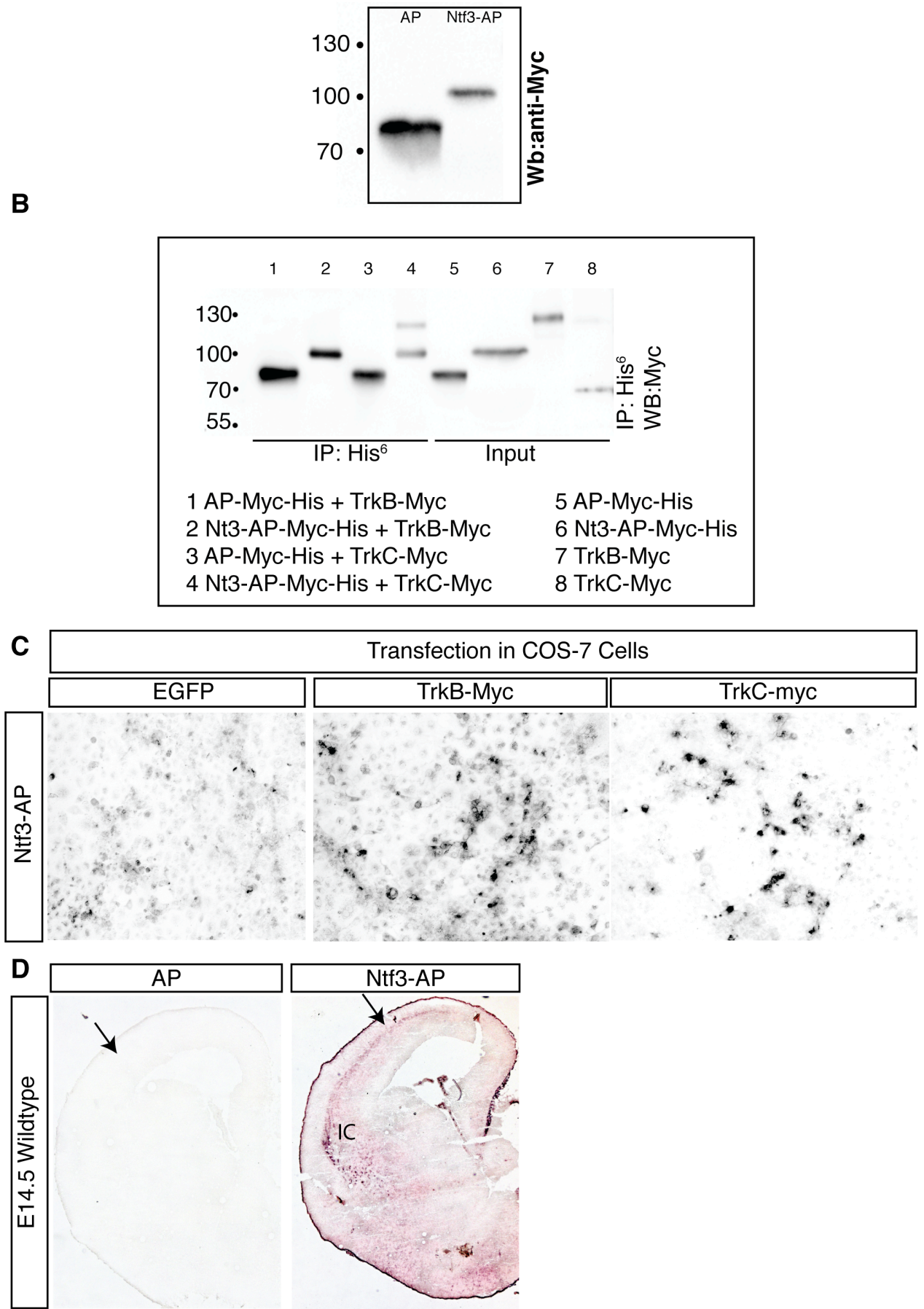

Figure 9. Localizing the receptors for Ntf3 in the developing cortex

(A) Scheme showing the design of the Ntf3-Alkaline phosphatase fusion plasmid construct. The plasmids were transfected in HEK293T cells and six days post 
transfection the supernatant was analyzed by western blot to validate the expression of the recombinant protein. Ntf3-AP as visualized by using a Myc tag antibody, can be seen running higher than untagged AP (B) for validating the binding ability of recombinant Ntf3-AP, the protein enriched supernatant was mixed with myc tagged TrkC or TrkB containing cell lysates. The samples were immunoprecipitated with a His tag antibody and probed for the presence of TrkC or TrkB using a Myc tag antibody. Ntf3-AP but not untagged AP could bind to TrkC (lanes 3-4). TrkB fails to co-immunoprecipitate with both AP and Ntf3-AP (lanes1-2) (C) To validate the ability of Ntf3-AP to bind to its receptors in the native state, Ntf3-AP or AP alone was over layed on TrkB or TrkC transfected COS-7 cells. In this case, Ntf3-AP could bind to both receptors (D) E14.5 sections were incubated with AP or Ntf3-AP to identify the location of the receptors in the developing cortex. Ntf3-AP marks the intermediate zone and fibers entering the internal capsule (IC).

Indeed, Ntf3-AP could bind to TrkC but not to TrkB (Figure 9B). However, since $\mathrm{Ntf3}$ is also known to bind to $\operatorname{TrkB}$ at higher concentrations, we performed an in vivo binding assay. Here, TrkC and $\operatorname{TrkB}$ plasmids were transfected in COS7 cells and the Ntf3-AP recombinant protein was allowed to bind to the receptors in their native state. As expected, Ntf3-AP did bind to TrkB but with much lower affinity as compared to TrkC (Figure 9C). Finally, in order to visualize the location of the Ntf3-receptor, we incubated E14.5 sections with the Ntf3-AP recombinant protein and used the enzymatic activity of AP to visualize the location of the receptor. While we observed a strong signal from the intermediate zone, no staining could be seen in the germinal zone of the cortex (Figure 9D). We however, could not rule out the possibility that the receptor was inaccessible to the exogenous ligand used here.

\section{Expression of TrkC and TrkB}

Since from the previous experiment, we could not conclusively identify the location of the receptor, we decided to study the expression pattern of the known Ntf3 receptors- TrkC and TrkB. At first, we limited our study to the full-length isoforms of both receptors. We performed in situ hybridization at E14.5 with probes against the fulllength TrkC and TrkB mRNAs (FL-TrkC, FL-TrkB). Since Ntf3 overexpression at E12.5 showed that it affects the ratio of apical to basal 
progenitors (Figure 6), we assumed that Ntf3 had to act through receptors located on neocortical progenitors. To our surprise, we did not find any expression of either $\operatorname{Trk} C$ or $\operatorname{Trk} B$ within the germinal zone of the developing cortex (Figure 10A,B).

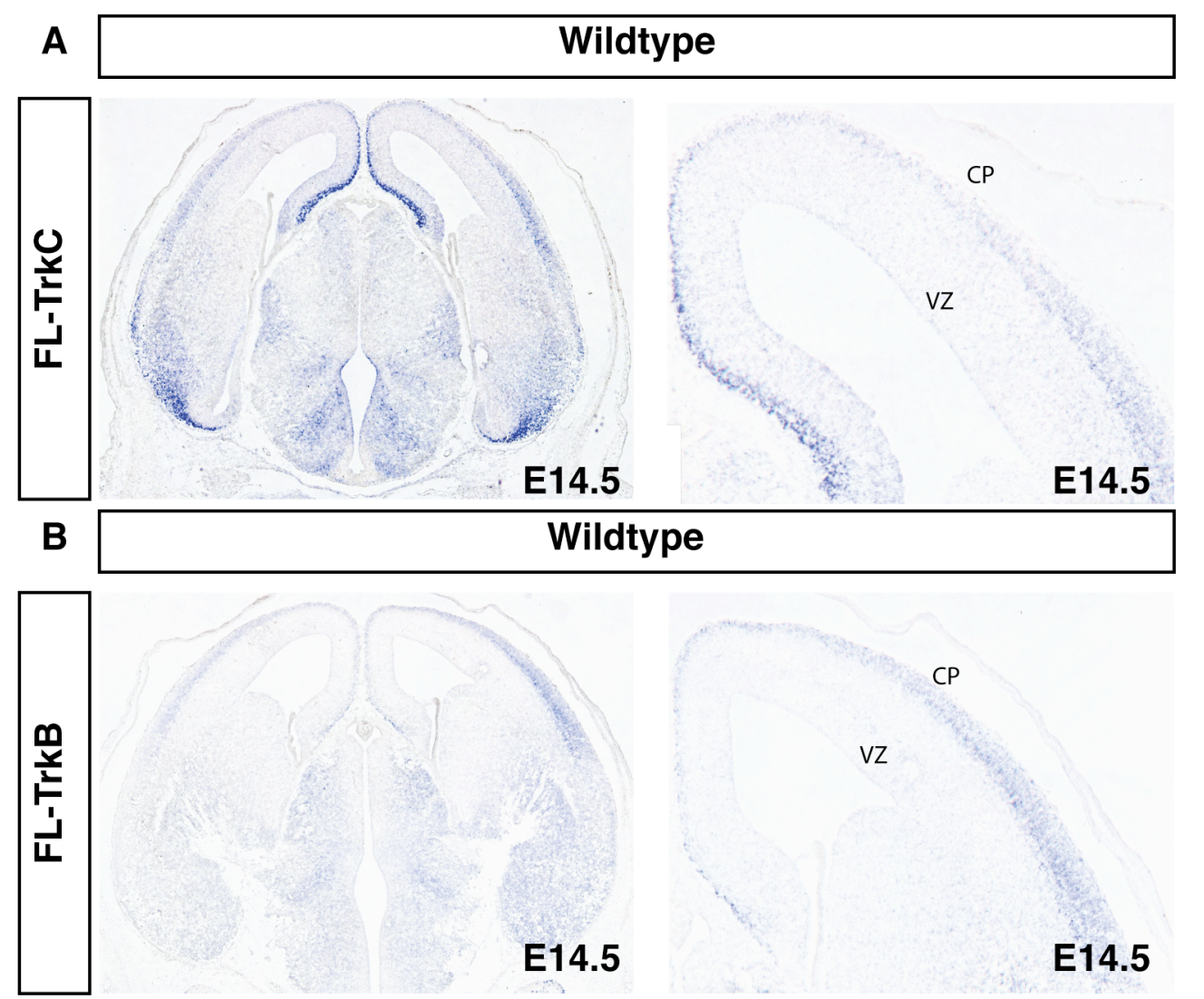

Figure 10. Expression of TrkC and TrkB

(A) In situ hybridization using a probe targeting the FL-TrkC mRNA at E14.5 shows that $\operatorname{Trk} C$ is not expressed in the ventricular zone. Expression of $F L-T r k C$ is confined to the postmitotic cortical plate. (B) Expression of FL-TrkB is also confined to the cortical plate, with no detectable expression within the cortical germinal zone. $\mathrm{VZ}=$ ventricular zone, $\mathrm{CP}=$ cortical plate

\section{Expression of Non-Catalytic (NC) TrkC and TrkB}

Since full length- TrkC and TrkB mRNAs are not expressed in progenitors, our search for a putative Ntf3 receptor expressed within the ventricular zone lead us to study the expression of the alternate splice variants of $\operatorname{Trk} C$ and $\operatorname{TrkB}$ receptors. Both NTRK3 (TrkC) and NTRK2 (TrkB) genes have been shown to also produce alternate truncated isoforms, which lack the intracellular kinase domains 
(Valenzuela et al., 1993). These Non-catalytic isoforms also have a distinct 3' UTR, suggesting differential post-transcriptional control. Using riboprobes specifically targeting the truncated isoforms, we observed that $N C$-TrkC and $N C$-TrkB were expressed in the ventricular zone of the developing cortex (Figure 11).
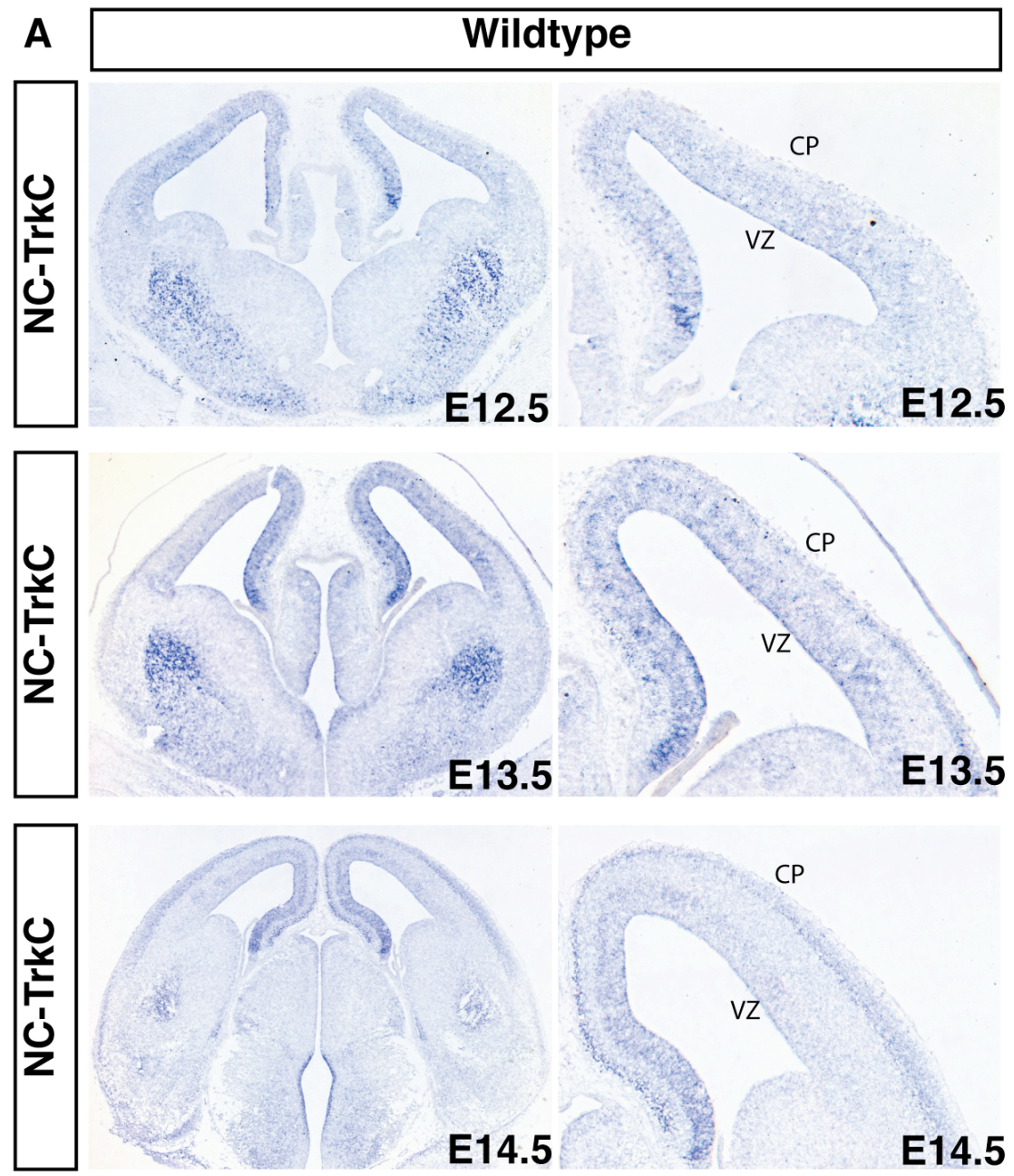

CP
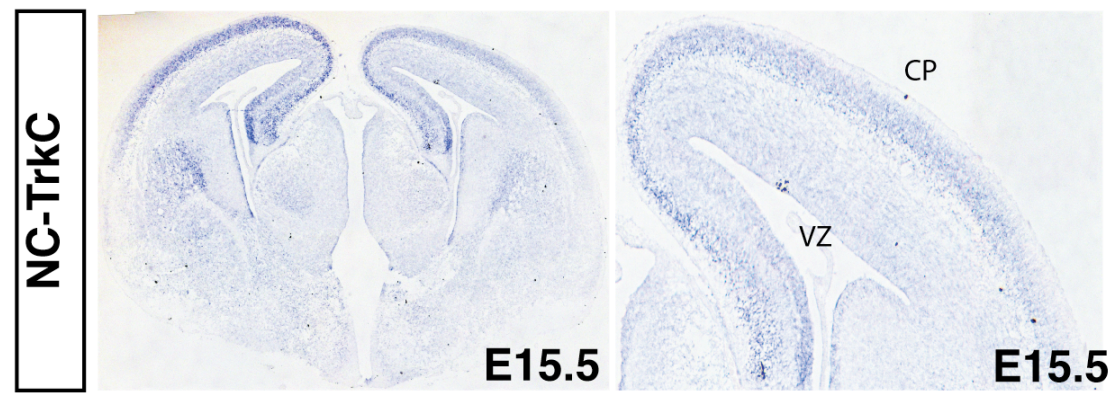

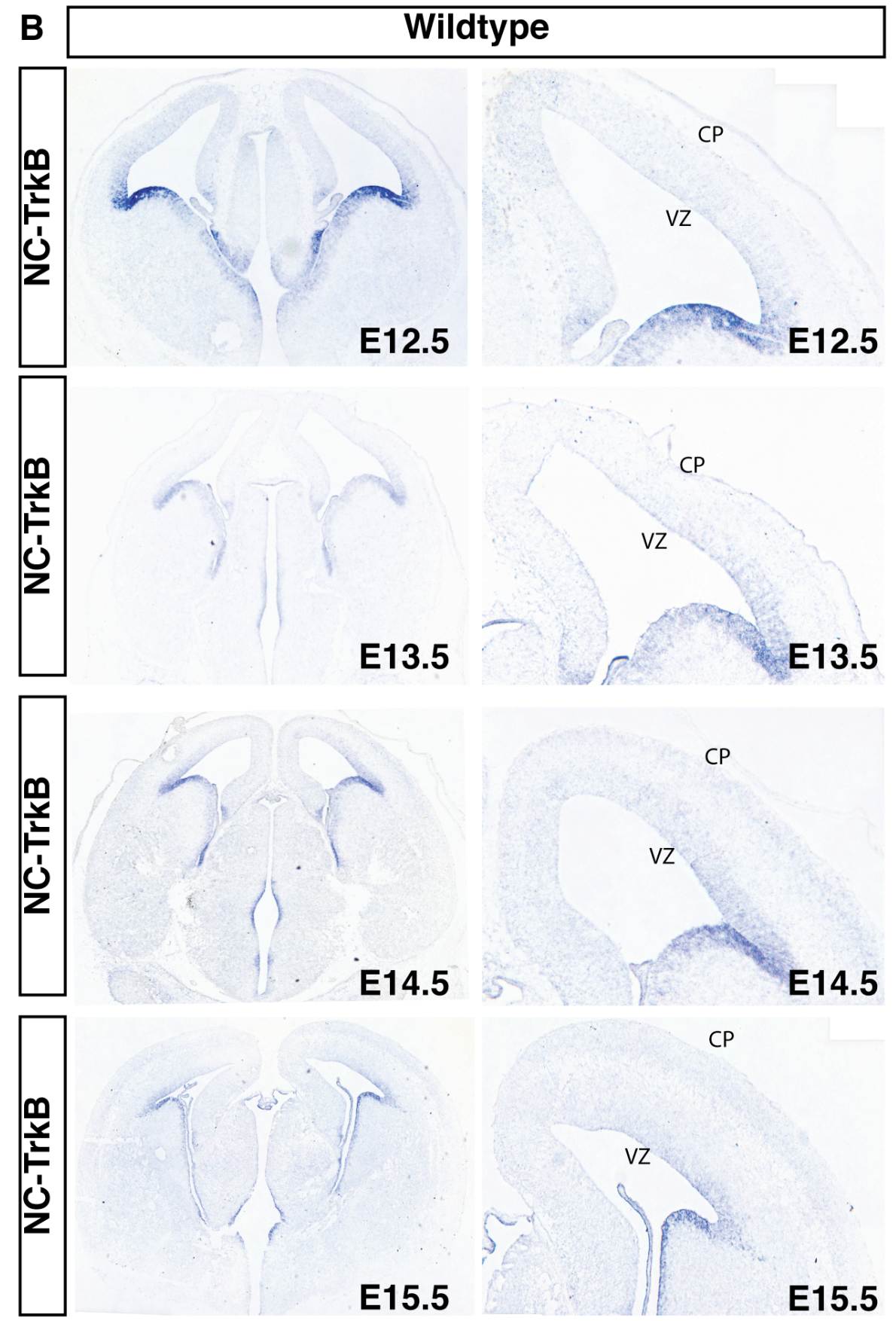

\section{Figure 11. Expression of NC-TrkC and NC-TrkB}

(A) In situ hybridization using a probe targeting $N C$-TrkC at various stages of development. At E12.5 and 13.5, NC-TrkC is expressed in the VZ. At E13.5, expression can also be seen in the young cortical plate. At E14.5, the expression of $N C$-TrkC follows a high medial-low lateral expression in the VZ, while the cortical plate expression remains uniform. At E15.5, expression of $N C-T r k C$ is lost in the VZ whereas the cortical plate signal is still present. (B) Expression pattern of $N C$-TrkB from E12.5-15.5. Unlike $N C$-TrkC, $N C$-TrkB expression within the postmitotic cortical plate is never detected. Expression within the VZ is restricted to the lateral boundary, at the junction of the pallium-subpallium ventricular zones. This expression is constant during the developmental stages studied. VZ=ventricular zone, $\mathrm{CP}=$ cortical plate 
While $N C$-TrkC was also expressed in the cortical plate, $N C$-TrkB was restricted to the germinal zone (Figure 11A,B). Unlike $N C$-TrkB, which showed a constant pattern of expression throughout early development (Figure 11B), the expression pattern of $N C-\operatorname{TrkC}$ was highly dynamic. While $N C$-TrkC was expressed strongly in the ventricular zone at E12.5 and E13.5, its expression showed a high medial-low lateral expression at E14.5 and reduced to undetectable levels by E15.5 (Figure 11A). The combination of the presence of $N C$ TrkC expression in the ventricular zone cells and its highly dynamic expression pattern made $N C$-TrkC an interesting gene to study in the context of cell fate switch in the developing cortex.

\section{NC-TrkC protein is also absent from the E15.5 ventricular zone}

In order to further establish the dynamic expression pattern of NCTrkC, we used an antibody that identifies both isoforms of TrkC. Similar to the mRNA expression pattern, TrkC immmunostaining was observed at the ventricular zone of E13.5 but not E15.5 neocortex (Figure 12A-B). Further, western blot analysis of E13.5 to E15.5 cortical protein lysates, clearly shows that while at E13.5 NC-TrkC (Figure 12C, lower band) dominates over FL-TrkC (Figure 12C, upper band), by E15.5 this ratio is reversed (Figure $12 \mathrm{C}, \mathrm{D}$, ratio of NCTrkC to FL-TrkC at E13.5 $=2.25 \pm 0.9$ compared to $0.299 \pm 0.012$ at E15.5, p-value=0.003). Thus, we went on study the role of NC-TrkC in cell fate determination in the developing cortex. 


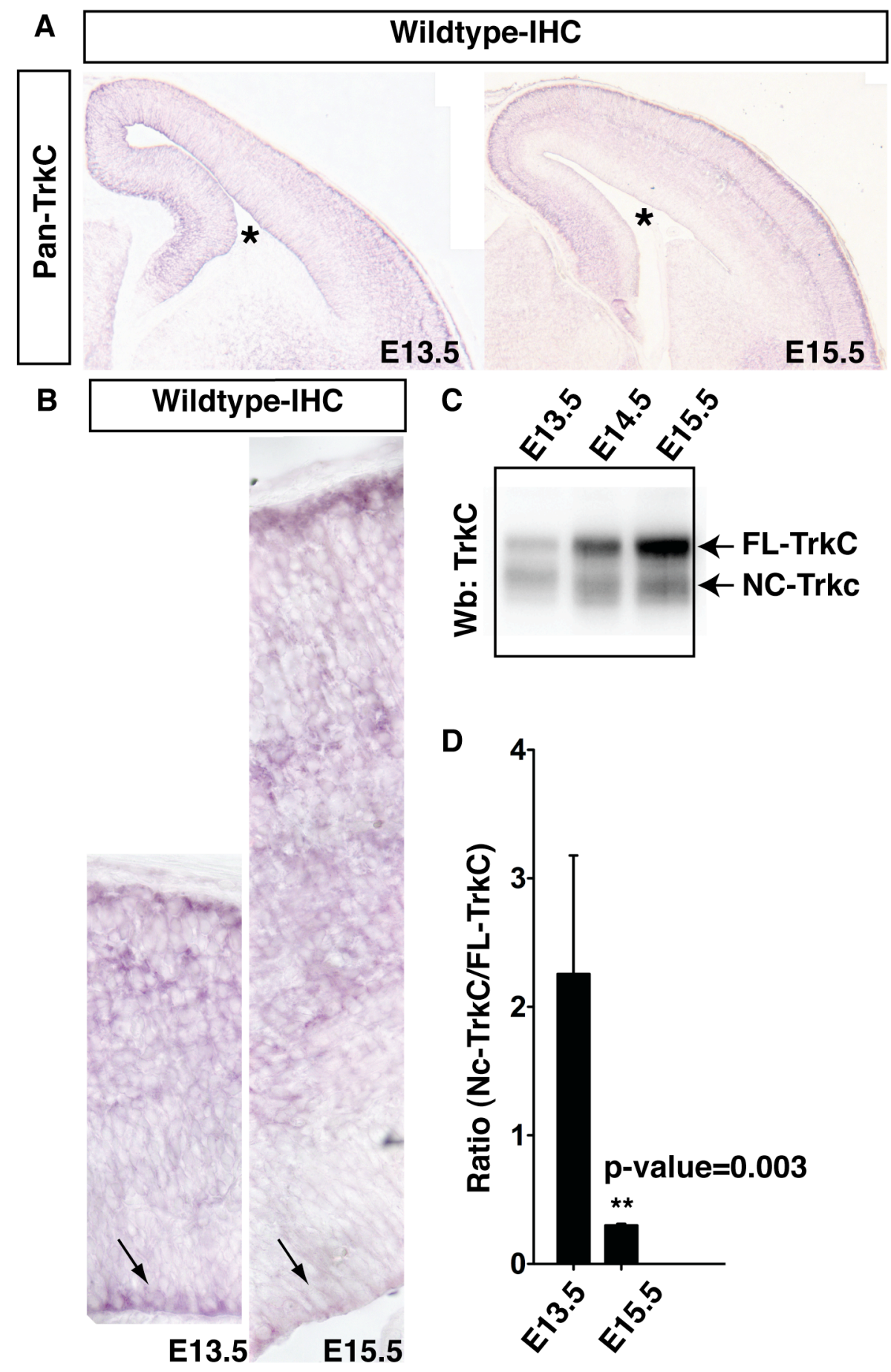

Figure 12. Ratio of NC-TrkC to FL-TrkC shifts from E13.5 to E15.5

(A) Immunohistochemistry against TrkC shows that at E13.5, TrkC is expressed strongly in the VZ and weakly in the cortical plate. At E15.5, the expression of TrkC in the cortical plate is high and the signal in the VZ is below detection (B) Higher magnification images of the developing cortex at E13.5 and E15.5 show the presence of TrkC expression in the VZ at E13.5 but not E15.5 (arrows) (C) Western blot analysis of E13.5, 14.5 and 15.5 cortical lysates shows the presence of the two isoforms of TrkC and their relative abundance (D) At E13.5 NC-TrkC dominates over FL-TrkC while the ratio is reversed by E15.5 (ratio of NC-TrkC to FL-TrkC at $\mathrm{E} 13.5=2.25 \pm 0.9$ compared to $0.299 \pm 0.012$ at $\mathrm{E} 15.5, \mathrm{p}$-value $=0.003$ ). 


\section{Over-expression of NC-TrkC leads to over-production of deep layer neurons at the expense of upper layer neurons}

In order to study the function of NC-TrkC in cortical cell fate determination, we over-expressed the receptor at E12.5 in cortical progenitors. The cDNA was followed by an IRES-EGFP sequence allowing us to study the fate of these cells. When we looked at the location of the $N C$-TrkC expressing cells four days after the injection, we observed that a vast majority of these GFP positive postmitotic cells were located in the deeper layers of the cortex, as compared to GFP only electroporations. On studying the molecular identity of these GFP positive cells, we observed an increase in the number of GFP positive cells that were also positive for layer VI (Tbr1) or layer $\mathrm{V}$ (Ctip2) markers upon $N C$-TrkC over-expression as compared to GFP alone over-expression (Figure 13A, B; Tbr1: 21.2 $\pm 4.9 \%$ from $n=8$ control versus $30.1 \pm 3.8 \%$ from $\mathrm{n}=5$ NC-TrkC over-expression; $\mathrm{p}$ value $=0.004$. Ctip2: $21.4 \pm 6.5 \%$ from $n=8$ control versus $35 \pm 4.8 \%$ from $\mathrm{n}=8 \quad N C$-TrkC over-expression; $\mathrm{p}$-value $=0.0003$ ). This increase in deeper layer markers was coupled with a decrease in the number of GFP positive cells also positive for an upper layer marker-Cux1 (Figure 13A, B; $42.2 \pm 5.4 \%$ from $n=6$ control versus $29.1 \pm 6.2 \%$ from $\mathrm{n}=6$ NC-TrkC over-expression; $\mathrm{p}$-value $=0.003$ ). These results thus suggested that NC-TrkC could program cortical progenitors to favor the production of deeper layer neurons at the expense of upper layer neurons.

Of the two-tyrosine binding sites present in the FL-TrkC- Shc binding site and Plc- $y$ binding site, NC-TrkC only possesses the Shc binding site- Y516. The tyrosine at this position upon phosphorylation leads to the recruitment of Shc, thus initiating downstream signaling.

We hence asked if this tyrosine (Y516) and its phosphorylation were necessary for the NC-TrkC mediated control over cortical cell fate. We 
introduced a mutated variant of $N C$-TrkC carrying a tyrosine to phenylalanine mutation at the $516^{\text {th }}$ position (Y516F) in cortical progenitors via in utero electroporation at E12.5. When we analyzed these brains we observed that NC-TrkC Y516F had no influence on cell fate. GFP positive cells co-localized with Tbr1, Ctip2 and Cux1 to the same extent as control GFP positive cells (Figure 13A, B; Tbr1: $21.2 \pm 4.9 \%$ from $\mathrm{n}=8$ control versus $19.1 \pm 5.1 \%$ from $\mathrm{n}=6$ NC-TrkC Y516F over-expression; Ctip2: $21.4 \pm 6.5 \%$ from $n=8$ control versus $26.5 \pm 3.1 \%$ from $\mathrm{n}=6 \quad$ NC-TrkC Y516F over-expression; Cux1: $42.2 \pm 5.4 \%$ from $\mathrm{n}=6$ control versus $42.4 \pm 5.6 \%$ from $\mathrm{n}=6$ NC-TrkC Y516F over-expression; all p-values $>0.05$ ).

Next, we asked whether the extracellular domain of NC-TrkC was important for its role in cell fate determination. Our interest was based on the lack of Ntf3 expression in the cortex during early development. To answer this, we introduced an extracellular domainlacking mutant of $N C$-TrkC $(\triangle \mathrm{ECD}-\mathrm{NC}-\mathrm{TrkC})$ in $\mathrm{E} 12.5$ cortical progenitors by in utero electroporation. We found that the overexpression of $\triangle E C D-N C$-TrkC resulted in the same phenotype as that achieved when the full length $N C$-TrkC was over-expressed. The proportion of GFP+ cells that co-labeled with Ctip2 and Tbr1 was significantly higher than that in control electroporations, while those that were Cux1+ was lowered (Figure 13A, B; Tbr1: $21.2 \pm 4.9 \%$ from $\mathrm{n}=8$ control versus $29.8 \pm 4.1 \%$ from $\mathrm{n}=5 \quad \Delta \mathrm{ECD}-\mathrm{NC}-\mathrm{TrkC}$ overexpression, $\mathrm{p}$-value $=0.007$; Ctip2: $21.4 \pm 6.5 \%$ from $\mathrm{n}=8$ control versus $39.8 \pm 4.3 \%$ from $\mathrm{n}=5 \Delta \mathrm{ECD}-N C$ - $T r k C$ over-expression, $\mathrm{p}$-value $<0.0001$; Cux1: $42.2 \pm 5.4 \%$ from $n=6$ control versus $29.2 \pm 5.3 \%$ from $n=5 \Delta E C D-$ $N C$-TrkC over-expression, p-value $=0.003$; all p-values between NcTrkC and $\triangle \mathrm{ECD}-\mathrm{NC}$-TrkC over-expression $>0.05$ ) 


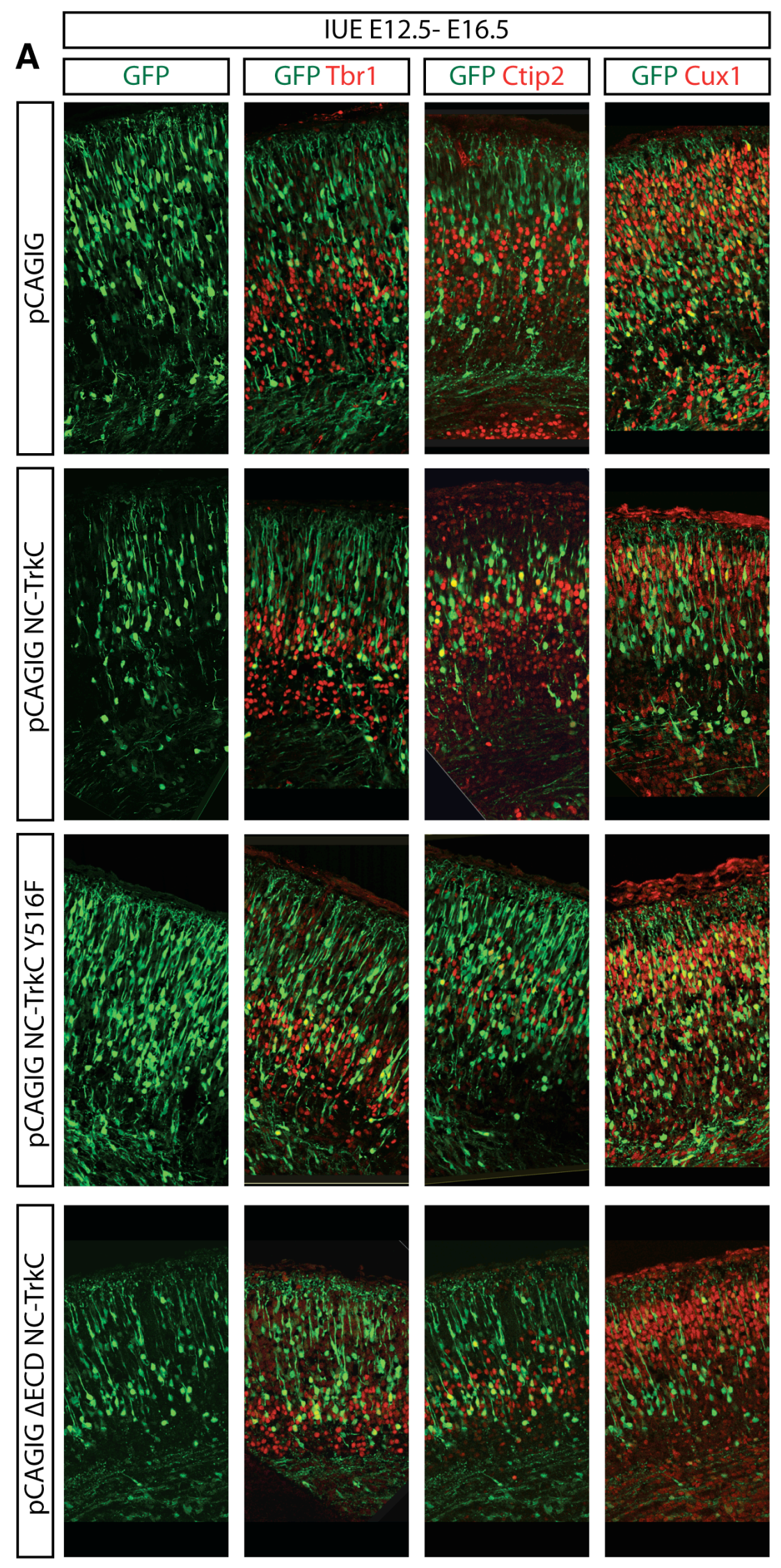


B

$\square$ pCAGIG

- pCAGIG NC-TrkC

$\square$ pCAGIG NC-TrkC Y516F

$\square \mathrm{pCAGIG} \triangle \mathrm{ECD}-\mathrm{NC}-\mathrm{TrkC}$

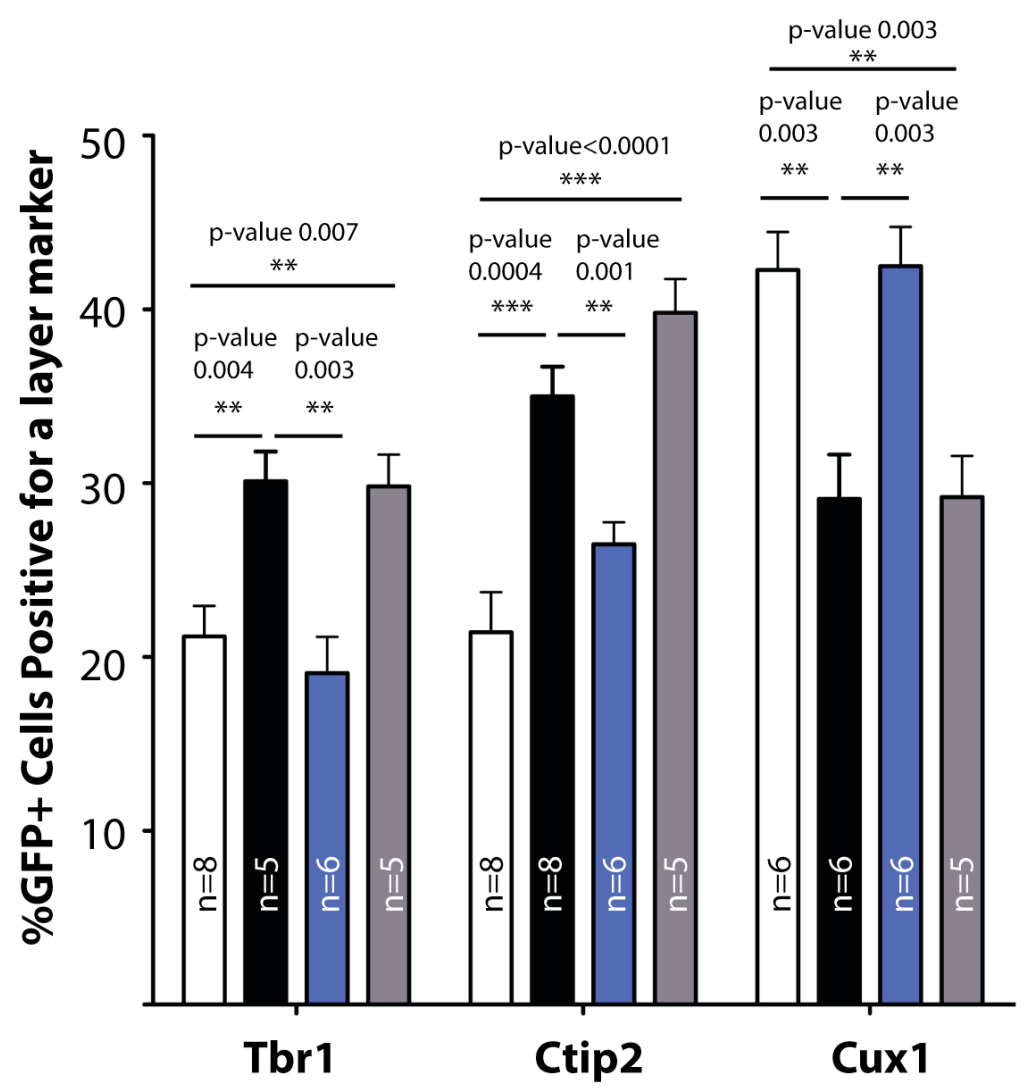

Figure 13. NC-TrkC over-expression leads to an increase in deeper layer production.

(A) Series of in utero electroporations (IUE) wherein the empty vector, $N C-\operatorname{TrkC}$, $N C$-TrkC Y516F or $\triangle \mathrm{ECD}$ NC-TrkC were over-expressed at E12.5 and the brains analyzed at E16.5. With the over-expression of $N C$-TrkC, cortical progenitors produce more Tbr1+ and Ctip2+ deep layer neurons and lesser Cux1+ upper layer neurons. Over-expression of the mutated $N C$-TrkC Y $516 \mathrm{~F}$ abolishes this effect. The over-expression of the $\triangle E C D N C$-TrkC mutant, where the entire extracellular domain has been deleted, also leads to an increased production of Tbr1+ and Ctip2+ cells, while leading to a decrease in the number of Cux1+ cells. (B) Percentage of GFP positive cells that were either positive for the deeper layer marker Tbr1 or Ctip2 or upper layer marker Cux1. P-values and number of samples analyzed are labeled within the figure. Error bars indicate mean \pm S.E.M. 


\section{NC-TrkC and pERK1/2 share opposing expression domains in the developing neocortex}

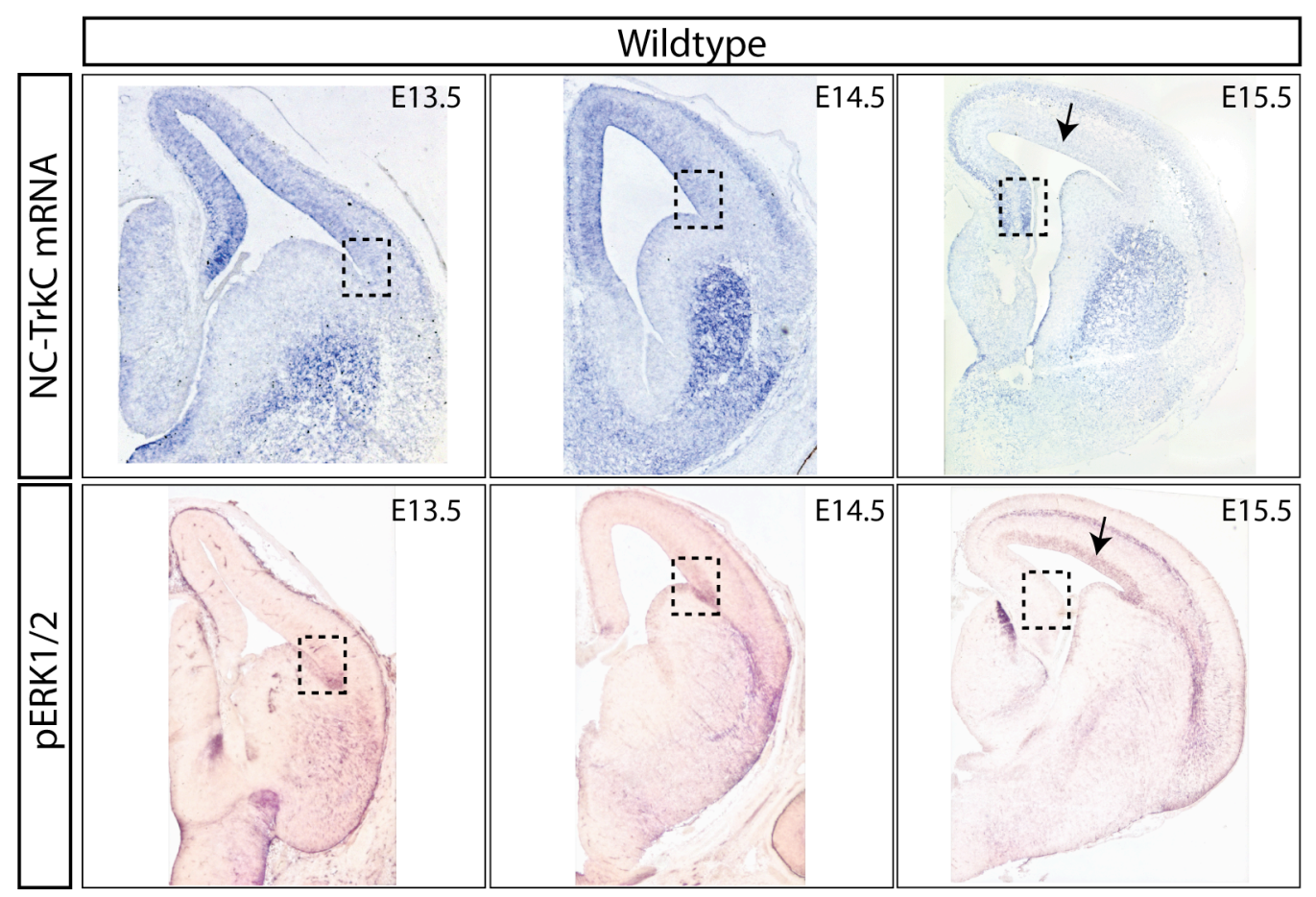

Figure 14. Comparison of NC-TrkC and p-ERK1/2 expression patterns.

At E13.5 NC-TrkC is expressed throughout the cortical VZ whereas pERK1/2 is only present at the very lateral edge. At E14.5 when the expression of $N C$-TrkC recedes from the lateral boundary of the VZ, pERK1/2 extends further medially. At E15.5, when $N C$-TrkC expression is completely lost from the VZ (arrow), pERK1/2 is present uniformly throughout the cortex (arrow). Also, at E15.5 when expression of NC-TrkC persists in the hippocampal anlage, pERK1/2 is not present.

One of the products of activation of receptor tyrosine kinases is the activation of the MAP kinase pathway (phosphorylation of ERK1/2). We asked if the presence of the NC-TrkC could be a negative regulator of such a pathway, thereby dampening ERK1/2 mediated signaling. The deletion of ERK1/2 is also known to cause an increase in the number of deeper layer neurons and a decrease in upper layer neuronal populations (Pucilowska et al., 2012). Since this is phenocopied by the over-expression of $N C$-TrkC, we had further reasons to believe that $\mathrm{NC}-\mathrm{TrkC}$ could negatively regulate ERK1/2 signaling. We studied the expression pattern of phosphorylatedERK1/2 from E13.5-15.5 and compared it to the expression of $N C$ - 
TrkC. We found that the expression pattern of $N C$-TrkC and pERK1/2 were opposing at all stages (Figure 14). At E13.5 NC-TrkC was expressed throughout most of the cortical VZ, barring the lateral most edge. Interestingly, at the same stage $\mathrm{pERK} 1 / 2$ is present only within this small region (Figure 14; left column). At E14.5, when NC-TrkC follows a high medial-low lateral expression, pERK $1 / 2$ extends further medially (Figure 14; middle column). At E15.5, when NC-TrkC expression is completely lost from the cortical VZ, pERK1/2 is present throughout the VZ (Figure 14; right column). This mutually exclusive pattern of $N C$-TrkC and pERK1/2 expression raised the question if NC-TrkC could negatively regulate ERK signaling.

\section{NC-TrkC negatively regulates ERK signaling in vitro}

To study if NC-TrkC could prevent ERK phosphorylation, we transfected HEK293T cells with NC-TrkC. To activate the MAP kinase pathway in HEK293T cells, we stimulated the cells with $100 \mathrm{ng} / \mathrm{ml}$ EGF and lysed the cells at varying time points. Over-expression of NCTrkC lead to a decrease in the p-ERK1/2 levels at all stages analyzed (Figure 15A). Phosphorylation of NC-TrkC at Tyr516 (Y516F, Shc binding site) could also be seen as a result of EGF mediated transactivation, as reported earlier (Figure 15A, (Puehringer et al., 2013)). To further investigate if signaling via the Y516 was necessary for the NC-TrkC mediate negative regulation of ERK signaling, we transfected the NC-TrkC Y516F mutant in HEK293T cells. Again, we observed a significant decrease in the amount of pERK1/2 when the wildtype NC-TrkC was expressed in comparison to the mutated NCTrkC (Figure 15B). This suggests that phosphorylation and/or signaling via Y516 is important for the negative regulation of ERK signaling by NC-TrkC. 


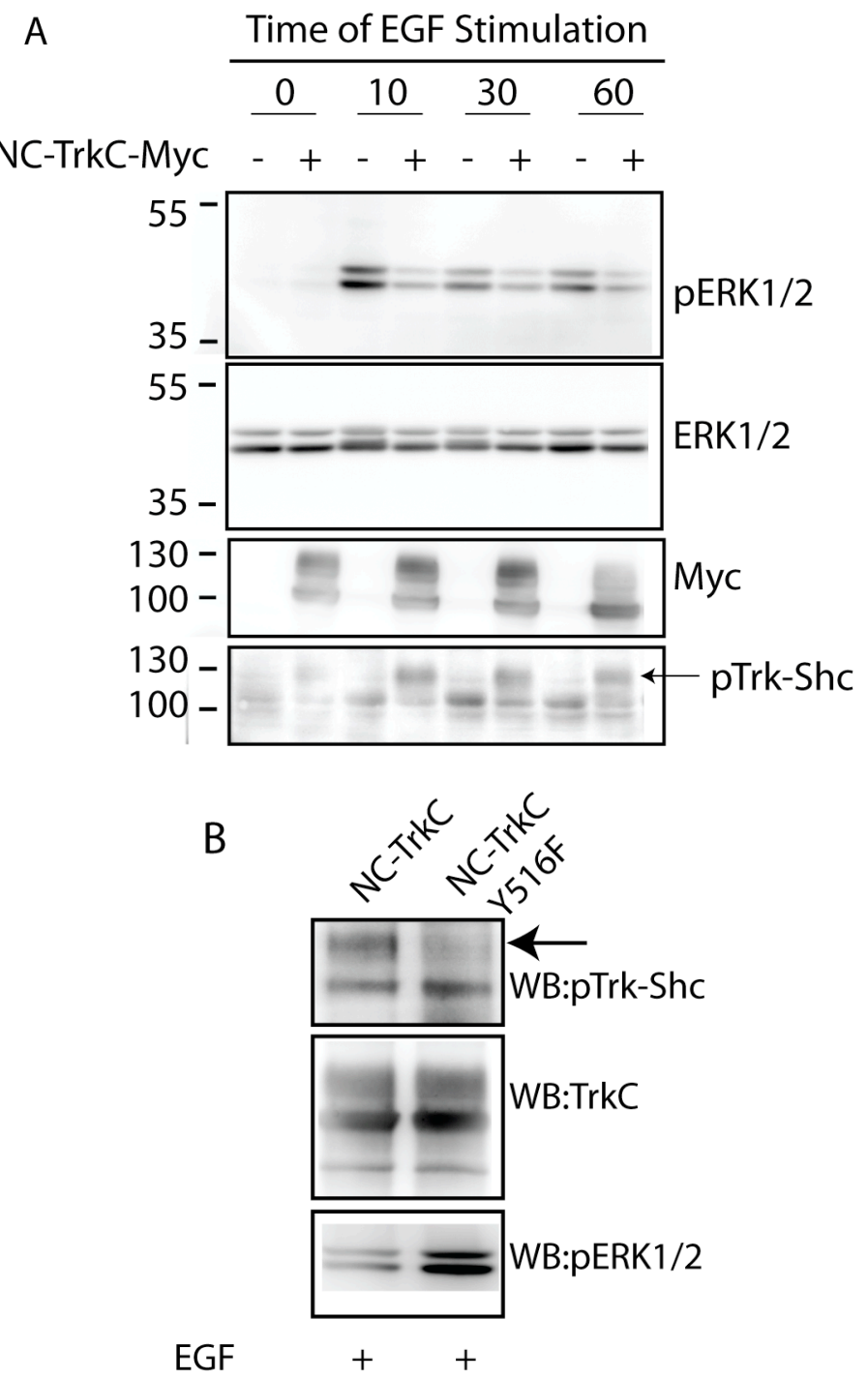

Figure 15. NC-TrkC negatively regulates ERK signaling in vitro

(A) HEK293T cells transfected with $N C$-TrkC were stimulated with EGF and the cells were harvested at different time points. Probing the blots for pERK1/2 shows that expression of $N C-\operatorname{TrkC}$ leads to a decrease in pERK1/2 levels. This effect was consistent throughout all the time points studied. EGF activation also leads to the phosphorylation of the TrkC Shc binding site (B) Decrease in p-ERK1/2 levels upon NC-TrkC transfection as compared to pERK1/2 levels in NC-TrkC Y516F mutant over-expressing cells.

\section{NC-TrkC interacts with BMPRIA both in vivo and in vitro}

The above data thus clearly highlights the important role played by NC-TrkC in cortical cell fate determination. We then investigated the signaling pathway activated downstream of NC-TrkC. Since, Nc-TrkC 
does not possess any kinase domain in the carboxy terminal of the protein, we wondered if the receptor could interact with other membrane proteins that could serve as co-receptors. In a completely serendipitous experiment, we observed that NC-TrkC could interact with the BMP class I receptor-BMPRIA. We over-expressed an EGFP tagged version of $N C$-TrkC along with a myc tagged version of BMPRIA in HEK293T cells (Figure 16A). 24 hours post transfection, the cells were harvested without stimulation or after stimulation with either Ntf3 or BMP-4 or both. After immunoprecipitation using an antibody against EGFP or Myc, we observed that NC-TrkC and BMPRIA coimmunoprecipitated (Figure 16A). The interaction was not affected by addition of either the NC-TrkC ligand-Ntf3 or the BMPRIA ligandBMP4 (Figure 16A). This suggests a constitutive interaction between the two receptors. To verify if these two receptors also interact in vivo, we immunoprecipitated NC-TrkC from E13.5 cortical lysates using an antibody specific to this isoform. When we probed for BMPRIA, we indeed observed a specific band at the predicted molecular weight of BMPRIA (Figure 16B). NC-TrkC was visualized using a pan-TrkC antibody (Figure 16B). The presence of a single band confirms the specificity of the immunoprecipitating antibody for the NC-TrkC isoform.

To further test the interaction of these two receptors, we cultured E13.5 cortical progenitors and transfected them with the tagged versions of these two receptors. A co-localized pixel map shows that the two receptors show a near complete over-lapping domain of expression (Figure 16C). 
A

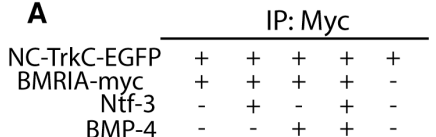

NC-TrkC-EGFP
BMPRIA-myc BMPRIA-myc
Ntf-3
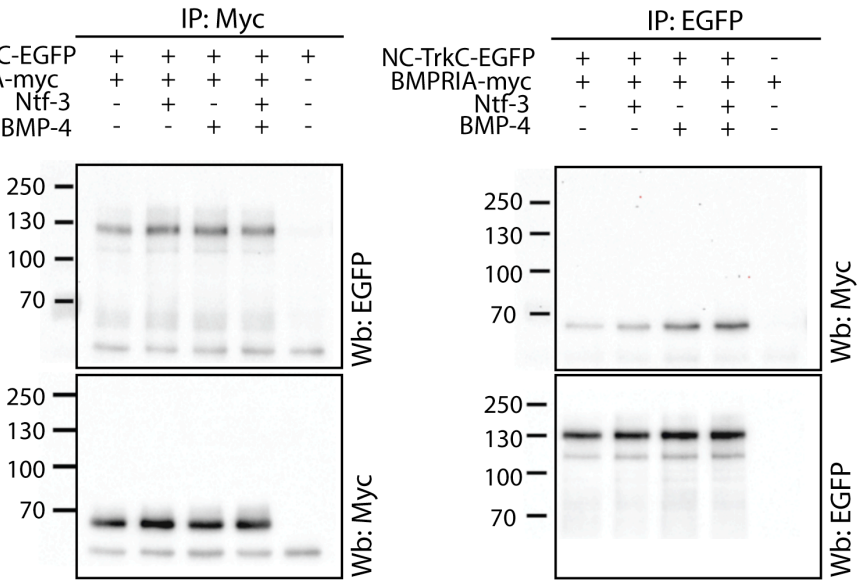
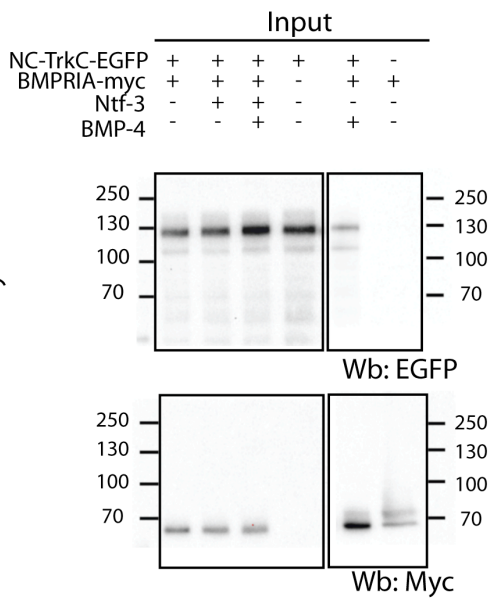
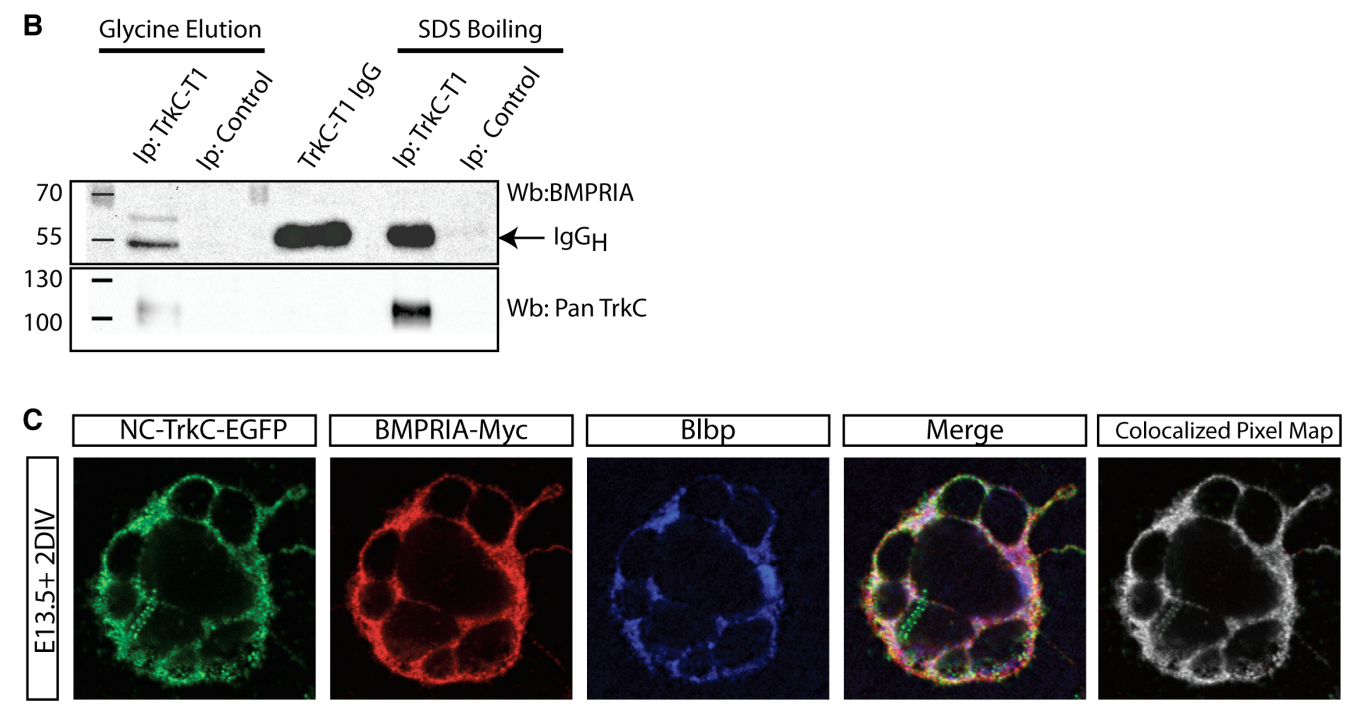

Figure 16. NC-TrkC and BMPRIA interact in vivo and in vitro.

(A) EGFP tagged $N C$-TrkC and Myc-tagged BMPRIA were co-transfected in HEK293T cells. 24 hours post transfection, the cells were either stimulated with Ntf-3 or BMP4 or both for two minutes. Immunoprecipitation of NC-TrkC using an anti-EGFP antibody or BMPRIA using an anti-Myc antibody shows that the two receptors interact in vitro constitutively. (B) Immunoprecipitation of NC-TrkC using an antibody specifically against the truncated TrkC isoforms (TrkC-T1) shows that BMPRIA co-immunoprecipitates from E13.5 cortical lysates. Glycine elution was used to minimize the amount of IgG released. NC-TrkC was visualized using a panTrkC antibody. IP control involved using only PrG sepharose beads without any antibody (C) Cultured E13.5 cortical progenitors were transfected with EGFP tagged $N C$-TrkC and Myc-tagged BMPRIA constructs. Blbp staining confirms the progenitor identity of these cells. A co-localized pixel map, shows that these receptors share a near complete sub-cellular expression domains. 


\section{The Intracellular Domain of NC-TrkC is required for interaction with BMPRIA}

A

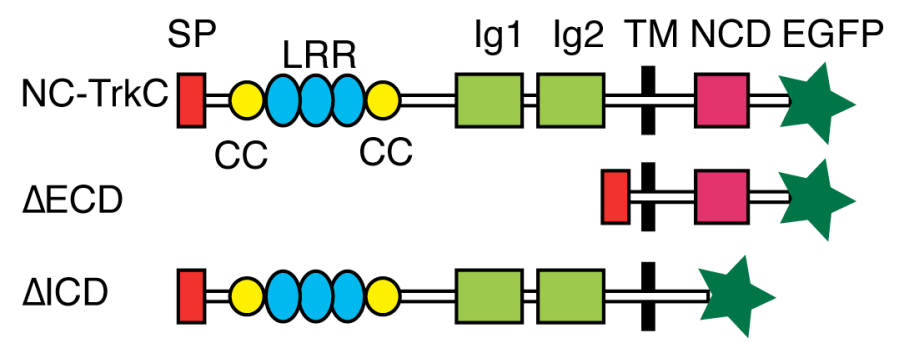

B

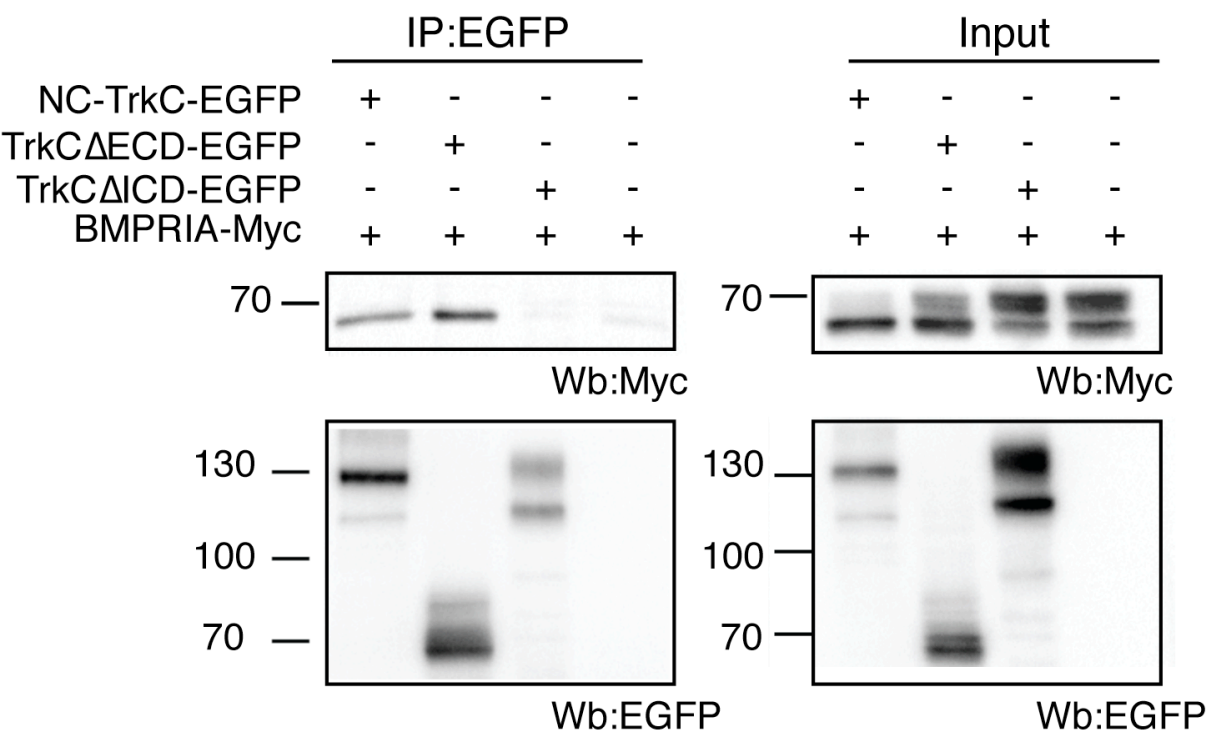

Figure 17. The Intracellular Domain of NC-TrkC is required for interaction with BMPRIA.

(A) Scheme showing the different deletion constructs of NC-TrkC used. $\triangle \mathrm{ECD}$ lacks the entire extracellular domain corresponding to amino acids 33-383 of mouse NCTrkC. $\triangle \mathrm{ICD}$ similarly lacked the intracellular domain proximal to the juxtamembrane region, corresponding to amino acids 393-614 of mouse NC-TrkC. $\mathrm{SP}=$ Signal Peptide, $\mathrm{CC}=$ Cysteine cluster $\mathrm{LRR}=$ Leucine rich region, Ig=Immunoglobulin like domain, $\mathrm{TM}=$ Transmembrane region, $\mathrm{NCD}=$ Non catalytic domain (B) The EGFP tagged deletion constructs of $N C$-TrkC were co-transfected with BMPRIA in HEK293T cells. Immunoprecipitation of NC-TrkC using an anti EGFP antibody shows that while the $\triangle \mathrm{ECD}$ mutant could still bind to BMPRIA, the $\triangle \mathrm{ICD}$ mutant could not bind any longer.

In order to identify the domain within NC-TrkC that interacts with BMPRIA, we cloned deletion constructs of NC-TrkC, that either lacks the extracellular domain ( $\triangle \mathrm{ECD}-\Delta \mathrm{aa} 33-383)$ or the intracellular domain ( $\triangle \mathrm{ICD}-\Delta$ aa 393-614) (Figure 17A, Takahashi et al., 2011). We transfected these deletion constructs along with Myc tagged-BMPRIA in HEK293T cells and immunoprecipitated NC-TrkC using an antiEGFP antibody. We found that the $\triangle \mathrm{ECD}-\mathrm{NC}-\mathrm{TrkC}$ binds BMPRIA with 
an affinity very similar to the full length NC-TrkC. The $\Delta \mathrm{ICD}-\mathrm{NC}-\operatorname{TrkC}$ however did not bind to BMPRIA (Figure 17B). These results thus show that NC-TrkC and BMPRIA interact with their intracellular domains, which might have implications for down-streaming signaling.

\section{NC-TrkC Y516F also binds to BMPRIA}

$\begin{array}{rlllllll}\text { NC-TrkC-EGFP } & + & - & - & & + & - & - \\ \text { NC-TrkC Y516F-EGFP } & - & + & - & & - & + & - \\ \text { BMPRIA-MyC } & + & + & + & & + & + & +\end{array}$
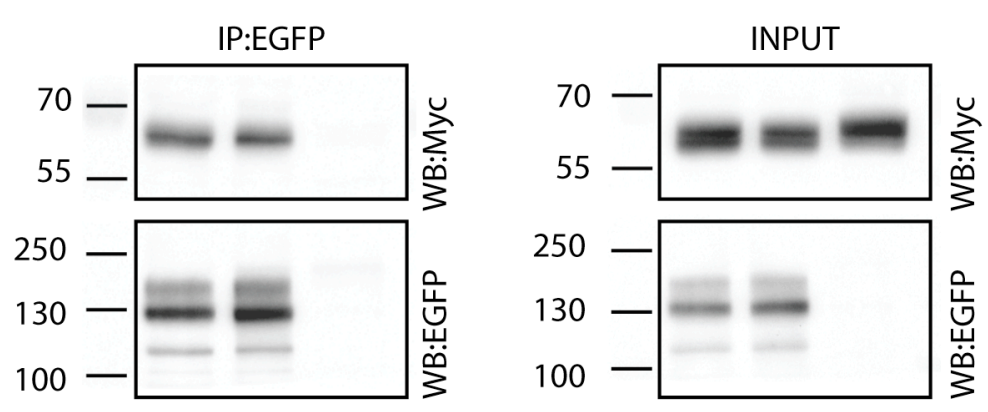

\section{Figure 18. NC-TrkC Y516F also binds to BMPRIA.}

NC-TrkC-EGFP or NC-TrkC Y516F -EGFP constructs were co-transfected with Myc tagged BMPRIA in N2A cells. Immunoprecipitation of NC-TrkC and NC-TrkC Y516F using an anti EGFP antibody shows that the Y516F mutation has no effect on the binding properties of the receptor with BMPRIA.

Since, the over-expression of the NC-TrkC Y516F mutant did not alter the cell fate in the developing cortex, we questioned if this could be a result of its inability to interact with BMPRIA. To answer this, we cloned a NC-TrkC Y516F-EGFP fusion construct and co-transfected it with a BMPRIA- myc tagged construct in N2A cells. We found that NCTrkC Y516F could also interact with BMPRIA and the interaction was comparable to the interaction of wildtype NC-TrkC and BMPRIA (Figure 18). 
16. BMPRIA is expressed throughout neurogenesis in the $\mathrm{VZ}$ of the developing cortex

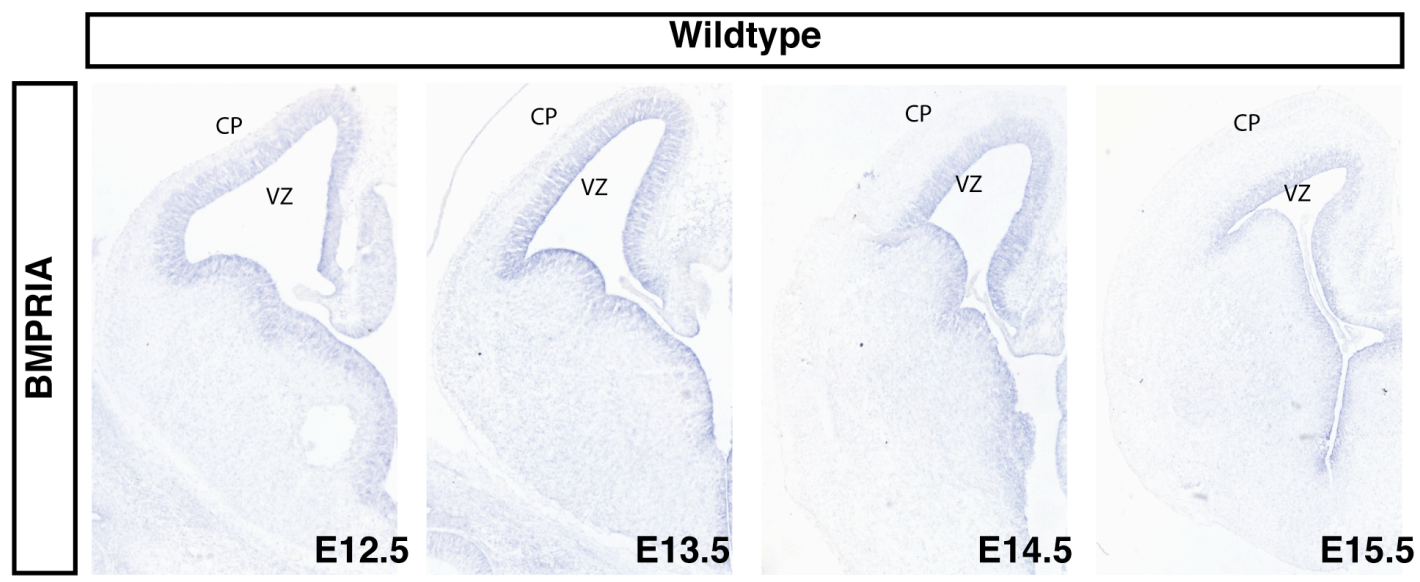

Figure 19. Expression pattern of BMPRIA.

In situ hybridization against the BMPRIA mRNA shows that BMPRIA has a consistent pattern of expression in the VZ between E12.5 and E15.5. VZ=ventricular zone, $\mathrm{CP}=$ cortical plate

In order to understand the relevance of the interaction of BMPRIA with NC-TrkC, we studied the expression pattern of BMPRIA during different stages of embryonic neurogenesis. Using a riboprobe against the BMPRIA mRNA, we found that BMPRIA is continuously expressed in the ventricular zone of the cortex from E12.5 till E15.5 (Figure 19). Since $N C$-TrkC is also expressed in the VZ, atleast from E12.5 to E14.5, we believed that this interaction could have important implications for cortical cell fate determination.

\section{BMPRII and NC-TrkC share opposing expression patterns}

Since BMPRIA interacts with NC-TrkC, we wondered if this could interfere with its interaction with BMPRII, which is required for activating BMPRIA in a ligand dependent manner. We initially studied the expression pattern of BMPRII to examine the degree of overlap in expression between the three genes. We found that BMPRII was expressed at very low levels in the VZ and follows a high lateral to low 
medial gradient at E13.5 and E14.5 (Figure 20). This expression pattern is opposite to that of NC-TrkC. Further, at E15.5, when the expression of $N C$-TrkC is lost from the VZ; BMPRII was expressed more uniformly throughout the cortical VZ (Figure 20). This data thus suggests that the interaction of NC-TrkC and BMPRIA is largely independent of the interaction of BMPRIA and BMPRII and thus might not directly influence BMPRIA mediated BMP signaling/Smad phosphorylation.

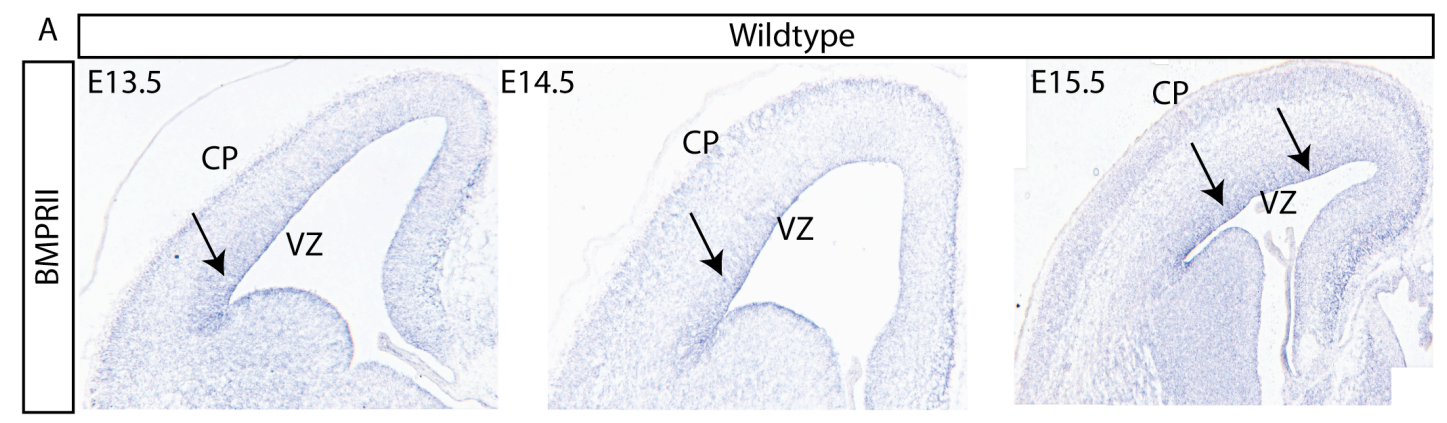

Figure 20. Expression pattern of BMPRII.

BMPRII is expressed at low levels at E13.5 and E14.5 in the lateral edges of the cortical VZ. At E15.5, though the expression is still low, the expression is uniformly present throughout the VZ. Stronger expression can also be seen in the cortical plate, particularly at $\mathrm{E} 14.5$ and $15.5 \mathrm{VZ}=$ ventricular zone, $\mathrm{CP}=$ cortical plate

\section{NC-TrkC enhances the kinase activity of BMPRIA in a ligand independent manner}

To understand the implications of the interaction between NC-TrkC and BMPRIA, we studied the influence of NC-TrkC on the intrinsic kinase activity of BMPRIA. Normally, ligand binding to BMPRII leads to phosphorylation and activation of BMPRIA, leading to further activation of the downstream signaling molecules but spontaneous mutations in the GS domain of BMPRIA, which precedes the kinase domain, have also been known to enhance the kinase activity of BMPRIA independent of ligand activation (Wieser et al., 1995).

Thus, we asked if the interaction between the NC-TrkC and BMPRIA receptors could in a similar manner influence the kinase activity of 
BMPRIA in a ligand independent way. To study this, we used the phosphorylation of Smad1, a physiological downstream effector of BMPRIA activation, as a measure of the kinase activity.

A

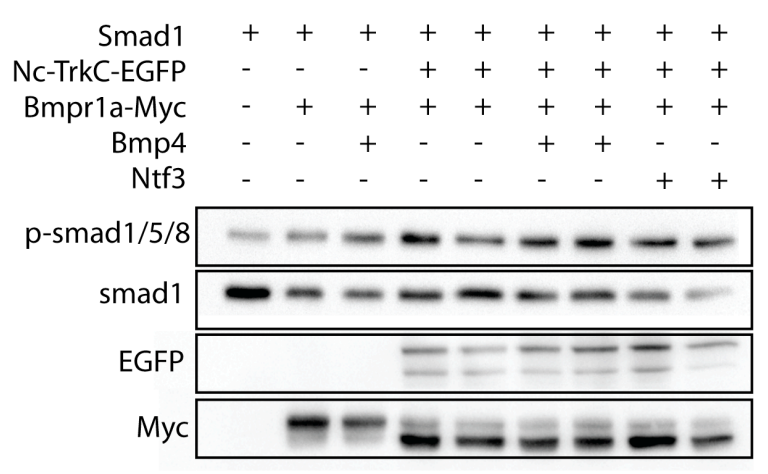

B

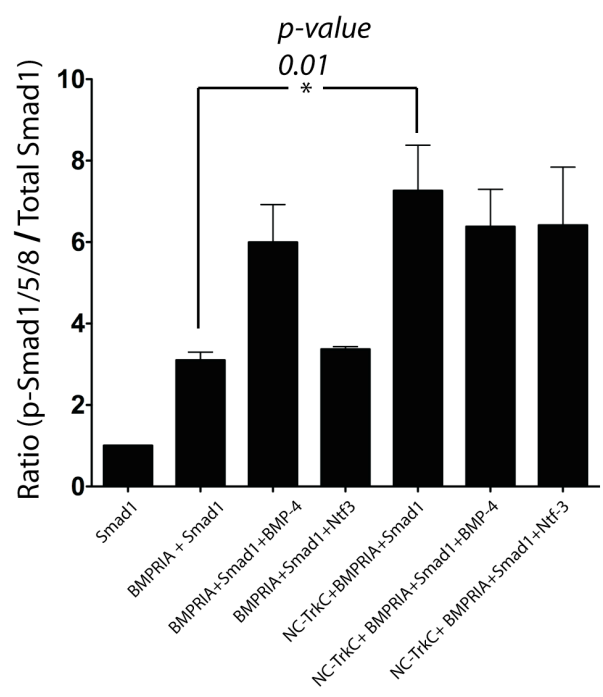

Figure 21. NC-TrkC enhances the kinase activity of BMPRIA.

(A) Smad1 along with myc tagged BMPRIA and EGFP tagged NC-TrkC was transfected in HEK293T cells. The cells were either not stimulated or stimulated with $10 \mathrm{ng} / \mathrm{ml} \mathrm{BMP}-4$ or $50 \mathrm{ng} / \mathrm{ml} \mathrm{Ntf-3}$ for five minutes. Western blot analysis for $\mathrm{p}$ Smad1/5/8, total Smad1 and EGFP and Myc was performed (B) Quantification of the relative amounts of $\mathrm{p}-\mathrm{Smad} 1 / 5 / 8$ to total Smad1 shows that NC-TrkC increases the intrinsic kinase activity of BMPRIA by 2.3 fold ( $p$-value=0.01). The extent of NCTrkC mediated increase in Smad 1 phosphorylation was ligand independent.

We transfected BMPRIA, NC-TrkC and Smad1 in HEK293T cells and investigated the extent of Smad1 phosphorylation. We found that the extent of Smad1 phosphorylation increased by 2.3 fold when NC-TrkC was co-transfected with BMPRIA (Figure 21A,B, p-value $=0.01$ ). Interestingly, the extent of Smad1 phosphorylation did not increase on the addition of BMP-4, a ligand for BMPRIA. These results collectively show that the interaction of NC-TrkC with BMPRIA can enhance the intrinsic kinase activity of BMPRIA, which is independent of the class II receptor or a ligand. 


\section{Generation of shRNA constructs to knock-down the expression of BMPRIA}

In order to study the role of BMPRIA in cell fate decisions in the developing cortex, we prepared four different shRNA clones against the mouse BMPRIA coding region. The shRNA clones were cloned into pSUPER.retro.neo-GFP (oligoengine).

The shRNA clones were transfected along with a BMPRIA-myc tagged construct in HEK293T cells. The protein samples were subjected to western blot analysis. Amongst the four clones, we found that shRNA 3 and 4 gave a very high knockdown efficiency (Figure 22). GAPDH served as the loading control. Clones 3 and 4 were used for subsequent analysis.

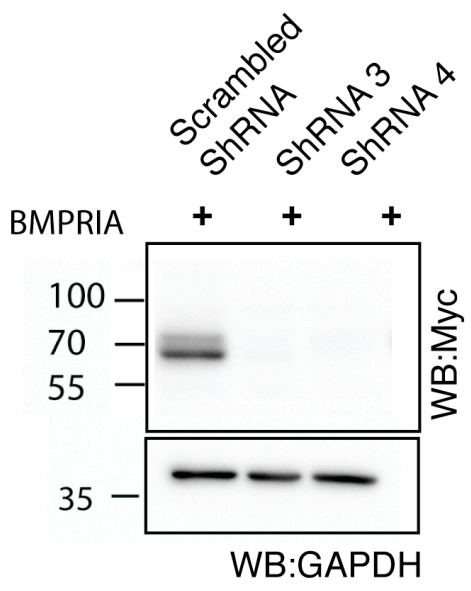

Figure 22. Generation of shRNA clones for the knock-down of BMPRIA expression.

Myc tagged BMPRIA was transfected along with either one of the four shRNA clones in HEK293T cells. Equal amounts of the total protein were loaded on a SDS-PAGE gel. Immunoblotting using an anti Myc antibody shows that shRNA clones 3 and 4 give a high efficiency knock down. GAPDH served as the loading control.

\section{Down-regulating BMPRIA leads to a premature production of upper layer neurons}

In order to study the role of BMPRIA in cortical development, we down-regulated its expression using shRNAs introduced by in utero electroporation at E12.5. When we analyzed the brains at E16.5, we 
observed a significant decrease in the number of GFP positive cells that co-localized with the deeper layer marker Ctip2 (Figure 23A). A scrambled shRNA co-electroporated with EGFP served as the control (Figure 23A,C $25.5 \pm 3.2 \%$ of GFP positive cells were also Ctip2 positive in control electroporation compared to $13.99 \pm 5.7 \%$ upon BMPRIA down-regulation, $\mathrm{n}=6$ each, $\mathrm{p}$-value $=0.0027$; student's t-test). This decrease in the number of deeper layer neurons generated upon down-regulation of BMPRIA, coincided with an increase in the number of upper layer neurons marked by Cux1 (Figure 23A,C $36.05 \pm 2.9 \%$ of GFP positive cells were also Cux 1 positive in control electroporation compared to $57.09 \pm 7.5 \%$ upon BMPRIA down-regulation, $\mathrm{n}=6$ for the control and 5 for BMPRIA shRNA electroporation, $p$-value $=0.002$; student's t-test). These results thus suggest that cortical progenitors that down-regulate BMPRIA preferentially produce upper layer neurons over deep layer neurons.

\section{NC-TrkC and BMPRIA controlled pathways interact genetically to control cortical cell fate}

Since we have shown that NC-TrkC and BMPRIA interact in vivo and in vitro, we hypothesized that the signaling pathways controlled by them could also interact to determine cortical cell fate. Further, our experiments have shown that over-expression of NC-TrkC promotes deeper layer cell fate while down-regulating BMPRIA leads to an increase in upper layer cell fate. To understand if these pathways interact, we over-expressed NC-TrkC and down-regulated BMPRIA simultaneously. 

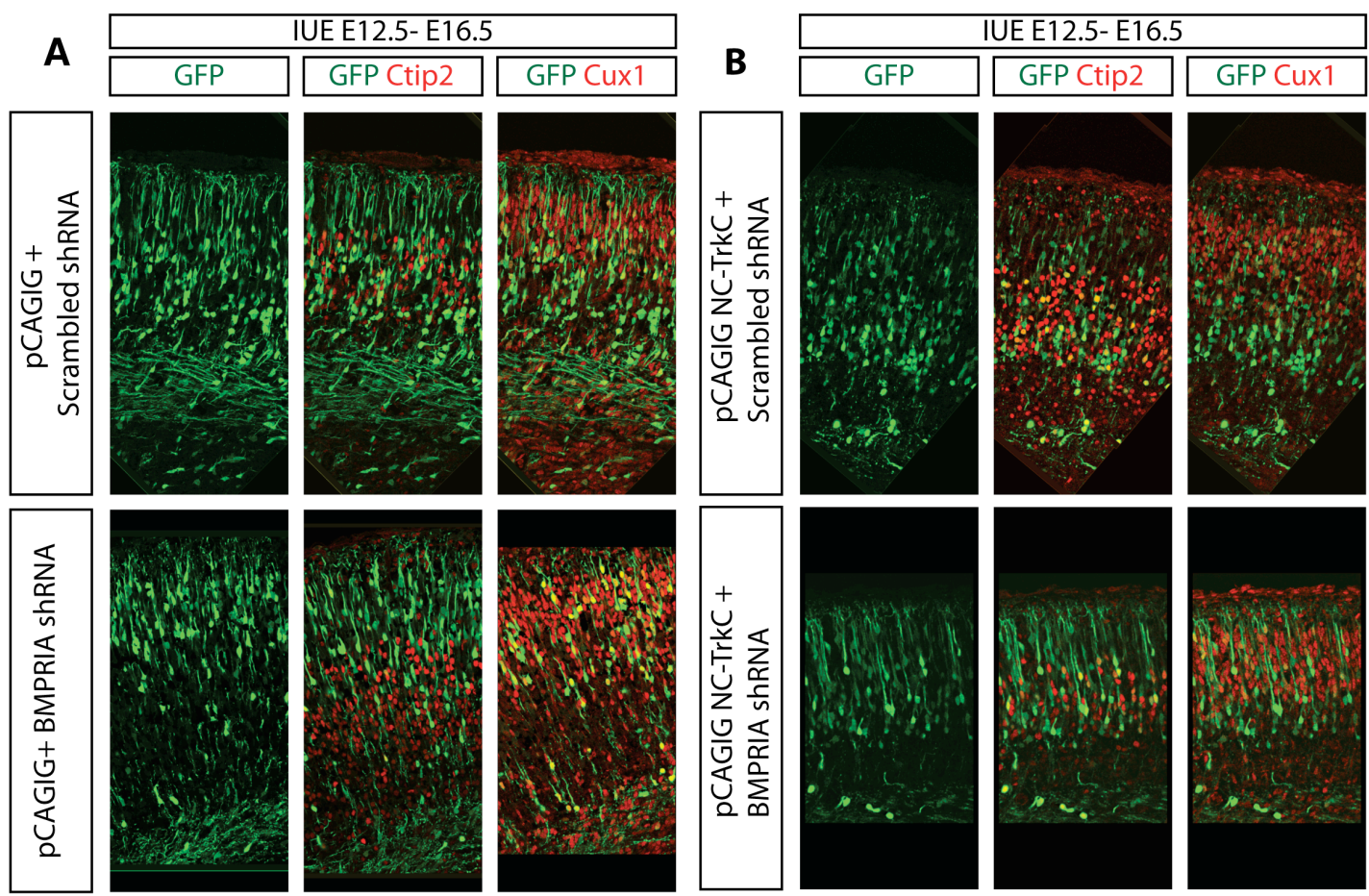

C
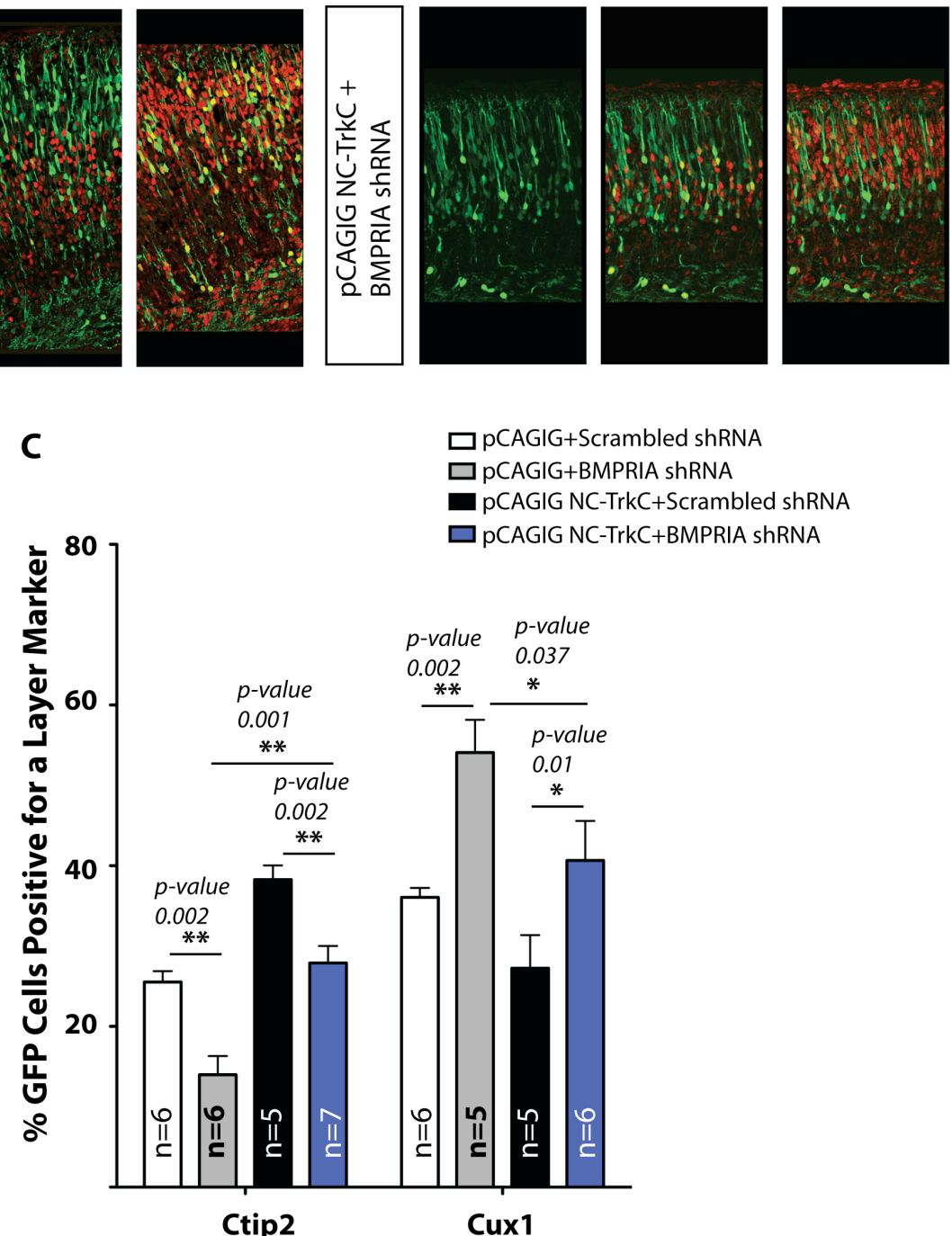
$\square$ pCAGIG NC-TrkC+BMPRIA shRNA

Ctip2

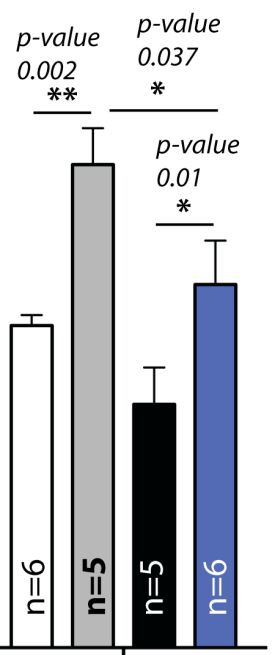

Cux1

Figure 23. Down-regulation of BMPRIA leads to an increased production of upper layer neurons and NC-TrkC-BMPRIA controlled pathways interact genetically.

(A) Down-regulation of BMPRIA by introducing shRNA constructs in cortical progenitors at E12.5 leads to a increased production of Cux1+ upper layer neurons from these progenitors and a reduction in the number of Ctip2+ deeper layer neurons (B) Over-expression of NC-TrkC and simultaneous down-regulation of BMPRIA negates the excess deeper layer Ctip2+ neurons generated upon NC-TrkC alone over-expression. The excess number of Cux $1+$ upper layer neurons generated upon BMPRIA down-regulation is also lowered when $N C$-TrkC is over-expressed along with the down-regulation of BMPRIA (C) Percentage of GFP positive cells that were either positive for the deeper layer marker Ctip2 or upper layer marker Cux1. P- 
values and number of samples analyzed are labeled within the figure. Error bars indicate mean \pm S.E.M.

We reasoned that if these two molecules do control genetic pathways that control cell fate determination, then the over-expression of one and the down-regulation of the other should restore the equilibrium in the system. Supporting our hypothesis, we observed that when $N C$ TrkC was over-expressed and BMPRIA down-regulated, the proportion of both the percentage of GFP positive cells that were Ctip2 positive or Cux1 positive were restored to control levels (Figure $23 \mathrm{~A}-\mathrm{C}$ ). The percentage of GFP positive cells upon $N C$-TrkC over-expression and BMPRIA down-regulation that were also Ctip2 positive was $27.89 \pm 5.6 \%(\mathrm{n}=7)$ compared to $13.99 \pm 5.7 \%$ when BMPRIA was downregulated $(\mathrm{n}=6, \mathrm{p}$-value $=0.001$, student's t-test) and $38.27 \pm 3.9 \%$ with $N C$-TrkC over-expression $(\mathrm{n}=5, \mathrm{p}$-value $=0.004)$. On the other hand the percentage of Cux 1 positive cells was $44.2 \pm 9.9 \%(n=6)$ compared to $57.09 \pm 7.5 \%$ when BMPRIA was down-regulated $(\mathrm{n}=5, \mathrm{p}$-value $=0.037$; student's t-test) and $27.2 \pm 9.2 \%$ when $N C$-TrkC was over-expressed $(\mathrm{n}=5, \mathrm{p}$-value $=0.016 ;$ student's $\mathrm{t}$-test $)$.

\section{FL-TrkC also interacts with BMPRIA}

Finally, we were also interested in studying if FL-TrkC could also interact with BMPRIA. Since FL-TrkC and BMPRIA do not have overlapping expression patterns in the developing cortex, this interaction would not be of relevance in vivo for the developing cortex. This interaction could nevertheless be important in other systems where these receptors are co-expressed. Further, a small region within the intracellular domain of $\mathrm{NC}-\mathrm{TrkC}$ and $\mathrm{FL}-\mathrm{TrkC}$ is common, supporting a probable interaction between FL-TrkC and BMPRIA. We transfected tagged versions of FL-TrkC and BMPRIA in HEK293T cells. Immunoprecipitation of either one of the two receptors again showed 
that they could interact in vitro (Figure 24). The interaction was again not affected by the addition of Ntf3 (Figure 24).

A

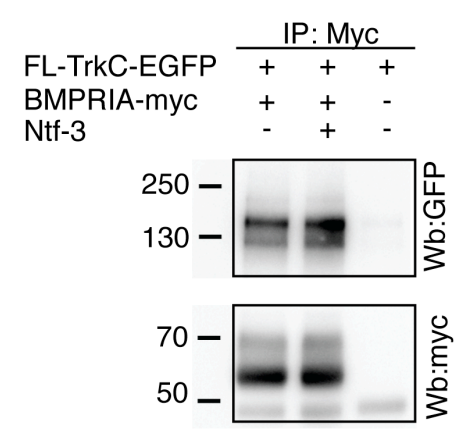

B

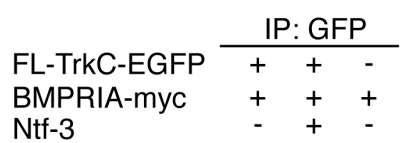
Ntf-3

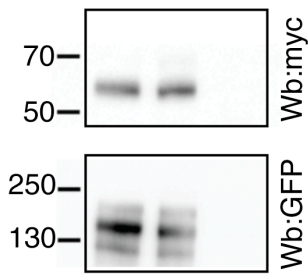

C

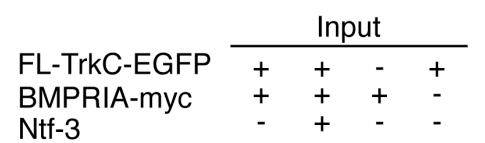
Ntf-3

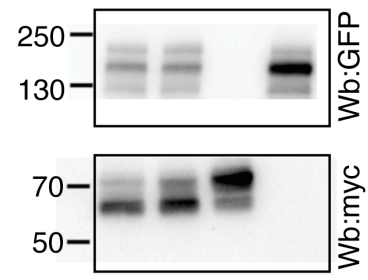

Figure 24. FL-TrkC can also interact with BMPRIA.

EGFP tagged FL-TrkC and Myc tagged BMPRIA were co-transfected in HEK293T cells. The cells were either not stimulated or stimulated with $50 \mathrm{ng} / \mathrm{ml} \mathrm{Ntf3}$ for two minutes. Upon Immunoprecipitation using an antibody against EGFP or Myc, we observed that that the two receptors co-immunoprecipitate. The interaction was unaffected by the addition of Ntf3.

Thus, our results conclusively establish the importance of the truncated TrkC receptor- $\mathrm{NC}-\mathrm{TrkC}$ in regulating cell fate decisionmaking in the developing cortex. NC-TrkC most likely influences this process via its negative regulation of ERK signaling. On the other hand, NC-TrkC and BMPRIA interact both in vitro and in vivo. We also showed that the downstream genetic programs controlled by these two receptors interact to determine cell fate in the cortex. Our data also suggests that Ntf3, which mediates feedback signaling from cortical postmitotic neurons to progenitors, may act through NC-TrkC in influencing cell fate.

We next asked, if pathways other than that controlled by Ntf3 also control cortical feedback signaling. 


\section{Cbln 4 is also upregulated in the Sip 1 mutant cortex}

Since the deletion of $N t f 3$ from the Sip1 mutant cortex did not rescue the Sip1 mutant phenotype, we wondered if other molecules could also contribute to feedback signaling in the Sip1 mutant. We found that the transneuronal cytokine-Cbln 4 was upregulated in the Sip1 mutant cortex at E14.5. This upregulation was restricted to the cortical plate (Figure 25A). We also studied the expression of two other family members- $C b \ln 1$ and $C b \ln 2$. We did not find expression of either of these two genes at E14.5 in the wildtype or the Sip1 mutant (Figure 25B).

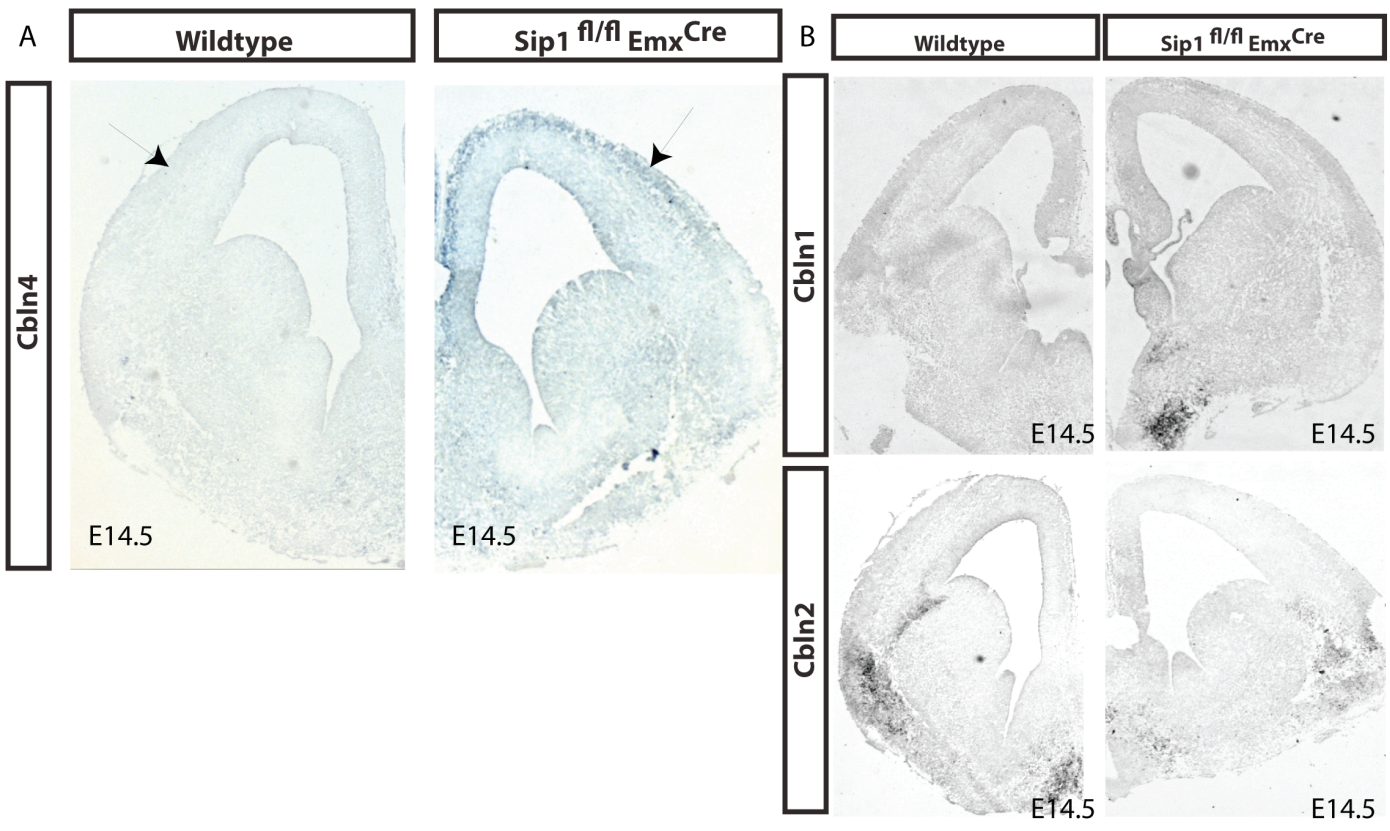

Figure 25. Cbln4 is upregulated in the Sip1 mutant cortex.

(A) Cbln 4 was found to be upregulated in the Sip1 mutant cortical plate at E14.5 (B) $C b \ln 1$ and $C b \ln 2$ on the other hand were not expressed at E14.5 in either the wildtype or the Sip1 mutant cortex. 


\section{Sip 1 can bind to the Cbln 4 enhancer region in vitro}

Since Cbln4 was upregulated in the Sip1 mutant cortex, we considered if Sip1 could directly repress the transcription of Cbln4. To test this, we cloned a short region of the Cbln4 enhancer region upstream of a gaussia luciferase-coding region (Figure 26A).

A

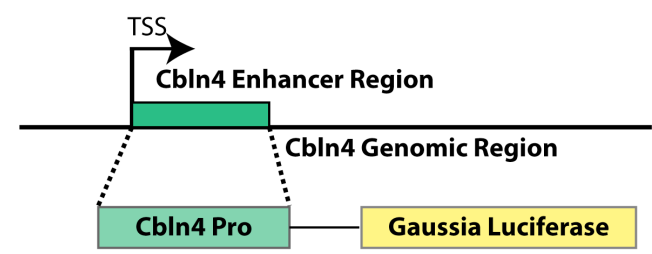

B
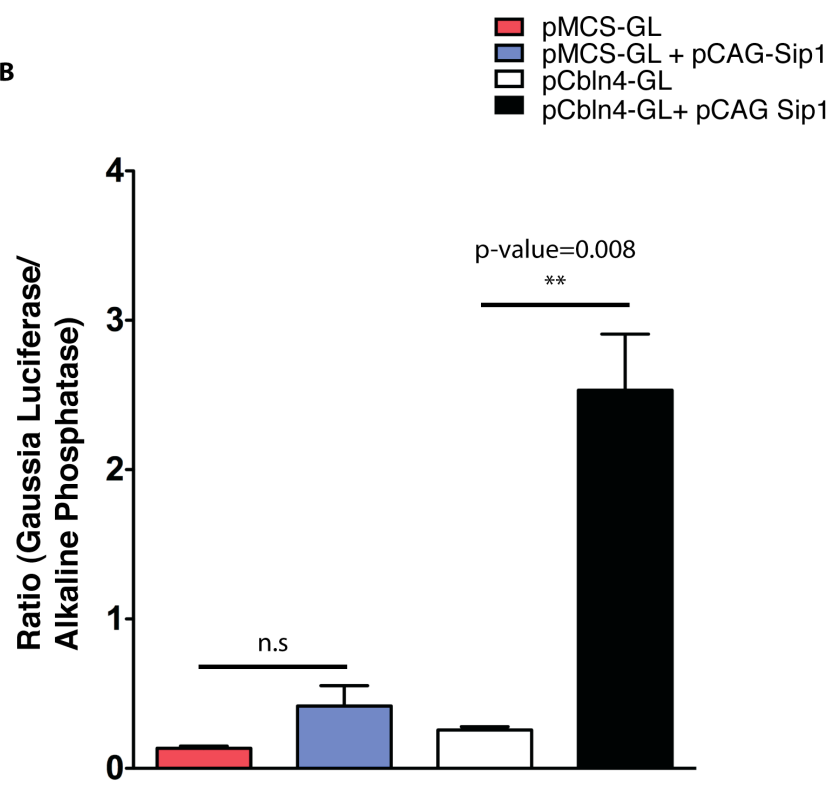

Figure 26. Sip 1 can bind to the Cbln4 enhancer region in vitro.

(A) Scheme showing the Cbln4 promoter sequence used for the luciferase assay (B) Ratio of Gaussia luciferase to Alkaline phosphatase. Sip 1 addition does not alter the enhancer activity of the empty vector $(n=3$, $p$-value $>0.05)$. The transcriptional activity of the Cbln4 enhancer was found to be 9.8 fold higher when Sip1 was co-transfected $(\mathrm{n}=3$, $\mathrm{p}$-value $=0.008)$.

We transfected this either alone or with Sip1 in HEK293T cells and used the ratio of Gaussia Luciferase to Alkaline phosphatase as a measure of the transcriptional regulation of Sip1 over the enhancer region. The sequence contained the bipartite Sip1 consensus binding motif CACCT(G) (Comijn et al., 2001). As expected, the addition of 
Sip1 did not alter the transcriptional rate of the control promoter (Figure 26B, ratio of gaussia luciferase to alkaline phosphatase without $\operatorname{Sip} 1=0.13 \pm 0.1$ and with $\operatorname{Sip} 1=0.41 \pm 0.13$, p-value $>0.05$ ). While we expected a decrease in the transcription of gaussia luciferase upon Sip1 binding to the Cbln 4 enhancer, we observed an increase (Figure 26B, ratio of gaussia luciferase to alkaline phosphatase without Sip1 $=0.25 \pm 0.02$ and with $\operatorname{Sip} 1=2.53 \pm 0.38$, p-value $=0.008$ ). While the transcriptional regulation of the Cbln 4 promoter by Sip1 was opposite to what was expected, this result still supports the binding of Sip1 to the promoter region in vitro. Indeed Sip 1 is known to function both as an activator or repressor depending on the genomic context and environment (Yoshimoto et al., 2005).

\section{Cbln4, 1 and 2 can also signal back to influence the proportions of basal and apical progenitors}

Since Cbln 4 was upregulated in the Sip 1 mutant cortex, we decided o study its role in feedback signaling by over-expressing it in a wildtype cortex. Further, since Cbln 1, 2 and 4 share a high degree of sequence homology; we studied the role of all three Cbln family members. Cbln3 was not included as it is known to be not secreted (Iijima et al., 2007). To examine if $C b \ln 4, C b \ln 1$ and $C b \ln 2$ affect the ratio of apical to basal progenitor population, we over-expressed these molecules exclusively in postmitotic neurons at E12.5. This was done as described previously (Figure 6A). When analyzed at E14.5, we observed that all three Cbln family molecules could enhance the proportion of Tbr2 positive basal progenitors (Figure 27A-D, difference in the proportion of Tbr2 positive cells in the electroporated region versus nonelectroporated region- for $E G F P$ electroporation $=-1.3 \pm 0.2 \%, \mathrm{n}=5$; $C b \ln 1-E G F P=15 \pm 5.7 \%, \mathrm{n}=3, \mathrm{p}$-value $=0.0017 ; \quad C b \ln 2=16.3 \pm 10.1 \%$, $\mathrm{n}=3, \mathrm{p}$-value $=0.0076 ; C b \ln 4-E G F P=12.1 \pm 5.3 \%, \mathrm{n}=4$, $\mathrm{p}$-value $=0.0009$ ). 

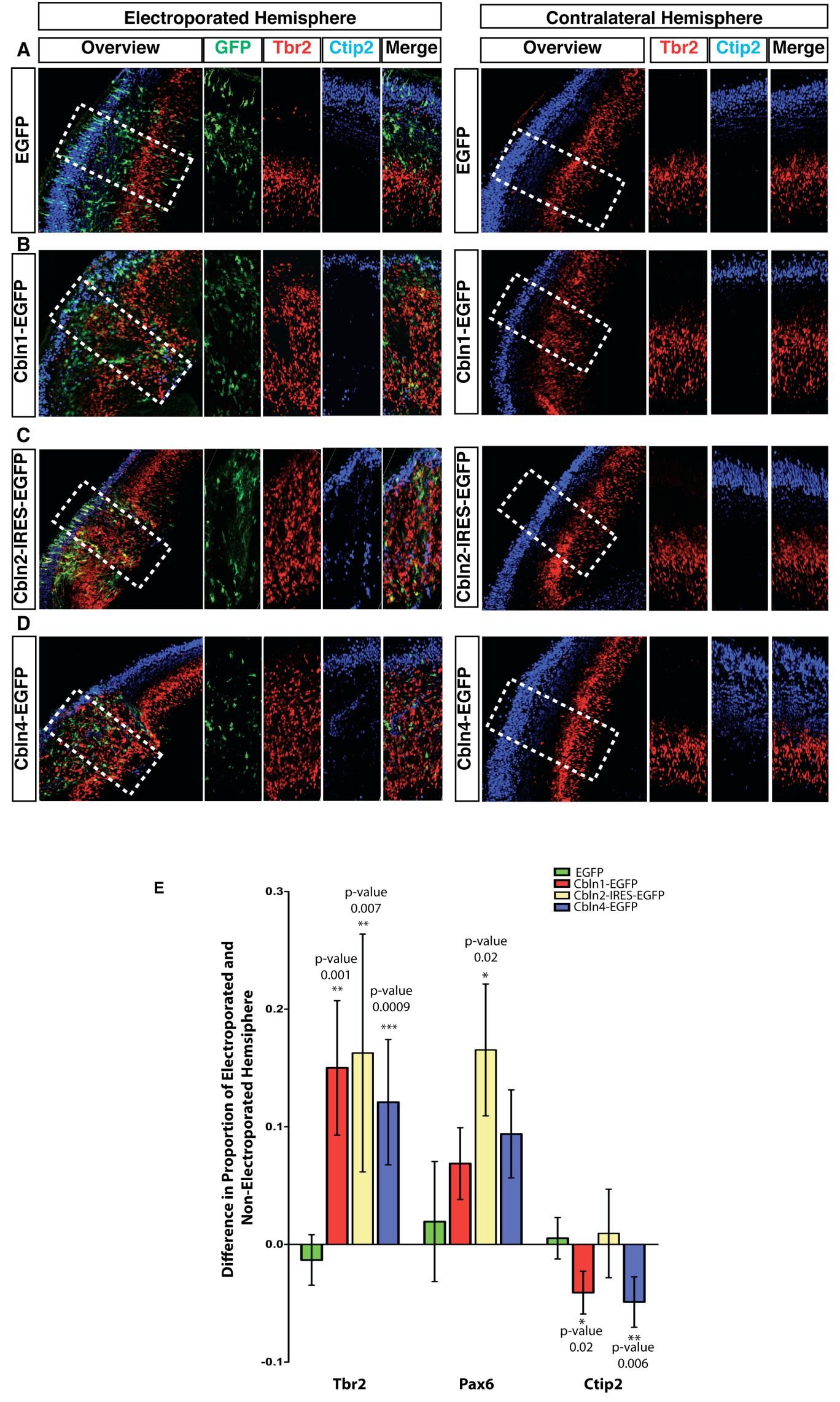
Figure 27. Over-expression of $C b \ln 1,2$ and 4 leads to an increase in Tbr2 positive basal progenitor population.

$C b \ln 1-E G F P, C b \ln 2$ and $C b \ln 4-E G F P$ were over-expressed at E12.5 and the brains were analyzed at E14.5. (A, E) Differences between the electroporated and nonelectroporated hemispheres upon EGFP over-expression with respect to the proportion of Tbr2 + cells $=1.3 \pm 2.1 \% \mathrm{n}=5, \mathrm{Pax} 6+$ cells $=1.9 \pm 5.1 \%, \mathrm{n}=3$ and Ctip2+ cells $=-0.5 \pm 1.7 \%, \mathrm{n}=5 \mathbf{( B ,} \mathbf{E})$ Over-expression of Cbln 1 -EGFP leads to a $15 \pm 5.7 \%$ increase in Tbr2+ cells compared to the contralateral hemisphere $(n=3, p$-value compared to EGFP over-expression= 0.0017). Pax6+ cells were not significantly changed between $C b \ln 1$ and empty vector over-expression $(\mathrm{n}=3, \mathrm{p}>0.05)$. Ctip2+ cells were reduced by $-4 \pm 1.8 \%$ upon $C b \ln 1$ over-expression $(n=3$, p-value $=0.02)(\mathbf{C}$, E) Over-expression of Cbln2 leads to a $16.3 \pm 10.1 \%$ increase in Tbr2+ cells compared to the contralateral hemisphere $(n=3$, $p$-value compared to EGFP overexpression $=0.0076$ ). Pax6+ cells were also significantly higher in the electroporated hemisphere $(16.5 \pm 5.6 \%, \mathrm{n}=3, \mathrm{p}=0.03)$. Ctip2+ cells were not significantly changed upon Cbln2 over-expression ( $\mathrm{n}=3, \mathrm{p}$-value $>0.05)$ (D, E) Overexpression of Cbln4-EGFP leads to a $12.1 \pm 5.3 \%$ increase in Tbr2+ cells compared to the contralateral hemisphere $(n=4, p$-value compared to EGFP over-expression= 0.0009). Pax6+ cells were not significantly changed between Cbln 4 and empty vector over-expression $(n=3, p>0.05)$. Ctip $2+$ cells were reduced by $-5 \pm 2 \%$ upon Cbln 4 over-expression $(\mathrm{n}=4, \mathrm{p}$-value $=0.006)$

This increase in Tbr2 positive cells resembled the increase caused by Ntf3 over-expression. However, unlike Ntf3 we did not observe any decrease in Pax6 positive cells (Figure 27A-D, difference in the proportion of Pax 6 positive cells in the electroporated region versus non-electroporated region for EGFP electroporation $=1.9 \pm 5.1 \%, \mathrm{n}=3$; $C b \ln 1-E G F P=6.8 \pm 3 \%, \mathrm{n}=3, \mathrm{p}$-value $>0.05 ; C b \ln 2=16.5 \pm 5.6 \%, \mathrm{n}=3, \mathrm{p}-$ value $=0.03 ; C b \ln 4-E G F P=9.4 \pm 3.7 \%, \mathrm{n}=4, \mathrm{p}$-value $>0.05)$. In fact, there was a slight increase in Pax6 positive cells upon over-expression of all three Cbln family members, indicating that these molecules and Ntf3 act on independent pathways. These results may explain as to why the Sip1 mutant phenotype was not rescued in the Sip1-Ntf3 double mutant. Up-regulation of Cbln 4 may also be one of the important reasons for the enhanced feedback signaling observed in the Sip1 mutant. 


\section{Cbln4 also promotes premature upper layer neurogenesis}

We found a decrease in the number of Ctip2 positive deep layer neurons already at E14.5 upon over-expression of both $C b \ln 1$ and Cbln4 (Figure 27A, C, D, difference in the proportion of Ctip2 positive cells in the electroporated region versus non-electroporated region for EGFP electroporation $=-0.5 \pm 1.7 \%, \mathrm{n}=5 ; C b \ln 1-E G F P=-4 \pm 1.8 \%, \mathrm{n}=3$, $\mathrm{p}$-value $=0.02 ; C b \ln 2=0.9 \pm 3.7 \%, \mathrm{n}=3, \mathrm{p}$-value $>0.05 ; C b \ln 4-E G F P=-$ $4.9 \pm 2.1 \%, n=4, p$-value=0.006). Hence, we wanted to study the effects of Cbln4 over-expression on laminar fate in the developing cortex. To do so, we over-expressed Cbln 4 with EGFP or EGFP alone at E12.5 in wildtype cortices by in utero electroporation. To determine the final position of the neurons born at E13.5, we injected BrdU into the mother intraperitonially. When we analyzed the brains at P4, a stage at which migration is mostly complete, we observed that in the EGFP alone expressing brains; most of the cells born at E13.5 occupied deeper layers of the cortex, with few cells reaching the upper layers (Figure 28, upper panel). However, with Cbln4 over-expression, majority of the neurons occupied the upper layers (Figure 28, lower panel). This indicates that when Cbln 4 is over-expressed in the cortex, a vast majority of neurons born at E13.5 within the electroporated region are upper layers neurons. This data supports our hypothesis that Cbln4 upregulation in the Sip1 mutant cortex is one of the reasons for the premature generation of upper layer neurons at the expense of deeper layer neurons.

Further, a general increase in the number of BrdU positive cells can be observed with the over-expression of Cbln4 (Figure 28). This might co-relate to an increase in both the number of Pax6 positive and Tbr2 positive cells observed at earlier stages (Figure 27). 

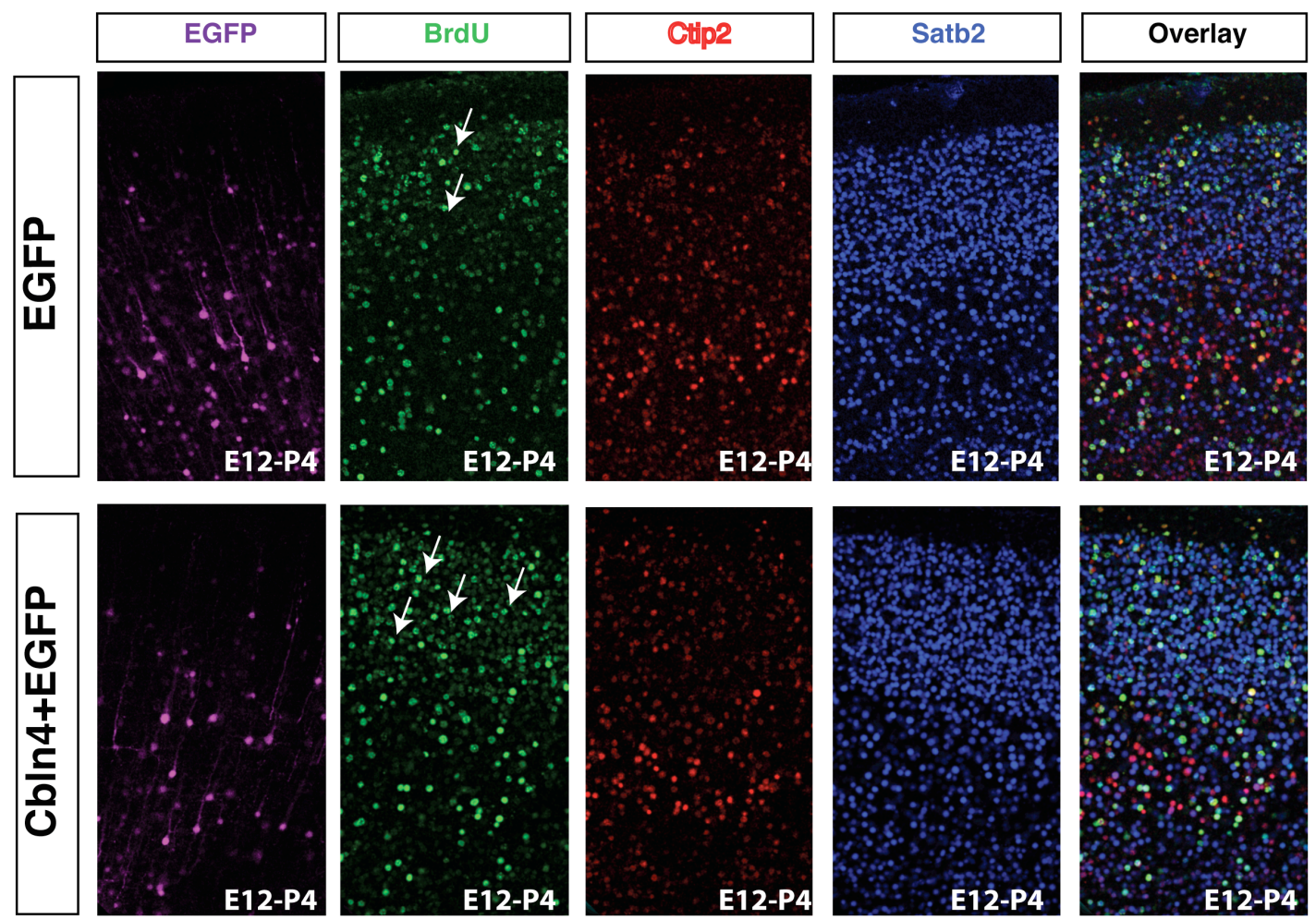

Figure 28. Cbln4 promotes premature upper layer neurogenesis.

A Cbln4 over-expressing plasmid along with EGFP or EGFP alone was overexpressed in neocortical neurons at E12.5. A BrdU pulse was given at E13.5 and the brains analyzed at P4. While in control plasmid electroporated brains, only a moderate number of neurons born at E13.5 occupy the upper layers of the cortex, upon Cbln 4 over-expression the number increased significantly (arrows). Also, a decrease in the number of Ctip2+ layer $\mathrm{V}$ cells can be seen in upon Cbln 4 overexpression.

\section{Receptors for Cbln4 are located along the radial glial process}

Since there are few cognate receptors known for the Cbln family, we decided to screen for putative receptor(s). In order to do so, we first wanted to localize the receptor in the developing cortex. We hence cloned a Cbln4-Alkaline phosphatase fusion construct and expressed it in HEK293T cells (Figure 29A). We later collected the supernatant from these cells and used the recombinant ligand to identify the location of the receptor (Figure 29B). 
A
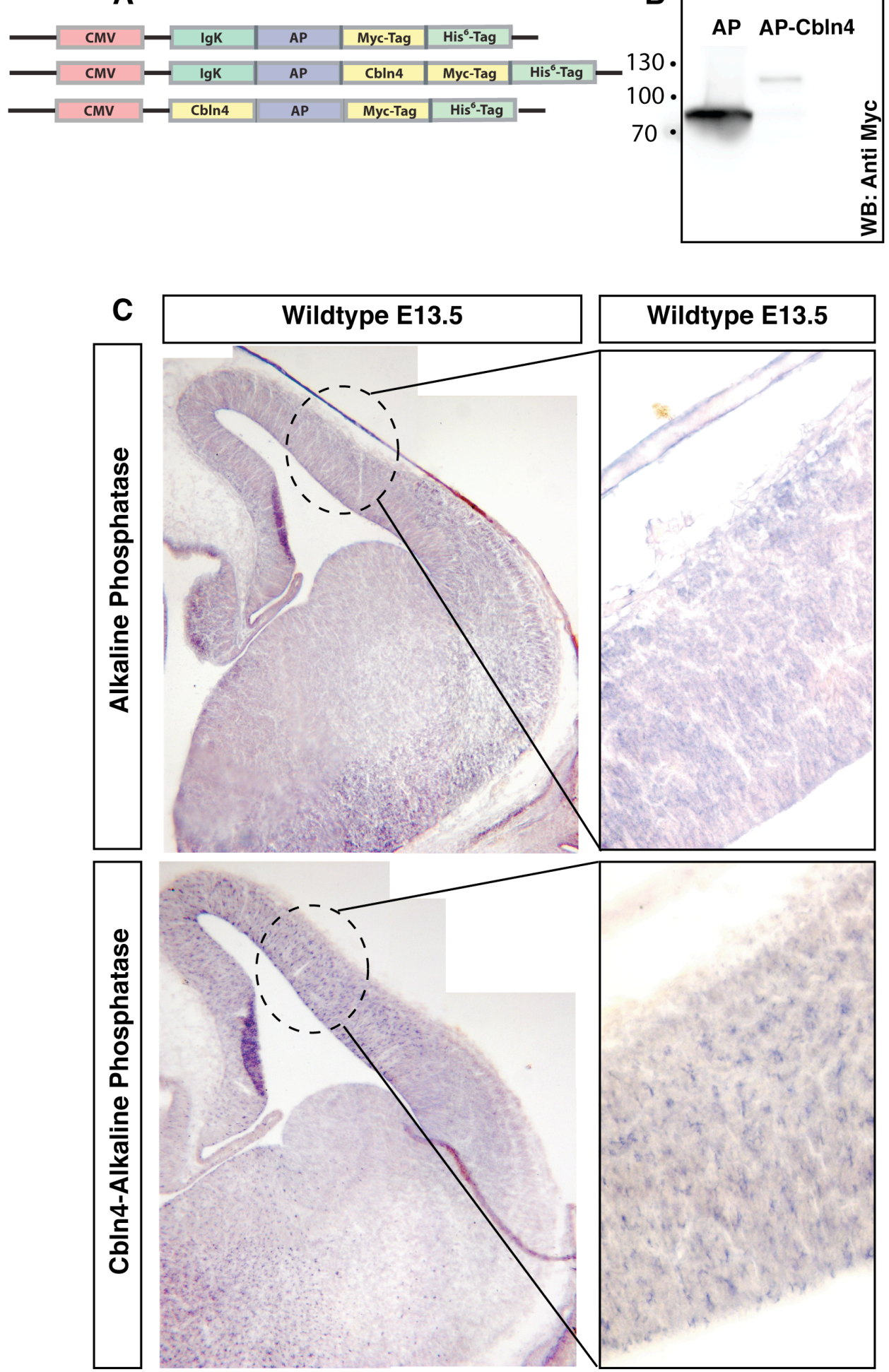

Figure 29. Receptor for Cbln4 is located within the developing cortex

(A) Scheme showing the different Cbln4-Alkaline phosphatase constructs used (B) Western blot image showing the presence of the AP tagged Cbln4 in the supernatant of transfected HEK293T cells (C) E13.5 wildtype sections were incubated with the untagged AP or the Cbln4-tagged AP. While AP alone does not give any specific signal, Cbln4-AP gave a distinct pattern within the cortex. Staining was not observed in any other part of the tissue. Within the cortex, the staining pattern was radial and segmented. 
Untagged Alkaline phosphatase, which served as the negative control did not give any specific staining. Cbln 4 tagged Alkaline phosphatase however, showed a dispersed staining pattern within the dorsal cortex (Figure 29C). Specific staining was absent from other areas in the forebrain. Within the cortex, interrupted staining was observed from the ventricular surface till the marginal zone (Figure 29C). Since, at E13.5 the cortex largely comprises of progenitor cells, we believe that this staining most likely represents the presence of receptors on the progenitors. Additionally, since the pattern of staining is radial, we believe that this could represent small segments of the radial glial process (Figure 29C). However, further co-localization studies will be required to confirm this assumption.

\section{Preparation of an E14.5 cortical cDNA library}

Since the over-expression of Cbln4 at E12.5 had an effect on the progenitors when analyzed at E14.5, we concluded the cognate receptor must be present between E13.5 and E14.5 in the cortex. We hence decided to construct a full-length cortex specific E14.5 cDNA library. The E14.5 cortical cDNA library was prepared using the fulllength cDNA library construction kit (Invitrogen). Post electroporation of two different fractions, representing cDNA clones of different sizes, into electrocompetent bacteria; the culture was plated in serial dilutions to estimate the total number of clones. Fraction 2 cDNA library in pDONR222 contained $5 \times 10 * 5 \mathrm{cfu}$ with an average insert size of $1.2 \mathrm{~Kb}$ and $100 \%$ recombinants (Figure 30 ). Fraction 3 cDNA library in pDONR222 contained $1.2 \times 10 * 6 \mathrm{cfu}$ with an average insert size of $0.8 \mathrm{~Kb}$ and $100 \%$ recombinants (Figure 30 ). Based on the average size and the percentage of total recombinants, these values indicate that the cDNA library preparation was successful. To transfer the cDNA library into an expression system, the LR cloning system was used to shuttle the library into a Gateway expression plasmid- pDEST 40 
(Invitrogen). The total number of clones in pDEST 40 was found to be $6.7 \times 10 * 5 \mathrm{cfu}$ with an average size of $1.02 \mathrm{~Kb}$ and $70 \%$ recombinants, from fraction 2 (Figure 30). Thus, this library can be used for screening for a Cbln4 cognate receptor in the developing cortex.
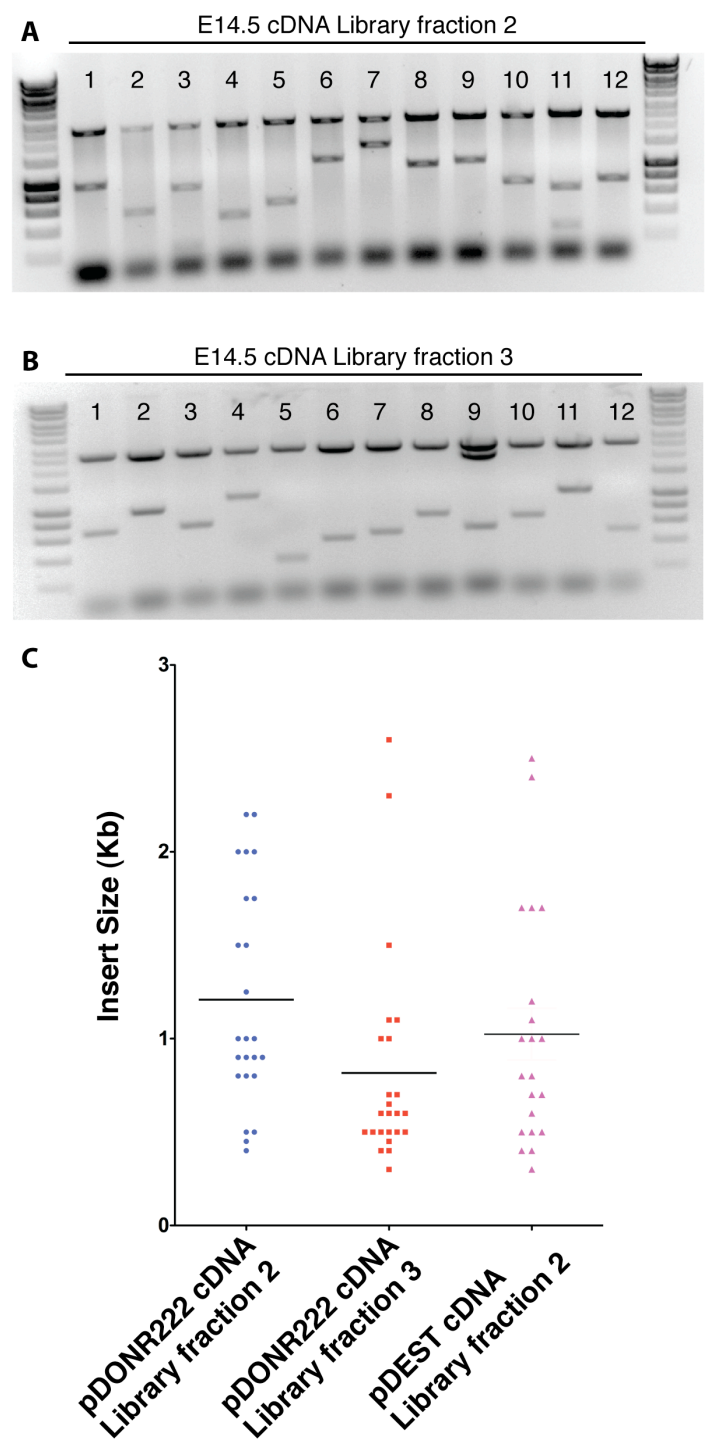

\section{Figure 30. Construction of an E14.5 cortex specific cDNA library}

(A) Examples of clones selected from the pDONR 222 cDNA library fraction 2, digested with the enzyme BsrG1 (B) Examples of clones selected from the pDONR 222 cDNA library fraction 3, digested with the enzyme BsrG1 (C) Quality assessment of the cDNA library. The library in pDONR222, fraction 2 contained $5 \times 10 * 5$ cfu with an average insert size of $1.2 \mathrm{~Kb}$. The library in pDONR222, fraction 3 contained $1.2 \mathrm{x}$ $10 * 6 \mathrm{cfu}$ with an average size of $0.8 \mathrm{~Kb}$. Both libraries had $100 \%$ recombinants. The library in pDEST, fraction 2 had $6.7 \times 10^{*} 5 \mathrm{cfu}$ with an average size of $1.02 \mathrm{~Kb}$ and $70 \%$ recombinants. 
Thus we demonstrate that the Cbln family of transneuronal cytokines can also signal to cortical progenitors when expressed in postmitotic neurons. To better understand the molecular pathway controlling this feedback signaling, it would be necessary to identify the cognate receptor for $\mathrm{Cbln} 4$ during cortical development. Here, we report the construction of a high quality, full-length E14.5 cDNA library. Receptor screening, by expressing pools of cDNA clones in mammalian cells and using recombinant Cbln4-AP fusion protein, would yield candidate receptors that could control important mechanisms that govern cell fate switch in the developing neocortex. 


\section{DISCUSSION}

\section{Ntf3 mediated feedback signaling}

Cortical progenitors cultured in vitro can faithfully recapitulate the entire sequence of corticogenesis suggesting a hardwired cellular program (Shen et al., 2006). However, when younger progenitors are transplanted into an older brain, they adapt to their new environment and immediately start producing late born neurons (Frantz and McConnell, 1996; Desai and McConnell, 2000). These two findings thus predict that though progenitors possess all the necessary genetic components to take them through the various stages of neurogenesis, environmental fine-tuning mechanisms must exist that control the timing of cell fate switch.

These environmental cues could originate from multiple sources like the meninges, thalamus or the cerebro-spinal fluid (CSF), all of which have been shown to have important implications on cortical progenitors (Dehay et al., 2001; Zarbalis et al., 2007; Lehtinen et al., 2011; Siegenthaler and Pleasure, 2011). We previously showed that deletion of Sip1 in postmitotic neurons has severe effects on cortical development (Miquelajauregui et al., 2007; Seuntjens et al., 2009). During neocortical development Sip1 controls feedback signaling that influences glia versus neuronal cell fate choice. We identified Fgf9 as an important player downstream of Sip1 that initiates gliogenesis (Seuntjens et al., 2009b). This study also suggested that a similar feedback mechanism might exist within the time span of neurogenesis wherein postmitotic neurons signal back to the progenitors and prevent the over-production of a subtype of neocortical neurons. However, such a feedback mechanism was proposed based on circumstantial evidence. It was neither corroborated with direct evidence, nor was the precise signal governing the switch from deep layer to upper layer cell fate identified. 
Here, using mosaic loss-of-function of Sip1, we demonstrate that Sip1 controls lamination via non-cell autonomous mechanism. We previously identified Ntf3 as a Sip1 target in the neocortex. In the current study we show that the binding of Sip1 to the Ntf3 promoter is functional. Moreover, using in vivo gain of function assay, we show that Ntf3 increases both, the proportion of basal progenitors and the proportion of upper layer neurons. These results, to our knowledge, for the first time conclusively show the presence of cortical feedback signals in neocortical layer specification. Our results also highlight that postmitotic neurons can influence the apical to basal progenitor balance leading to a radial expansion of the cortex. A radial expansion of the cortex has been previously reported with such a shift from apical to basal progenitor population (Nonaka-Kinoshita et al., 2013; Stahl et al., 2013).

Although to our knowledge, Ntf3 expression has not been conclusively detected in the early developing cortex, our results indicate that there still might be a direct implication of the importance of neurotrophinTrk signaling pathway in the process of cell fate switch. For instance, over-expression of dominant negative $\operatorname{TrkB} / \mathrm{C}$ has been shown to reduce the total number of proliferating cortical progenitors (Bartkowska et al., 2007). This finding directly implies that signaling via these receptors is necessary for governing cell cycle parameters. It is possible that in the wildtype scenario, in order to cause cell fate switch, the activation of the Trk receptors is not dependent on their natural ligands but rather on non-classical signaling mechanisms. For example, recent work has shown that EGFR can transactivate both TrkB and TrkC and that the phosphorylation of TrkB and TrkC was unchanged in BDNF and Ntf3 mutants (Ernfors et al., 1994; Puehringer et al., 2013) clearly showing that mechanisms beyond the classical ligand dependent activation of Trk receptors exist in the developing cortex. In such a scenario, we could explain the cell fate switch initiated by Ntf3 in Sip1 mutants as a hyper-activation of a 
system that is normally controlled by other stimuli. It is also possible that Ntf3 is present in the developing cortex but has not been detected. Possible sources of Ntf3 could be incoming thalamo-cortical axons or the CSF both of which have been shown to bring important information to the developing cortex (Dehay et al., 2001; Lehtinen et al., 2011). Additionally, the marginal increase in the proportion of Sox5 positive layer VI neurons in Ntf3 mutants indicate that Ntf3 is required for controlling important aspects of cortical lamination. However, since the deletion of Ntf3 from the Sip1 cortex does not rescue the Sip1 mutant phenotype, it is probable that multiple pathways exist for controlling cortical feedback signaling.

Recent work points to the existence of lineage specific progenitors (Franco et al., 2012). One hypothesis for the switch from deep layer to upper layer neuron production in the Sip1 mutant and in the Ntf3 over-expression studies, would be the preferential effect of Ntf3 on upper layer specific progenitors (Franco and Muller, 2013). In such a scenario, Ntf3 over-expression could promote early differentiation of upper layer specific progenitors. Since this would prematurely exhaust the progenitor pool, the increase in basal progenitor population seen with $N t f 3$ over-expression could be an additional step in order to prevent such a situation.

The presence of secreted molecules like Ntf3 in the cortical plate (CP) that act as feedback signals influencing progenitors located within the ventricular zone (VZ) and sub-ventricular zone (SVZ) raises another intriguing question about how these signals reach the VZ-SVZ from the CP. Signals originating from the $\mathrm{CP}$ could either bind to their cognate receptor along the radial glial process or diffuse into the $\mathrm{VZ}$ and bind to the receptor on the radial glial cell body (Seuntjens et al., 2009). In the first scenario the effect of Ntf3 over-expression should be local since radial glial processes are widespread and thus signaling would be restricted to a smaller number of progenitors. In the second scenario, signals diffusing to the $\mathrm{VZ}$ should produce a widespread 
effect, since the area occupied by radial glial cell bodies is much smaller than the size of the cortex they produce (Figure 31). Our results do not provide evidence to support one or the other hypothesis, however we believe that using such a system in combination with optical methods like FRET could address this issue (Figure 31).
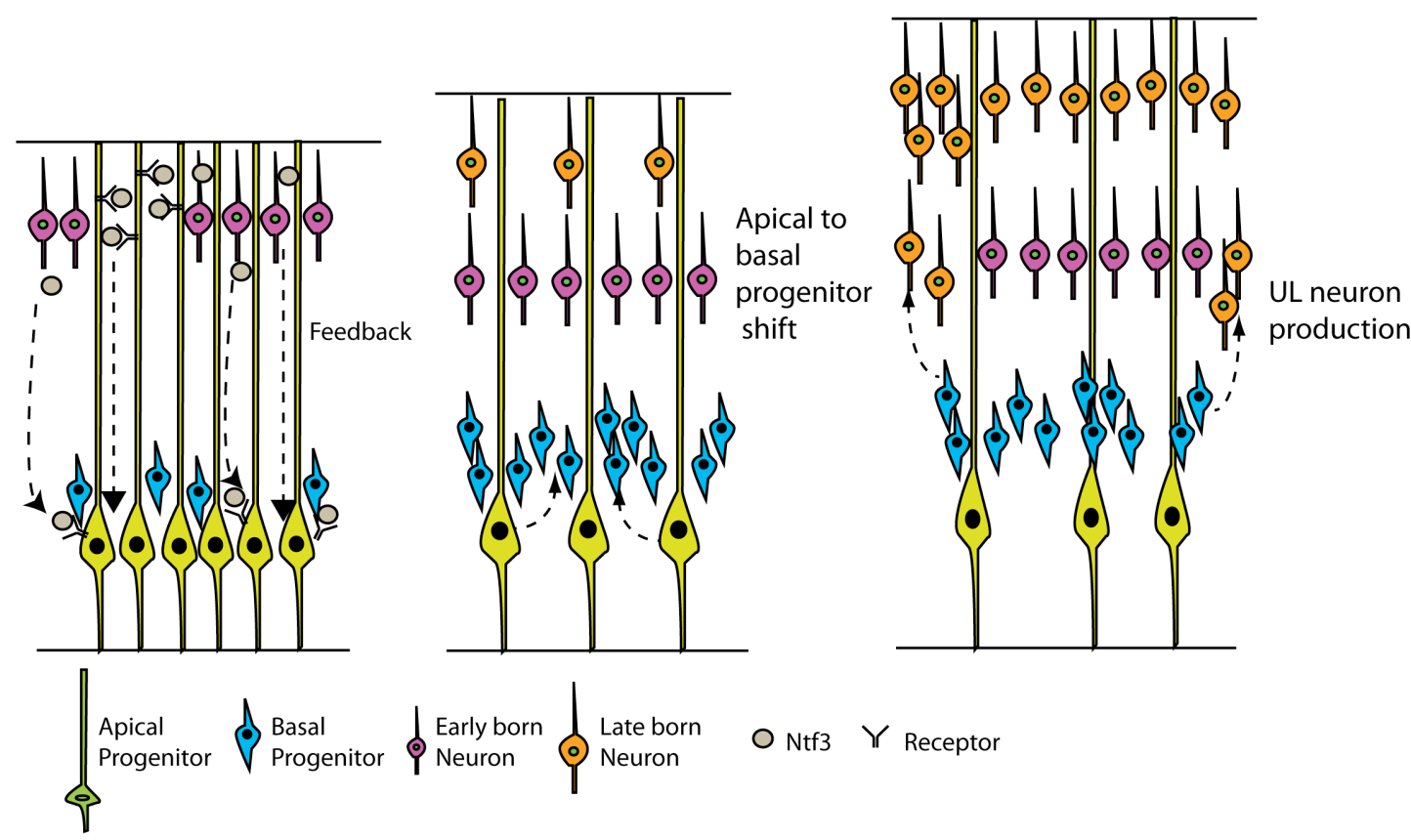

Figure 31. Model depicting the two possible modes of Ntf3 mediated signaling. Receptors located along the radial glial process or on the cell body could sense Ntf3 released by postmitotic neurons. Such a signaling initiates the generation of basal progenitors, which in turn could lead to the expansion of UL neurons.

We believe that we have provided the first evidence for the presence of postmitotic neuron to progenitor feedback signaling in laminar cell fate determination, Ntf3 being one such signal that influences both the ratio of apical to basal progenitors and deep layer to upper layer neurons. 


\section{Expression Pattern of NC-TrkC mirrors the transition from deep layer to upper layer production.}

Generation of cortical neurons occurs between E11.5 and E16.5 in the mouse. Each layer has a distinct peak of production- layer VI at $\mathrm{E} 12.5$, layer $\mathrm{V}$ at E13.5, layer IV at E14.5 and layers II-III at E15.5 (Molyneaux et al., 2007). Further, the onset of neurogenesis begins in rostrolateral positions and progresses caudomedially (Sanderson and Weller, 1990; Hill and Walsh, 2005; Bayatti et al., 2008). This implies that neurogenesis at the lateral edge of the neocortex is developmentally more advanced than the medial regions. Thus, molecules displaying such a pattern of expression may govern the transition from deeper layer to upper layer neuronal production. The POU-III family of transcription factors has been shown to be necessary for upper-layer neurogenesis (Dominguez et al., 2013). Correspondingly, their expression pattern was shown to mirror the generation of upper layer neurons in the VZ, by showing a high lateral-low medial expression at mid corticogenesis. Similarly, Tbr2, a T-box transcription factor essential for basal progenitor mediated upper layer neurogenesis, shows a high lateral-low medial gradient of expression (Bulfone et al., 1999; Englund et al., 2005). The noncoding RNA svet1, whose expression first appears around E13.5 in the SVZ, was also shown to increase with the onset of upper layer neurogenesis. The expression of svet 1 persists later in upper layer neurons suggesting a lineage relationship between the SVZ progenitors and the upper layer neurons they generate (Tarabykin et al., 2001). Similarly the transcription factor Cux2 has been shown to be expressed in dividing SVZ cells and also later on in upper layer neurons (Zimmer et al., 2004). Cux2 also appears around E13.5 and the expression levels increase as upper layer neurogenesis begins. More recently, Cux2 was also shown to mark upper layer specific apical progenitors, the numbers of which increase with corticogenesis (Franco et al., 2012). 
Surprisingly even the mutant for the apical progenitor marker Pax6 (Pax6sey/sey mutant) displays problems only with specification of upper layer neurons and not deep layer neurons (Stoykova and Gruss, 1998; Tarabykin et al., 2001; Nieto et al., 2004; Zimmer et al., 2004).

While many molecules appear later during development at the germinal zone and parallel the generation of upper layer neurogenesis, not many molecules with the opposite pattern of expression have been identified. Expression of such molecules should peak during deep layer neurogenesis and drop during upper layer neuronal production. To our knowledge, so far, no molecule with such a pattern of expression has been identified. Here, we show that the non-catalytic isoform of the neurotrophin receptor $\operatorname{TrkC}(N C-\operatorname{Trk} C)$ is expressed at high levels in the ventricular zone during early neurogenesis (E12.5E13.5). At E14.5, when the lateral boundaries of the neocortical VZ have already started generating upper layer neurons, $N C$-TrkC is down regulated and expression persists only in the dorso-medial cortex. At E15.5, when the progenitor zone of the neocortex is mostly producing only upper layer neurons, $N C$-TrkC expression is completely lost. Thus, we believe that $N C$-TrkC is one of the first molecules to have been shown to possess an expression pattern that would suggest a role in determining deeper layer cell fate.

Receptors lacking a kinase domain have long been thought to act as dominant negatives to the full-length receptor (Dorsey et al., 2012; Fenner, 2012; Yanpallewar et al., 2012b). This assumption however would not hold true when the different isoforms have divergent expression patterns (Menn et al., 1998b, 2000b; Rose et al., 2003). In the context of the developing neocortex, both isoforms of TrkB and $\operatorname{TrkC}$ have well defined and segregated expression patterns. While NCTrkC is expressed both in the germinal zone and the cortical plate, FLTrkC is expressed only in the cortical plate. This suggests that NCTrkC has a unique role, which goes beyond acting as a dominant negative of $F L-T r k C$, within cortical progenitors. On the other hand, 
since both the isoforms are co-expressed in postmitotic neurons, it is possible that within these cells, $N C$-TrkC acts as a dominant negative. However, since there is little or no Ntf3 expression within the developing cortex, what is the role of such a dominant negative NCTrkC, still remains unanswered.

The two different isoforms of $\operatorname{TrkB}$ also display mutually exclusive expression domains. FL-TrkB is expressed in postmitotic neurons and $N C$-TrkB in the lateral VZ. Numerous pieces of work have shown the importance of TrkB mediated signaling during corticogenesis (Medina et al., 2004; Bartkowska et al., 2007; Puehringer et al., 2013). Unfortunately, none of this work differentiates between the importance of the individual isoforms and their functions in controlling cortical development. Work done in other systems have attributed unique functions to the truncated Trk isoforms. For example, truncated TrkB has been shown to control $\mathrm{Ca}^{2+}$ signaling within glial populations (Rose et al., 2003). It is also known that waves of calcium propagate through radial glial cells and the amplitude and frequency of these waves increases as neurogenesis progresses (Weissman et al., 2004). Thus, it would be reasonable to study the role of NC-TrkB in governing radial glial proliferation and cell fate determination.

\section{NC-TrkC influences cell fate by favoring deep layer neurogenesis}

To study the role of $\mathrm{NC}-\mathrm{TrkC}$ in cortical cell fate switch, we employed gain-of-function experiments. By doing so, we showed that NC-TrkC over-expression could shift neurogenesis in favor of deeper layer neuronal production. This supported our hypothesis based on the expression pattern of $N C$-TrkC that it could be a deep layer neuronal fate determinant.

$N C$-TrkC expression drops as upper layer neurogenesis begins. This poses the question about the cause and the consequence. Does NC- 
TrkC down-regulation pave the way for upper layer neurogenesis or does the progressive commitment to upper layer fate lead to a downregulation of $N C$-TrkC? Our experiments here do not support either hypothesis and analysis of TrkC mutants would be needed to answer this question. Alternatively, one could over-express the NC-TrkC at later stages to study if the fate of older progenitors can be reversed.

Apart from the over expression studies with NC-TrkC, another interesting evidence that helped further our understanding about how $\mathrm{NC}-\mathrm{TrkC}$ may control cell fate was the over-expression of the $\mathrm{Y} 516 \mathrm{~F}$ NC-TrkC mutant which is incapable of binding to the signaling molecule Shc. This mutant carries a tyrosine to phenylalanine Y516F mutation, thereby rendering the receptor incapable of being phosphorylated at this residue, thus preventing the recruitment of Shc to the receptor. Since the over-expression of this mutant NC-TrkC did not lead to changes in cell fate, it can be concluded that signaling via this tyrosine is essential for cell fate determination.

The FL-TrkC upon ligand binding autophosphorylates and subsequently phosphorylates the tyrosine at the $516^{\text {th }}$ position. This leads to Shc recruitment and downstream signaling. However, in the context of the NC-TrkC, since the receptor has no kinase domain, it is not clear as to which kinase phosphorylates this tyrosine and what happens downstream of this tyrosine phosphorylation. Recent work has shown that in cortical progenitors, Trk receptors are transactivated by the EGF-receptor via Src kinases (Puehringer et al., 2013b). This work also shows that Trk receptors expressed in embryonic cortical precursors are non-responsive to Ntf3 or BDNF. One possible explanation for this is that since only the non-catalytic isoforms of the Trk receptors are expressed by cortical progenitors, they are incapable of carrying out signaling by direct ligand binding. However, EGF mediated transactivation could lead to the phosphorylation of both NC-TrkC and NC-TrkB. Under this circumstance, Shc should be recruited to the phosphorylated NC-TrkC receptor. Further, it remains to be answered as to what happens 
downstream of Shc recruitment by NC-TrkC. It is counter intuitive and highly unlikely that the recruitment of Shc by NC-TrkC would lead to the activation of the MAP kinase pathway, because of the following reasons:

a) NC-TrkC has no kinase domain to phosphorylate Shc

b) It would seem redundant to activate the same pathway as that activated directly downstream of EGFR activation, since EGFR can also directly recruit Shc and activate the MAP Kinase (MAPK) pathway.

On the other hand, it could be suggested that NC-TrkC recruitment of Shc leads to a dampening of MAP kinase signaling. Indeed, pERK1/2 is expressed in a high lateral-low medial pattern, which is opposite to that of $N C$-TrkC at E14.5. This is further supported by the appearance of p-ERK1/2 throughout the VZ at E15.5, when NC-TrkC has been downregulated. It is also interesting to note that the phenotype of the ERK1/2 double mutant is very similar to the over-expression of NC$\operatorname{Trk} C$, which involves producing lesser upper layer neurons and more deep layer neurons (Pucilowska et al., 2012). Further, in the Sip1 mutant, which generates upper layer neurons prematurely, p-ERK1/2 expression at E14.5 extends further medially as compared to wild type controls, suggesting that appearance of $\mathrm{p}$-ERK $1 / 2$ is correlative to upper layer neurogenesis (Seuntjens et al., 2009c).

Our data also suggests that in vitro, NC-TrkC can dampen ERK signaling. The negative regulation of MAPK signaling by NC-TrkC could perhaps be explained by the sequestering of Shc by NC-TrkC post transactivation by EGFR. However, if this were the only reason, then NC-TrkB, which overlaps with p-ERK1/2 expression at E13.5 and 14.5, should also have dampened MAPK signaling.

It is also unclear if $N C$-TrkC promotes deeper layer neurogenesis only by negatively regulating ERK signaling or if it has independent functions during early corticogenesis. This could be answered by co- 
expressing NC-TrkC and constitutively active ERK, which would allow us dissect out the NC-TrkC- MAPK dependent and independent role.

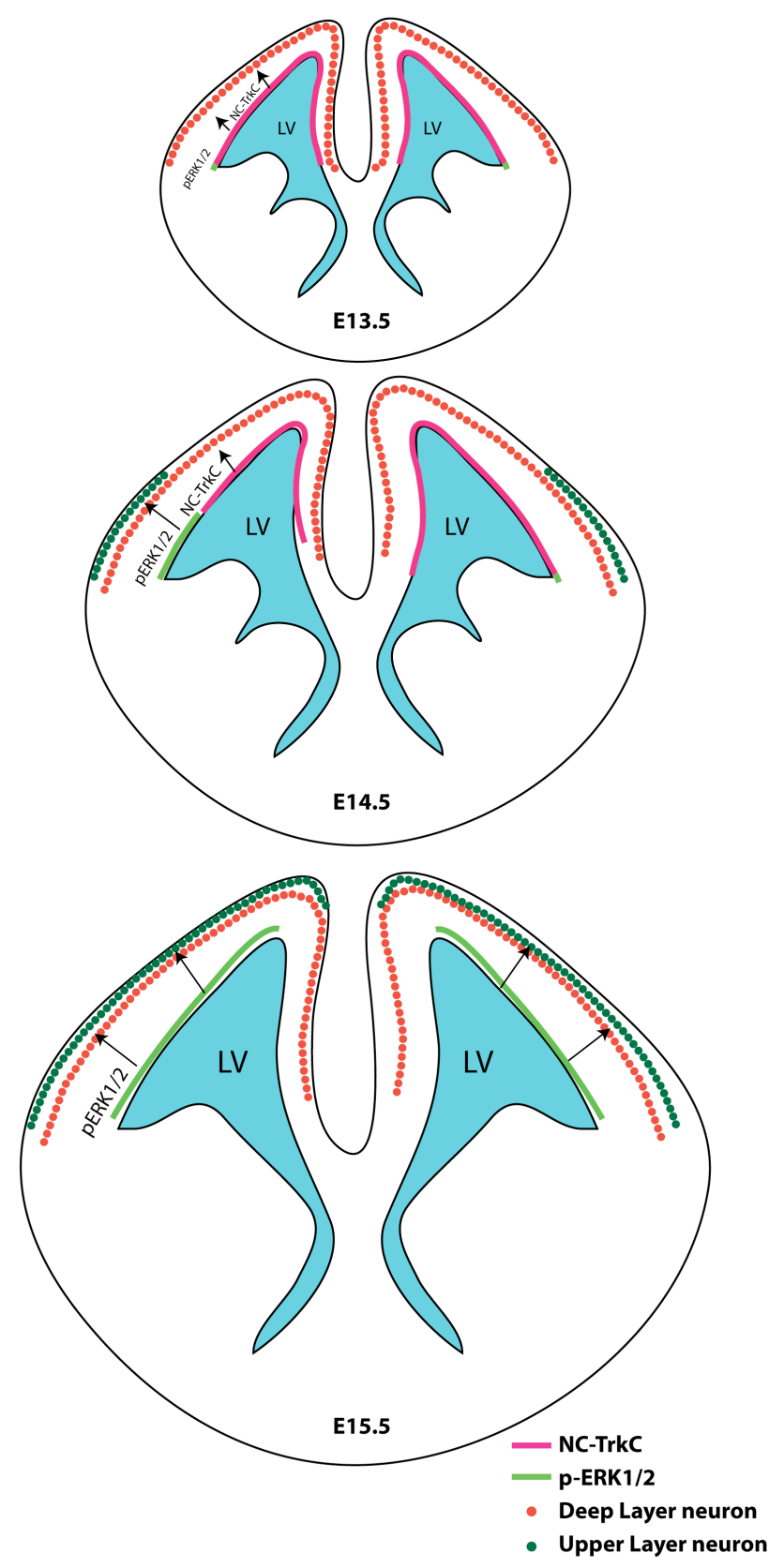

Figure 32. Expression pattern of NC-TrkC and p-ERK1/2.

During early corticogenesis (E13.5), $N C$-TrkC is expressed throughout the cortical $\mathrm{VZ}$ promoting deep layer neurogenesis. At the same time p-ERK1/2 is present at very low levels, close to the lateral edge of the cortical VZ. At E14.5, when the expression of $N C-T r k C$ is restricted to more medial regions of the cortical $\mathrm{VZ}, \mathrm{p}$ ERK1/2 shifts further medially, which corresponds to the shift in deep layer to upper layer neuronal production. At E15.5, when $N C$-TrkC is absent from the cortical VZ, p-ERK1/2 is present throughout the dorsal progenitor zone and promotes upper layer neurogenesis. 


\section{A Ligand for the receptor?}

During cortical development, expression of important signaling molecules such as BDNF, NTf3 or EGF has not been detected (Ernfors et al., 1994; Puehringer et al., 2013a). EGF expression in the embryonic striatum has although been reported. However, mice lacking their cognate receptors show a wide variety of defects including proliferation, migration and maturation (Medina et al., 2004; Puehringer et al., 2013a)

Recent work done by Puehringer et al. suggests that EGFR transactivation leads to TrkB/C phosphorylation (Puehringer et al., 2013a). Using cortical progenitor cultures the authors show that in vitro EGF stimulation leads to Trk phosphorylation and downstream signaling including ERK1/2 activation (Puehringer et al., 2013a). It is also important to note that while in vitro, EGF activation leads to ERK1/2 phosphorylation in early progenitors, pERK1/2 levels normally do not rise in vivo in the cortex before E15.5. Thus, EGF dependent signaling may also not be intrinsic to very early progenitors.

The lack of these above-mentioned ligands during development raises the question as to why would a system evolve to retain functional receptors without any ligand. This would then suggest a ligand independent role for these receptors, including NC-TrkC. Indeed, our experiments involving the over-expression of the NC-TrkC $\triangle \mathrm{ECD}$ mutant demonstrate that NC-TrkC by itself does not need to respond to extracellular cues for controlling cell fate switch. This poses an important question for the Ntf3 mediated feedback signaling. If NCTrkC does not require its extracellular domain for cell fate determination, how does Ntf3 mediate its feedback effect on NC-TrkC expressing progenitors?

It is also noteworthy that Ntf3 mediated feedback-signaling leads to the opposite outcome as that of NC-TrkC over-expression. Thus, one may hypothesize that $\mathrm{Ntf3}$ leads to down-regulation of NC-TrkC levels. 
One possible mechanism for this can be explained on the basis of work done by Mateos et al. This work describes the shedding of the extracellular domain of $\mathrm{NC}-\mathrm{TrkC}$ in response to $\mathrm{Ntf3}$ stimulation (Mateos et al., 2003). This phenomenon was not observed in the fulllength receptor. This could lead to the internalization of the remaining receptor thus down-regulating NC-TrkC levels. This work also showed the involvement of metalloproteinase in the shedding of the extracellular domain of NC-TrkC. Metalloproteinase such as ADAM10 have been also shown to be important for cortical development via the regulation of Notch signaling (Muraguchi et al., 2007; Jorissen et al., 2010). Thus a possible pathway linking Ntf3 to NC-TrkC and ADAM10 may connect cortical feedback signaling to cell fate decision-making.

\section{NC-TrkC interacts with BMPRIA}

One of the central reasons for our hypothesis that NC-TrkC functions as more than a dominant negative receptor, was based on its interaction with BMPRIA. While there has been a lot of work focusing on the interaction of the signaling pathways controlled by Trk receptors and BMP receptors, few pieces of work have studied the physical interaction of these receptors (Aubin et al., 2004; Guo and Wang, 2009). FL-TrkC is known to interact with BMPRII in cancer cell lines and prevents the interaction of the BMP class I and class II receptors, thereby preventing BMP signaling (Jin et al., 2007). We thus, wondered if the interaction of NC-TrkC and BMPRIA could also similarly prevent the association of BMPRIA and II, thereby preventing BMP signaling. However, the expression pattern of BMPRII and NCTrkC is, to a large extent, non-overlapping. While BMPRII is expressed high laterally and low medially, NC-TrkC is expressed high medially and low laterally at E14.5. Thus, we proposed that the interaction of BMPRIA and NC-TrkC could be relevant in activating a different pathway. Our finding that NC-TrkC and BMPRIA interact with their 
intracellular domains further supports a possible role for controlling downstream signaling with respect to this interaction.

One possible outcome of this interaction could be the usage of the kinase activity of BMPRIA in the NC-TrkC mediated signaling. Here, BMPRIA would serve as a co-receptor for $\mathrm{NC}-\mathrm{TrkC}$, thus initiating the signaling cascade. Indeed our results demonstrate that NC-TrkC can enhance the kinase activity of BMPRIA in a ligand independent manner. The classical BMP signaling requires ligand binding to class II BMP receptors, which in turn activate class I BMP receptors, which then activate downstream effectors (Liu and Niswander, 2005). Using an in vitro system we asked whether the interaction of BMPRIA with NC-TrkC could enhance its intrinsic kinase activity. Single amino acid mutations within the GS domain of the class I BMPR have been shown to dramatically enhance its kinase activity (Wieser et al., 1995). Along the same lines, the constitutive association of BMPRIA with NCTrkC could enhance its kinase activity. Indeed, when we analyzed ligand independent Smad1 phosphorylation by BMPRIA in the absence of the class II receptors, we observed that NC-TrkC could greatly enhance the kinase activity of BMPRIA.

Since the over-expression of the Shc binding mutant of NC-TrkC (Y516F) did not influence cell fate, it can be assumed that signaling via this tyrosine is essential. Or in other words, Shc recruitment to NC-TrkC is necessary for cell fate determination. However, NC-TrkC itself cannot further phosphorylate Shc. Since NC-TrkC interacts with BMPRIA, Shc would be brought in close proximity of BMPRIA. This could serve to phosphorylate several possible Serine/Threonine sites on Shc, which have distinct functions compared to the tyrosine activated Shc (Zheng et al., 2013). This kind of a signaling mechanism would lead to the integration of signaling pathways and perhaps increase the repertoire of responses a cell could initiate using the same number of receptors. 


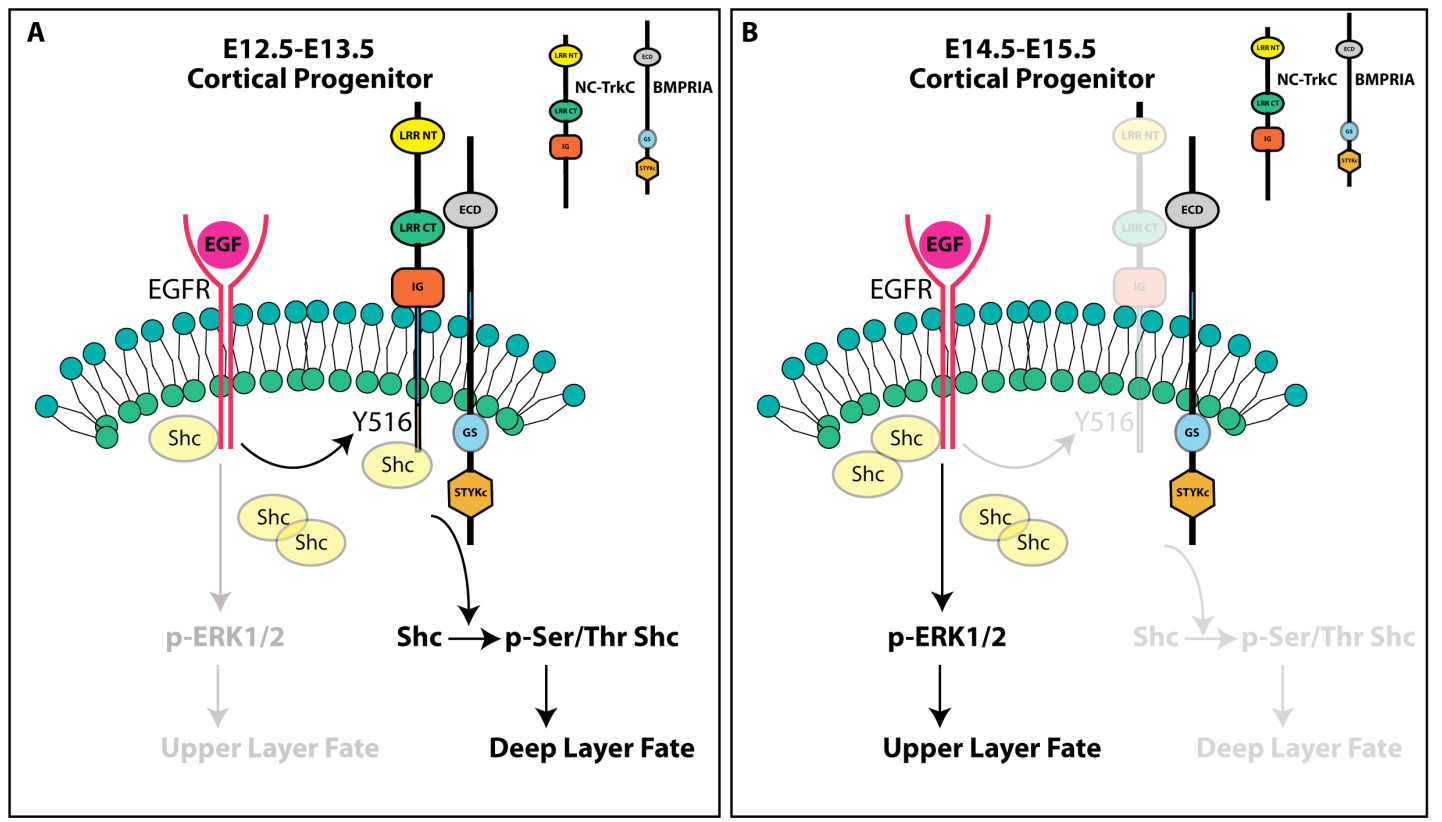

Figure 33. Model proposing NC-TrkC control over cell fate determination.

(A) During early corticogenesis, EGFR transactivation of NC-TrkC leads to the recruitment of Shc to NC-TrkC, thereby lowering free Shc available for EGFR mediates MAPK pathway activation. NC-TrkC enhances BMPRIA kinase activity and thereby promotes phosphorylation of Shc on Serine/Threonine residues. The final outcome of lowered ERK phosphorylation and Ser/Thr phosphorylation of Shc leads to a deep layer cell fate. (B) During late neurogenesis, NC-TrkC levels decline, thereby allowing Shc activation downstream of EGFR and hence ERK phosphorylation. The absence of Ser/Thr phosphorylated Shc accompanied by an increase in ERK phosphorylation leads to the promotion of upper layer cell fate.

\section{Multiple pathways control cortical feedback signaling}

Since the deletion of $N t f 3$ from the Sip 1 mutant cortex does not rescue the Sip1 mutant phenotype, it implied that either Ntf3 was not involved in feedback signaling or that multiple pathways are involved in feedback signaling. Our results with the over-expression of Ntf3 clearly demonstrate the important role of $N t f 3$ in feedback signaling. Thus, we postulated that multiple pathways may exist downstream of Sip1 that contribute to cortical feedback signaling.

Using microarray data collected from comparing Sip1 mutant cortices to wildtype cortices, we narrowed in on a family of transneuronal cytokines. Cbln4, a member of this family, was upregulated in the Sip1 mutant. This was further verified with in situ hybridization. While 
Cbln 4 is upregulated in the Sip 1 mutant cortex, in vitro Sip 1 activates transcription of a Cbln4 enhancer region. This was surprising given that Sip1 normally functions as a transcriptional repressor (Comijn et al., 2001). However, is certain systems and genomic contexts, Sip1 is known to function as an activator too (Yoshimoto et al., 2005). Thus, while we cannot assign a direct role to Sip1 in regulating the expression of $C b \ln 4$, we found that Sip1 can bind to the enhancer region in vitro and thus making it likely that it does so in vivo too.

Since the various member of the Cbln family of proteins share a high degree of homology, we studied the role of all of them in feedback signaling (Iijima et al., 2007; Yuzaki, 2008). However, since Cbln3 is not secreted by itself, it was omitted from our functional studies. Over-expression of $C b \ln 1,2$ and 4 lead to an increase in the number of Tbr2 positive basal progenitors, similar to that achieved on Ntf3 over-expression. However, the effect of the Cbln family on the apical Pax6 positive population differed from that of Ntf3. While Ntf3 lowered the number of Pax6 positive cells, all three Cbln family members caused an increase in the number of $\mathrm{VZ}$ progenitors. Thus, while Ntf3 shifts the balance between apical and basal progenitors, the Cbln family causes a general increase in proliferation of cortical progenitors. This is also confirmed by the increase in BrdU positive cells observed in the cortical plate after Cbln4 in utero electroporation. More detailed phenotypic analysis of the effects of Cbln family overexpression would be required to understand the role of this family in cell fate switch.

Another experiment that hints towards a different signaling pathway employed by Ntf3 and the Cbln family is the location of their cognate receptors. The receptor for Ntf3- NC-TrkC is located in the VZ and the protein localizes to the ventricular lumen. Using alkaline phosphatase tagged Cbln4, we localized the receptor for Cbln4 within the cortical plate. The pattern of signal produced resembled segments of radial glia processes. While the E14.5 cDNA library still needs to be screened 
for candidate receptors, the location of the cognate receptor supports the usage of two alternate pathways by these molecules.

The Cbln family is also interesting from another point of view. Cbln 1 , the most studied member of this family, has been known to function as a bi-directional signaling molecule during synaptic development (Uemura et al., 2010). Cbln 1 binds to GluRd2 post-synaptically and Neurxin 1 pre-synaptically. It is thus possible that the Cbln family plays a similar role in the developing cortex, wherein they bind to receptors on the radial glial process and cortical postmitotic neurons. This kind of a signaling mechanism may regulate feedback signaling and postmitotic maturation of neurons. This might be necessary for coupling neuronal differentiation to neuronal production. 


\section{REFERENCES}

Anderson GJ, Darshan D (2008) Small-molecule dissection of BMP signaling. Nat Chem Biol 4:15-16.

Angevine JB, Sidman RL (1961) Autoradiographic study of cell migration during histogenesis of cerebral cortex in the mouse. Nature 192:766-768.

Anthony TE, Klein C, Fishell G, Heintz N (2004) Radial glia serve as neuronal progenitors in all regions of the central nervous system. Neuron 41:881-890.

Arnold SJ, Huang G-J, Cheung AFP, Era T, Nishikawa S-I, Bikoff EK, Molnár Z, Robertson EJ, Groszer M (2008) The T-box transcription factor Eomes/Tbr2 regulates neurogenesis in the cortical subventricular zone. Genes Dev 22:2479-2484.

Aubin J, Davy A, Soriano P (2004) In vivo convergence of BMP and MAPK signaling pathways: impact of differential Smad1 phosphorylation on development and homeostasis. Genes Dev 18:1482-1494.

Barnabé-Heider F, Wasylnka JA, Fernandes KJL, Porsche C, Sendtner M, Kaplan DR, Miller FD (2005) Evidence that embryonic neurons regulate the onset of cortical gliogenesis via cardiotrophin-1. Neuron 48:253-265.

Bartkowska K, Paquin A, Gauthier AS, Kaplan DR, Miller FD (2007) Trk signaling regulates neural precursor cell proliferation and differentiation during cortical development. Development 134:4369-4380.

Bayatti N, Sarma S, Shaw C, Eyre J a, Vouyiouklis D a, Lindsay S, Clowry GJ (2008b) Progressive loss of PAX6, TBR2, NEUROD and TBR1 mRNA gradients correlates with translocation of EMX2 to the cortical plate during human cortical development. Eur J Neurosci 28:1449-1456.

Bodmer J-L, Schneider P, Tschopp J (2002) The molecular architecture of the TNF superfamily. Trends Biochem Sci 27:1926.

Brennan C, Fabes J (2003) Alkaline phosphatase fusion proteins as affinity probes for protein localization studies. Sci STKE 2003:PL2.

Bulfone a, Martinez S, Marigo V, Campanella M, Basile a, Quaderi N, Gattuso C, Rubenstein JL, Ballabio a (1999) Expression pattern of the Tbr2 (Eomesodermin) gene during mouse and chick brain development. Mech Dev 84:133-138.

Carim-Todd L, Bath KG, Fulgenzi G, Yanpallewar S, Jing D, Barrick CA, Becker J, Buckley H, Dorsey SG, Lee FS, Tessarollo L (2009) Endogenous truncated TrkB.T1 receptor regulates neuronal complexity and TrkB kinase receptor function in vivo. J Neurosci 29:678-685.

Chao M V (2003) Neurotrophins and their receptors: a convergence point for many signalling pathways. Nat Rev Neurosci 4:299-309. 
Choe Y, Siegenthaler J a, Pleasure SJ (2012) A cascade of morphogenic signaling initiated by the meninges controls corpus callosum formation. Neuron 73:698-712.

Comijn J, Berx G, Vermassen P, Verschueren K, Van Grunsven L, Bruyneel E, Mareel M, Huylebroeck D, Van Roy F (2001) The twohanded $\mathrm{E}$ box binding zinc finger protein SIP1 downregulates Ecadherin and induces invasion. Mol Cell 7:1267-1278.

Conti L, De Fraja C, Gulisano M, Migliaccio E, Govoni S, Cattaneo E (1997) Expression and activation of SH2/PTB-containing ShcA adaptor protein reflects the pattern of neurogenesis in the mammalian brain. Proc Natl Acad Sci U S A 94:8185-8190.

Conti L, Sipione S, Magrassi L, Bonfanti L, Rigamonti D, Pettirossi V, Peschanski M, Haddad B, Pelicci P, Milanesi G, Pelicci G, Cattaneo E (2001) Shc signaling in differentiating neural progenitor cells. Nat Neurosci 4:579-586 Available at: http: / / www.ncbi.nlm.nih.gov/pubmed/11369938.

Cordon-Cardo C, Tapley P, Jing SQ, Nanduri V, O'Rourke E, Lamballe F, Kovary K, Klein R, Jones KR, Reichardt LF (1991) The trk tyrosine protein kinase mediates the mitogenic properties of nerve growth factor and neurotrophin-3. Cell 66:173-183.

De Vries L, Finana F, Cachoux F, Vacher B, Sokoloff P, Cussac D (2010) Cellular BRET assay suggests a conformational rearrangement of preformed TrkB/Shc complexes following BDNFdependent activation. Cell Signal 22:158-165.

Dehay C, Savatier P, Cortay V, Kennedy H (2001a) Cell-cycle kinetics of neocortical precursors are influenced by embryonic thalamic axons. J Neurosci 21:201-214.

Dehay C, Savatier P, Cortay V, Kennedy H (2001b) Cell-cycle kinetics of neocortical precursors are influenced by embryonic thalamic axons. J Neurosci 21:201-214.

Desai AR, McConnell SK (2000) Progressive restriction in fate potential by neural progenitors during cerebral cortical development. Development 127:2863-2872.

Dickinson ME, Selleck MA, McMahon AP, Bronner-Fraser M (1995) Dorsalization of the neural tube by the non-neural ectoderm. Development 121:2099-2106.

Dominguez MH, Ayoub AE, Rakic P (2013) POU-III transcription factors (Brn1, Brn2, and Oct6) influence neurogenesis, molecular identity, and migratory destination of upper-layer cells of the cerebral cortex. Cereb Cortex 23:2632-2643.

Dorsey SG et al. (2012) Genetic deletion of trkB.T1 increases neuromuscular function. AJP Cell Physiol 302:C141-C153.

Englund C, Fink A, Lau C, Pham D, Daza RAM, Bulfone A, Kowalczyk T, Hevner RF (2005a) Pax6, Tbr2, and Tbr1 are expressed sequentially by radial glia, intermediate progenitor cells, and postmitotic neurons in developing neocortex. J Neurosci 25:247251. 
Ernfors P, Lee KF, Jaenisch R (1994) Mice lacking brain-derived neurotrophic factor develop with sensory deficits. Nature 368: 147-150.

Esteban PF, Yoon H-Y, Becker J, Dorsey SG, Caprari P, Palko ME, Coppola V, Saragovi HU, Randazzo PA, Tessarollo L (2006) A kinase-deficient TrkC receptor isoform activates Arf6-Rac1 signaling through the scaffold protein tamalin. J Cell Biol 173:291-299.

Fenner BM (2012) Truncated TrkB: Beyond a dominant negative receptor. Cytokine Growth Factor Rev 23:15-24.

Fishell G, Hanashima C (2008) Pyramidal neurons grow up and change their mind. Neuron 57:333-338.

Flanagan BJG, Lu Q, Vanderhaeghen P (1990) [ 2 ] Alkaline Phosphatase Fusions of Ligands or Receptors as in Situ Probes for Staining of Cells, Tissues, and Embryos. 321.

Flanagan JG, Cheng HJ (2000) Alkaline phosphatase fusion proteins for molecular characterization and cloning of receptors and their ligands. Methods Enzymol 327:198-210.

Franco SJ, Gil-Sanz C, Martinez-Garay I, Espinosa A, Harkins-Perry SR, Ramos C, Muller U (2012a) Fate-restricted neural progenitors in the mammalian cerebral cortex. Science (80- ) 337:746-749.

Franco SJ, Muller U (2013) Shaping our minds: stem and progenitor cell diversity in the mammalian neocortex. Neuron 77:19-34 Available at: http:/ /www.ncbi.nlm.nih.gov/pubmed/23312513.

Frantz GD, McConnell SK (1996) Restriction of late cerebral cortical progenitors to an upper-layer fate. Neuron 17:55-61.

Goebbels S, Bormuth I, Bode U, Hermanson O, Schwab MH, Nave K-A (2006) Genetic targeting of principal neurons in neocortex and hippocampus of NEX-Cre mice. Genesis 44:611-621.

Gomes JR, Costa JT, Melo C V., Felizzi F, Monteiro P, Pinto MJ, Inacio AR, Wieloch T, Almeida RD, Graos M, Duarte CB (2012) Excitotoxicity Downregulates TrkB.FL Signaling and Upregulates the Neuroprotective Truncated TrkB Receptors in Cultured Hippocampal and Striatal Neurons. J Neurosci 32:4610-4622.

Gorski JA, Talley T, Qiu M, Puelles L, Rubenstein JLR, Jones KR (2002) Cortical excitatory neurons and glia, but not GABAergic neurons, are produced in the Emx1-expressing lineage. J Neurosci 22:6309-6314.

Götz M, Huttner WB (2005) The cell biology of neurogenesis. Nat Rev Mol Cell Biol 6:777-788.

Guo C, Eckler MJ, McKenna WL, McKinsey GL, Rubenstein JLR, Chen B (2013) Fezf2 expression identifies a multipotent progenitor for neocortical projection neurons, astrocytes, and oligodendrocytes. Neuron 80:1167-1174.

Guo X, Wang X (2009) Signaling cross-talk between TGF- $\beta$ / BMP and other path- ways. :71-88.

Haubensak W, Attardo A, Denk W, Huttner WB (2004a) Neurons arise in the basal neuroepithelium of the early mammalian 
telencephalon: a major site of neurogenesis. Proc Natl Acad Sci U S A 101:3196-3201.

Heins N, Malatesta P, Cecconi F, Nakafuku M, Tucker KL, Hack M a, Chapouton P, Barde Y-A, Götz M (2002) Glial cells generate neurons: the role of the transcription factor Pax6. Nat Neurosci 5:308-315 Available at: http:/ / www.ncbi.nlm.nih.gov/pubmed/11896398 [Accessed January 24, 2014].

Higashi Y, Maruhashi M, Nelles L, Putte T Van De, Verschueren K, Miyoshi T, Yoshimoto A, Kondoh H, Huylebroeck D (2002) Generation of the Floxed Allele of the SIP1 ( Smad-Interacting Protein 1 ) Gene for Cre-Mediated Conditional Knockout in the Mouse. 84:82-84.

Hill RS, Walsh C a (2005) Molecular insights into human brain evolution. Nature 437:64-67.

Iacopetti P, Michelini M, Stuckmann I, Oback B, Aaku-Saraste E, Huttner WB (1999) Expression of the antiproliferative gene TIS2 1 at the onset of neurogenesis identifies single neuroepithelial cells that switch from proliferative to neuron-generating division. Proc Natl Acad Sci U S A 96:4639-4644.

Iijima T, Miura E, Matsuda K, Kamekawa Y, Watanabe M, Yuzaki M (2007) Characterization of a transneuronal cytokine family Cbln-regulation of secretion by heteromeric assembly. Eur J Neurosci 25:1049-1057.

Jin W, Yun C, Kim H-S, Kim S-J (2007) TrkC binds to the bone morphogenetic protein type II receptor to suppress bone morphogenetic protein signaling. Cancer Res 67:9869-9877 Available at: http:/ /www.ncbi.nlm.nih.gov/pubmed/17942918 [Accessed January 27, 2014].

Jing S, Tapley P, Barbacid M (1992) Nerve growth factor mediates signal transduction through trk homodimer receptors. Neuron 9:1067-1079.

Jorissen E, Prox J, Bernreuther C, Weber S, Schwanbeck R, Serneels L, Snellinx A, Craessaerts K, Thathiah A, Tesseur I, Bartsch U, Weskamp G, Blobel CP, Glatzel M, De Strooper B, Saftig P (2010) The disintegrin/metalloproteinase ADAM10 is essential for the establishment of the brain cortex. J Neurosci 30:4833-4844.

Kishore U, Gaboriaud C, Waters P, Shrive AK, Greenhough TJ, Reid KBM, Sim RB, Arlaud GJ (2004) C1q and tumor necrosis factor superfamily: modularity and versatility. Trends Immunol 25:551561.

Klein R, Conway D, Parada LF, Barbacid M (1990) The trkB tyrosine protein kinase gene codes for a second neurogenic receptor that lacks the catalytic kinase domain. Cell 61:647-656.

Klein R, Nanduri V, Jing SA, Lamballe F, Tapley P, Bryant S, CordonCardo C, Jones KR, Reichardt LF, Barbacid M (1991) The trkB tyrosine protein kinase is a receptor for brain-derived neurotrophic factor and neurotrophin-3. Cell 66:395-403. 
Kowalczyk T, Pontious A, Englund C, Daza RAM, Bedogni F, Hodge R, Attardo A, Bell C, Huttner WB, Hevner RF (2009) Intermediate neuronal progenitors (basal progenitors) produce pyramidalprojection neurons for all layers of cerebral cortex. Cereb Cortex 19:2439-2450.

Lamballe F, Klein R, Barbacid M (1991) trkC, a new member of the trk family of tyrosine protein kinases, is a receptor for neurotrophin3. Cell 66:967-979.

Lehtinen MK, Zappaterra MW, Chen X, Yang YJ, Hill AD, Lun M, Maynard T, Gonzalez D, Kim S, Ye P, D’Ercole AJ, Wong ET, LaMantia AS, Walsh CA (2011) The cerebrospinal fluid provides a proliferative niche for neural progenitor cells. Neuron 69:893-905.

Lemmon MA, Schlessinger J (1994) Regulation of signal transduction and signal diversity by receptor oligomerization. Trends Biochem Sci 19:459-463.

Liu A, Niswander L a (2005) Bone morphogenetic protein signalling and vertebrate nervous system development. Nat Rev Neurosci 6:945-954.

Mabie PC, Mehler MF, Kessler J a (1999) Multiple roles of bone morphogenetic protein signaling in the regulation of cortical cell number and phenotype. J Neurosci 19:7077-7088.

Malatesta P, Hartfuss E, Götz M (2000) Isolation of radial glial cells by fluorescent-activated cell sorting reveals a neuronal lineage. Development 127:5253-5263 Available at: http: / /www.ncbi.nlm.nih.gov/pubmed/11076748.

Martin-Zanca D, Barbacid M, Parada LF (1990) Expression of the trk proto-oncogene is restricted to the sensory cranial and spinal ganglia of neural crest origin in mouse development. Genes Dev 4:683-694.

Martínez-Cerdeño V, Noctor SC, Kriegstein AR (2006) The role of intermediate progenitor cells in the evolutionary expansion of the cerebral cortex. Cereb Cortex 16 Suppl 1:i152-i161.

Mateos S, Calothy G, Lamballe F (2003) The noncatalytic TrkCNC2 receptor is cleaved by metalloproteases upon neurotrophin-3 stimulation. Oncogene 22:740-745.

Matsuda K, Miura E, Miyazaki T, Kakegawa W, Emi K, Narumi S, Fukazawa Y, Ito-Ishida A, Kondo T, Shigemoto R, Watanabe M, Yuzaki M (2010) Cbln1 is a ligand for an orphan glutamate receptor delta2, a bidirectional synapse organizer. Science 328:363-368.

McConnell SK, Ghosh A, Shatz CJ (1989) Subplate neurons pioneer the first axon pathway from the cerebral cortex. Science 245:978982.

Medina DL, Sciarretta C, Calella AM, Von Bohlen Und Halbach O, Unsicker K, Minichiello L (2004) TrkB regulates neocortex formation through the Shc/PLCgamma-mediated control of neuronal migration. EMBO J 23:3803-3814.

Menn B, Timsit S, Calothy G, Lamballe F (1998a) Differential expression of TrkC catalytic and noncatalytic isoforms suggests 
that they act independently or in association. J Comp Neurol 401:47-64.

Menn B, Timsit S, Represa A, Mateos S, Calothy G, Lamballe F (2000a) Spatiotemporal expression of noncatalytic TrkC NC2 isoform during early and late CNS neurogenesis: a comparative study with TrkC catalytic and p75NTR receptors. Eur J Neurosci 12:3211-3223.

Middlemas DS, Lindberg RA, Hunter T (1991) trkB, a neural receptor protein-tyrosine kinase: evidence for a full-length and two truncated receptors. Mol Cell Biol 11:143-153.

Minichiello L (2009) TrkB signalling pathways in LTP and learning. Nat Rev Neurosci 10:850-860.

Miquelajauregui A, Van de Putte T, Polyakov A, Nityanandam A, Boppana S, Seuntjens E, Karabinos A, Higashi Y, Huylebroeck D, Tarabykin V (2007) Smad-interacting protein-1 (Zfhx1b) acts upstream of Wnt signaling in the mouse hippocampus and controls its formation. Proc Natl Acad Sci U S A 104:12919-12924 Available at: http:/ /www.ncbi.nlm.nih.gov/pubmed/17644613.

Miura E, Ijima T, Yuzaki M, Watanabe M (2006) Distinct expression of Cbln family mRNAs in developing and adult mouse brains. Eur J Neurosci 24:750-760.

Miyata T, Kawaguchi A, Okano H, Ogawa M (2001) Asymmetric inheritance of radial glial fibers by cortical neurons. Neuron 31:727-741.

Mizutani K, Saito T (2005) Progenitors resume generating neurons after temporary inhibition of neurogenesis by Notch activation in the mammalian cerebral cortex. Development 132:1295-1304.

Molyneaux BJ, Arlotta P, Menezes JRL, Macklis JD (2007) Neuronal subtype specification in the cerebral cortex. Nat Rev Neurosci 8:427-437 Available at:

http:/ / www.ncbi.nlm.nih.gov/pubmed/17514196 [Accessed February 20, 2014].

Muraguchi T, Takegami Y, Ohtsuka T, Kitajima S, Chandana EPS, Omura A, Miki T, Takahashi R, Matsumoto N, Ludwig A, Noda M, Takahashi C (2007) RECK modulates Notch signaling during cortical neurogenesis by regulating ADAM10 activity. Nat Neurosci 10:838-845.

Nguyen VH, Trout J, Connors SA, Andermann P, Weinberg E, Mullins MC (2000) Dorsal and intermediate neuronal cell types of the spinal cord are established by a BMP signaling pathway. Development 127:1209-1220.

Nieto M, Monuki ES, Tang H, Imitola J, Haubst N, Khoury SJ, Cunningham J, Gotz M, Walsh C a (2004) Expression of Cux-1 and Cux-2 in the subventricular zone and upper layers II-IV of the cerebral cortex. J Comp Neurol 479:168-180.

Nityanandam A (2009) Investigation of Sip1 gene interactions in the development of the mammalian telencephalon. PhD thesis. 
Noctor SC, Flint a C, Weissman T a, Dammerman RS, Kriegstein a R (2001) Neurons derived from radial glial cells establish radial units in neocortex. Nature 409:714-720.

Noctor SC, Martínez-Cerdeño V, Ivic L, Kriegstein AR (2004) Cortical neurons arise in symmetric and asymmetric division zones and migrate through specific phases. Nat Neurosci 7:136-144.

Nonaka-Kinoshita M, Reillo I, Artegiani B, Martinez-Martinez MA, Nelson M, Borrell V, Calegari F (2013a) Regulation of cerebral cortex size and folding by expansion of basal progenitors. EMBO J 32:1817-1828.

Panchision DM, Pickel JM, Studer L, Lee SH, Turner P a, Hazel TG, McKay RD (2001) Sequential actions of BMP receptors control neural precursor cell production and fate. Genes Dev 15:20942110.

Pucilowska J, Puzerey P a, Karlo JC, Galán RF, Landreth GE (2012) Disrupted ERK signaling during cortical development leads to abnormal progenitor proliferation, neuronal and network excitability and behavior, modeling human neuro-cardio-facialcutaneous and related syndromes. J Neurosci 32:8663-8677.

Puehringer D, Orel N, Luningschror P, Subramanian N, Herrmann T, Chao M V, Sendtner M (2013a) EGF transactivation of Trk receptors regulates the migration of newborn cortical neurons. Nat Neurosci 16:407-415.

Rakic P (1974) Neurons in rhesus monkey visual cortex: systematic relation between time of origin and eventual disposition. Science 183:425-427.

Rakic P (2003) Developmental and evolutionary adaptations of cortical radial glia. Cereb Cortex 13:541-549.

Ravichandran KS (2001) Signaling via Shc family adapter proteins. Oncogene 20:6322-6330.

Renn CL, Leitch CC, Dorsey SG (2009) In vivo evidence that truncated trkB.T1 participates in nociception. Mol Pain 5:61.

Rose CR, Blum R, Pichler B, Lepier A, Kafitz KW, Konnerth A (2003) Truncated TrkB-T1 mediates calcium signalling in glia cells. 426.

Saito T (2006) In vivo electroporation in the embryonic mouse central nervous system. Nat Protoc 1:1552-1558.

Samanta J, Burke GM, McGuire T, Pisarek AJ, Mukhopadhyay A, Mishina Y, Kessler J a (2007) BMPR1a signaling determines numbers of oligodendrocytes and calbindin-expressing interneurons in the cortex. J Neurosci 27:7397-7407.

Sanderson KJ, Weller WL (1990) Gradients of neurogenesis in possum neocortex. Brain Res Dev Brain Res 55:269-274 Available at: http:/ / www.ncbi.nlm.nih.gov/pubmed/2253327.

Seuntjens E, Nityanandam A, Miquelajauregui A, Debruyn J, Stryjewska A, Goebbels S, Nave K-A, Huylebroeck D, Tarabykin V (2009a) Sip1 regulates sequential fate decisions by feedback signaling from postmitotic neurons to progenitors. Nat Neurosci 12:1373-1380. 
Shen Q, Wang Y, Dimos JT, Fasano CA, Phoenix TN, Lemischka IR, Ivanova NB, Stifani S, Morrisey EE, Temple S (2006) The timing of cortical neurogenesis is encoded within lineages of individual progenitor cells. Nat Neurosci 9:743-751.

Siegenthaler JA, Pleasure SJ (2011) We have got you "covered": how the meninges control brain development. Curr Opin Genet Dev 21:249-255 Available at:

http:/ / www.ncbi.nlm.nih.gov/pubmed/21251809.

Soppet D, Escandon E, Maragos J, Middlemas DS, Reid SW, Blair J, Burton LE, Stanton BR, Kaplan DR, Hunter T, Nikolics K, Parada LF (1991) The neurotrophic factors brain-derived neurotrophic factor and neurotrophin-3 are ligands for the trkB tyrosine kinase receptor. Cell 65:895-903.

Stahl R, Walcher T, De Juan Romero C, Pilz GA, Cappello S, Irmler M, Sanz-Aquela JM, Beckers J, Blum R, Borrell V, Götz M (2013) Trnp1 regulates expansion and folding of the mammalian cerebral cortex by control of radial glial fate. Cell 153:535-549.

Stoykova A, Gruss P (1998) Pax6 Controls Radial Glia Differentiation. 21:1031-1044.

Takahashi H, Arstikaitis P, Prasad T, Bartlett TE, Wang YT, Murphy TH, Craig AM (2011) Postsynaptic TrkC and presynaptic PTPo function as a bidirectional excitatory synaptic organizing complex. Neuron 69:287-303.

Takahashi T (1995) The Cell Cycle of the Pseudostratified Embryonic Murine Cerebral Wall Ventricular Epithelium of the. 15:60466057.

Tarabykin V, Stoykova A, Usman N, Gruss P (2001) Cortical upper layer neurons derive from the subventricular zone as indicated by Svet1 gene expression. Development 128:1983-1993.

Timmer JR, Wang C, Niswander L (2002) BMP signaling patterns the dorsal and intermediate neural tube via regulation of homeobox and helix-loop-helix transcription factors. Development 129:24592472.

Tsoulfas P, Soppet D, Escandon E, Tessarollo L, Mendoza-Ramirez JL, Rosenthal A, Nikolics K, Parada LF (1993) The rat trkC locus encodes multiple neurogenic receptors that exhibit differential response to neurotrophin-3 in PC12 cells. Neuron 10:975-990.

Uemura T, Lee S-J, Yasumura M, Takeuchi T, Yoshida T, Ra M, Taguchi R, Sakimura K, Mishina M (2010) Trans-synaptic interaction of GluRdelta2 and Neurexin through Cbln 1 mediates synapse formation in the cerebellum. Cell 141:1068-1079.

Valenzuela DM, Maisonpierre PC, Glass DJ, Rojas E, Nuez L, Kong Y, Gies DR, Stitt TN, Ip NY, Yancopoulos GD (1993) Alternative Forms of Rat TrkC with Different Functional Capabilities. 10:963974.

Van de Putte T, Maruhashi M, Francis A, Nelles L, Kondoh H, Huylebroeck D, Higashi Y (2003) Mice lacking ZFHX1B, the gene that codes for Smad-interacting protein-1, reveal a role for multiple neural crest cell defects in the etiology of Hirschsprung 
disease-mental retardation syndrome. Am J Hum Genet 72:465470.

Verstappen G, van Grunsven LA, Michiels C, Van de Putte T, Souopgui J, Van Damme J, Bellefroid E, Vandekerckhove J, Huylebroeck D (2008) Atypical Mowat-Wilson patient confirms the importance of the novel association between ZFHX1B/SIP1 and NuRD corepressor complex. Hum Mol Genet 17:1175-1183.

Wei P, Pattarini R, Rong Y, Guo H, Bansal PK, Kusnoor S V, Deutch AY, Parris J, Morgan JI (2012) The Cbln family of proteins interact with multiple signaling pathways. J Neurochem 121:717-729

Weissman T a, Riquelme P a, Ivic L, Flint AC, Kriegstein AR (2004) Calcium waves propagate through radial glial cells and modulate proliferation in the developing neocortex. Neuron 43:647-661.

Wieser R, Wrana JL, Massague J (1995) GS domain mutations that constitutively activate T beta R-I, the downstream signaling component in the TGF-beta receptor complex. EMBO J 14:21992208.

Yanpallewar SU, Barrick CA, Buckley H, Becker J, Tessarollo L (2012a) Deletion of the BDNF Truncated Receptor TrkB.T1 Delays Disease Onset in a Mouse Model of Amyotrophic Lateral Sclerosis. PLoS One 7:e39946.

Yoshimoto A, Saigou Y, Higashi Y, Kondoh H (2005) Regulation of ocular lens development by Smad-interacting protein 1 involving Foxe3 activation. Development 132:4437-4448.

Yuzaki M (2008) Cbln and C1q family proteins: new transneuronal cytokines. Cell Mol Life Sci 65:1698-1705.

Zarbalis K, Siegenthaler JA, Choe Y, May SR, Peterson AS, Pleasure SJ (2007) Cortical dysplasia and skull defects in mice with a Foxc1 allele reveal the role of meningeal differentiation in regulating cortical development. Proc Natl Acad Sci U S A 104:14002-14007.

Zheng Y, Zhang C, Croucher DR, Soliman M a, St-Denis N, Pasculescu A, Taylor L, Tate S a, Hardy WR, Colwill K, Dai AY, Bagshaw R, Dennis JW, Gingras A-C, Daly RJ, Pawson T (2013) Temporal regulation of EGF signalling networks by the scaffold protein Shc1. Nature 499:166-171.

Zimmer C, Tiveron M-C, Bodmer R, Cremer H (2004a) Dynamics of Cux2 expression suggests that an early pool of SVZ precursors is fated to become upper cortical layer neurons. Cereb Cortex 14:1408-1420. 
